\title{
Cultural Identity in Film Posters
}

Re-positioning Latin Americans in Mainstream Media Films

A 90-point thesis submitted to the Victoria University of Wellington. In fulfillment of the requirements for the degree of Master of Design Innovation

Victoria University of Wellington, 2019

Jessica Freire 


\section{ACKNOWLEDGMENTS}

To my supervisors, Catherine Caudwell and Nan O'Sullivan, I thank you for the time, effort, encouragement, and expertise you have given me in this process. You both inspire me to be a better person and a better designer. You can't imagine what a privilege this has been.

To the 2019 MDI cohort, but especially to Maddy Hazelton, Rose Lastovicka, and Will Zheng, thank you for creating a positive, creative and fun space, which made the long days at university that little bit brighter.

To Alex, thank you for being a constant and unwavering source of love, comfort, warmth, cheesy jokes, and for never saying no to eating food with me. Knowing I always have your support and strength to fall back on has made this process so much easier.

I most importantly dedicate this to my parents. I wouldn't be where I am, or who I am if it weren't for you. You are, and always will be, my inspiration. This thesis is not only a manifestation of myself but also of you. You raised me to love life, to love learning, to love movies (very crucial), and to love who I am. Beyond being amazing parents, you play a role in my life of best friends, \#1 fans, managers, and role models. I hope you see yourselves in these pages as much as I do. You came to this country and built all of this for me. I hope this makes it worth it. 


\section{ABSTRACT}

This thesis investigates the current representation of the Latin American identity in mainstream media cinematic posters. While in recent years, the film industry has begun to acknowledge issues in cultural representation, current Latin American portrayals continue to lack depth and rely on ill-informed historical stereotypes.

Cinematic promotional posters were once considered an art form, but recent technological developments and the Hollywood culture has led them to become formulaic, unoriginal, and lifeless. In an attempt to enrich the conversation around diversity, and reinterpret the power of the film poster, the visual portrayal of the Latin American identity in film posters will be analysed and redressed to present complex, multidimensional characters and narratives that embrace and emphasise their current cultural identity. This research portfolio presents a visual analysis of 120 film posters, identifying and categorising key themes, tropes, and elements that form stereotypical representations. This analysis informs an iterative design process. It utilises Latin American visual design language to reinterpret the possibilities that film posters have in creating elaborate narratives that treat audiences with respect and complexity. The resulting designs were used as prompts for discussion and critique with relevant stakeholders, to further inform conversations about cultural representation through design and inform further iterations.

This process ultimately suggests a method of culturally embedded film promotion design. By re-imaging film posters through Latin American design traditions, I will offer an alternative perspective on Latin American characters that challenge dominant stereotypes. 



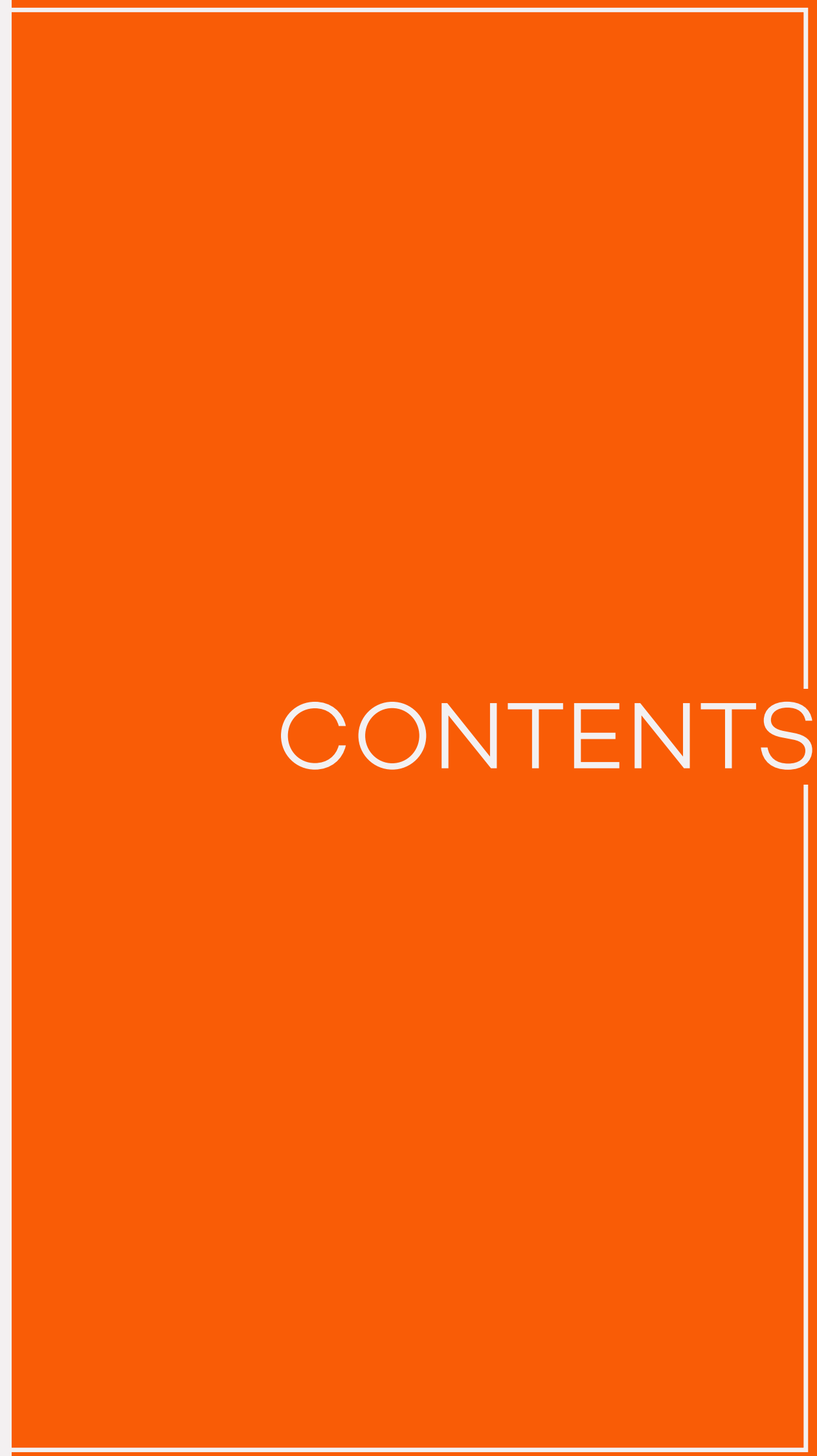


Acknowledgments.................................................................................................... p.iv

Abstract ............................................................................................. p.vi

Contents.................................................................................................. p.ix

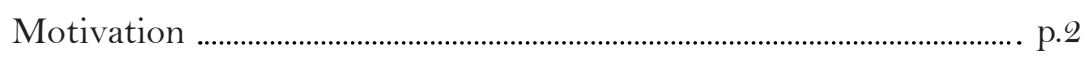

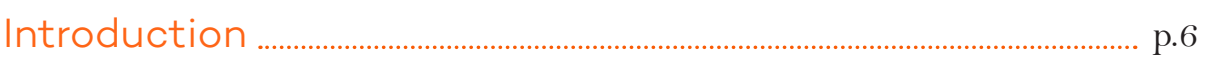

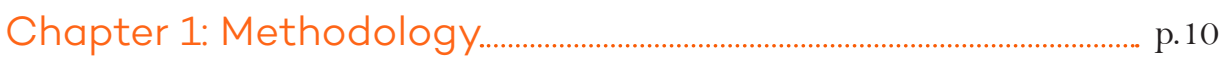

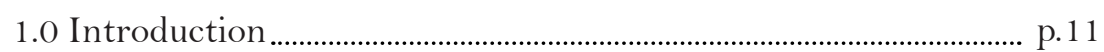

1.1 Research Question, Aims and Objectives.......................................... p.11

1.2 Research Approach................................................................................. p. 12

1.3 Methods .......................................................................................................

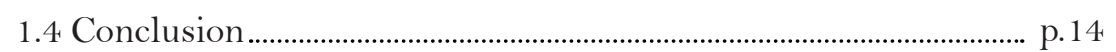

Chapter 2: Literature Review...................................................... p.16

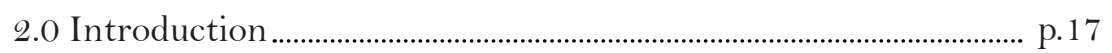

2.1 A Well-Designed Film Poster ................................................................... p. .17

2.2 Latin American Artistic Background................................................ p.20

2.3 Stereotypes in Film and their Physiological Implications.......... p.22

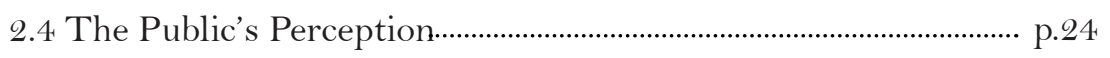

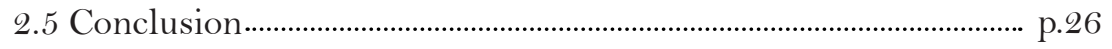

Chapter 3: Cultural Interpretations:................................................... p.28

How do they see us?

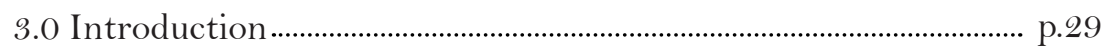

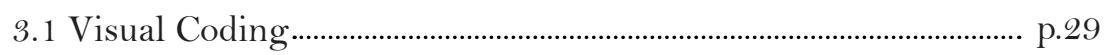

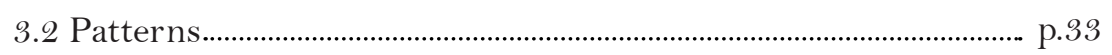

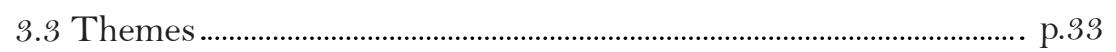

3.4 Analysis .............................................................................................. p.

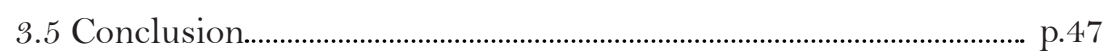

Chapter 4: Cultural Re-Interpretations:........................................ p. 50

How do we see ourselves?

4.0 Introduction …………………………………………………………... p p

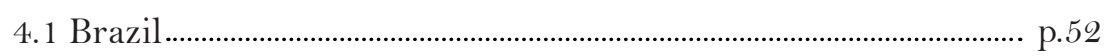

4.2 Colombia ……………………………………………………………………….. p.

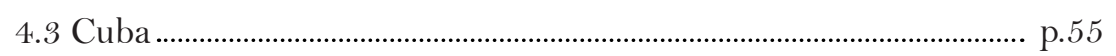

4 .4 Conclusion ……………………………………………………………………. p. p

Chapter 5: Cultural Re-Design …….................................................. p.60

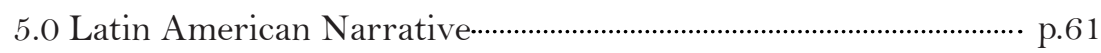

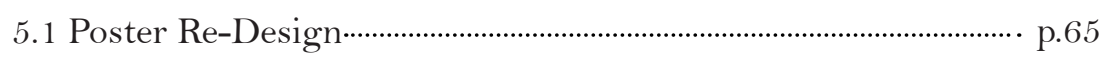

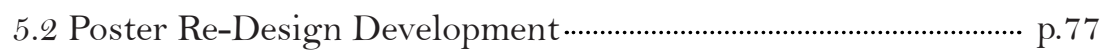

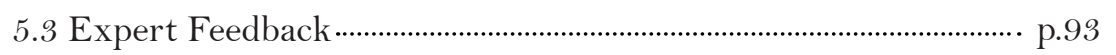

5.4 Final Poster Development ……………………………………….... p. 102

5.5 Development Critique …………………………………………………….. p. 115

5.6 Conclusion ……………………………………………………………... p.

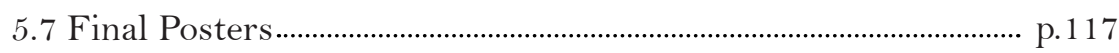

5.8 Context: Poster Installation ……………………………………………….... p. 128 
Chapter 6: Reflections.

p. 132

6.1 Introduction

p. 133

6.2 Strengths, Weaknesses, and Limitations.

p. 133

6.3 Future Considerations

p. 135

6.4 Research Aim

p. 136

Conclusion

p. 138

List of Figures.

p. 142

References.

p. 148

Appendix

p. 158 

MOTIVATION 
Films have always been my haven and passion. During my lifetime, I have held the belief that films and the impressions they leave, shape the world around us. Films allowed me to experience life through a variety of different lenses and perspectives.

Not only have movies inspired my personal life, mannerisms and beliefs, but the world of cinema has also stimulated my professional career. It was by watching films and being in awe of their storylines, aesthetics, narratives, costume and sets, that I discovered the field of design and fell in love with the possibilities it held.

My undergraduate studies showed me the many ways that design is intertwined with Film, and I continued to be intrigued by the capabilities and enhancements that design has on the cinematic fields of special effects, set design and costume design. Film narratives and visual effects connect the audience to worlds beyond their scope of experience. While the amazement and wonder embedded in this experience continue to engage its audience, I believe there is a responsibility to better understand and depict the diversity apparent in the narratives.

The numerous incidences of misrepresentation in mainstream media films have deeply impacted me as a Latina. I was born in Brazil and who I am today, what I look like, and my history, have roots in Africa, Italy, Portugal, and Lebanon. I am a cultural mix of influences and subcultures that can only be seen in Latin America. However, others do not know much about us beyond the concept that our women are exotic, our men are dishonest, and our food is spicy.

While these characteristics are not entirely false, they are not the only characteristics of either "my people" or "my place". My own experiences of limited appreciation of cultural differences and cultural judgement by others on my identity, have led me to seek ways that design can engage in better education and dissemination of cultural difference. I argue that cinematic stereotypes seen in film and television, have led people to believe that every single Latin American possesses only the shallow qualities I have mentioned above.

Films have always been my constant. However, it has become tiring only to see my culture and ethnicity reflected on screen in a negative and belittling way. I wanted to play my part as a designer and a film 
lover in the path to correcting this issue. Too often has my vast and beautiful culture been minimised to a few visual stereotypes that are no longer acceptable. This thesis is an exploration of how 'others' see us and how 'we' see ourselves. In an attempt to be part of a conversation that will one day stop this vicious mainstream media treatment entirely, in the hope of there no longer being a definition between the 'them' and 'us', to celebrate every culture fully for everything that it is. 



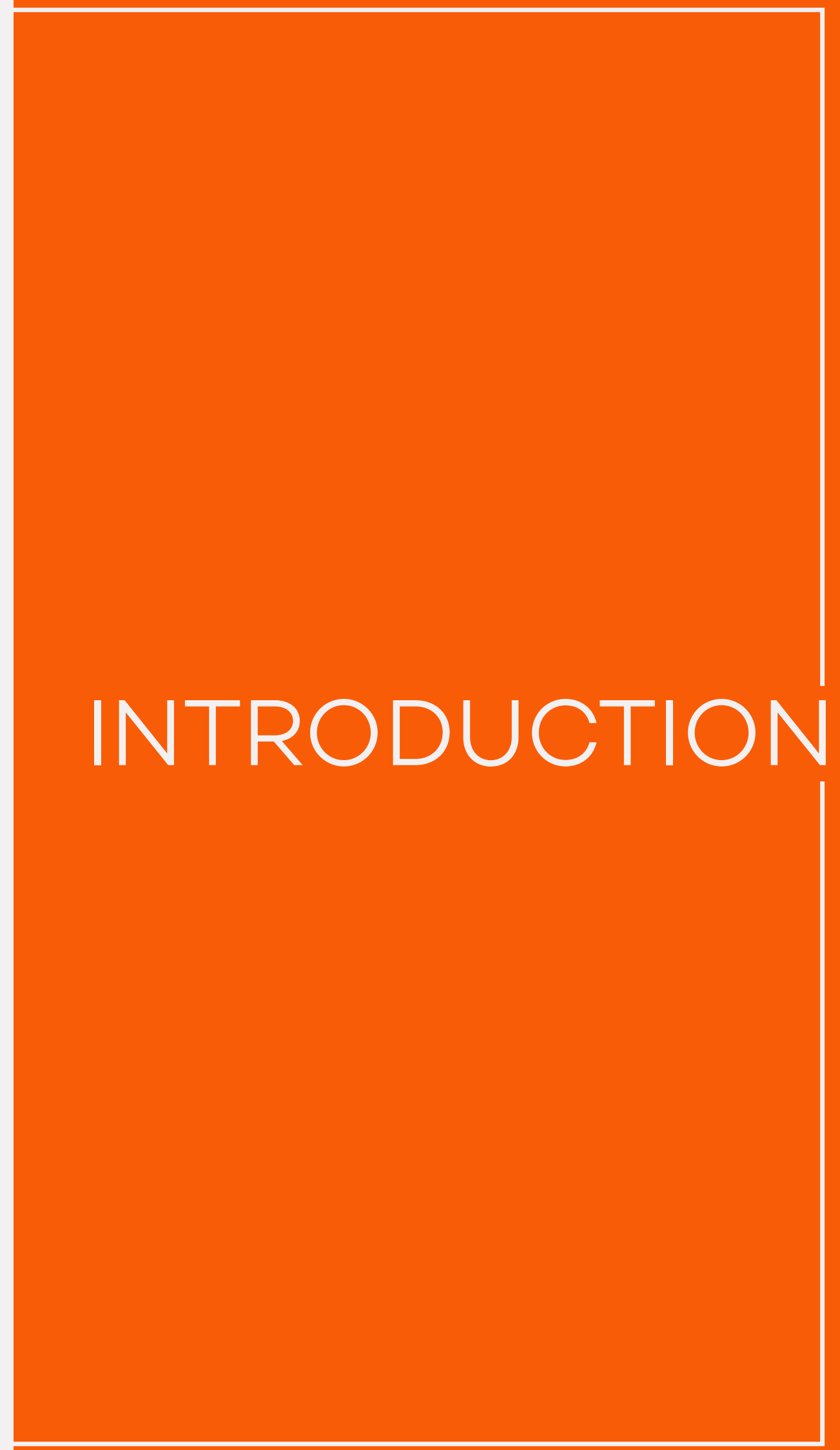


Recently, there has been a significant shift in questioning how mainstream media deals with diversity and equality. Online authors like Ryzik (2016) highlight in their articles the experience and issues encountered by a range of minority groups in Hollywood. While the written word is an active step towards a more inclusive film industry, it is noticeable that little happens beyond the 'conversation'. Media industries appear to feel satisfied with discussions but lack the initiative to do much beyond the words. This research, as well as critiquing the status quo, will use design as a visual tool to challenge stereotypes, in this global journey to overall equality.

Influenced by the scholar Berg's (2002) description of what a 'stereotype' is, this study will use the term as the act of making judgements and assigning negative qualities to other individuals or groups. As Berg further states, within film culture, this is the visual manifestation of identities created by our hierarchical societies. Over the last decade, social scrutiny of stereotypes in films has increased substantially. However, Latin American stereotypes are present to this day (Berg, 2002). Which is why the representation of minority groups in western cinema must move beyond caricatures and cliches, into more evolved and updated representations of minority culture.

Authors like Erigha (2015), Katzew (2011), and Berg (2002), explore in their texts the implications of this misrepresentation, and why it is still a reality. The absence of minority cultures on screen fuels inaccurate age-old perceptions by the broader, possibly global, audiences. These perceptions are damaging as it encourages a narrow perspective of certain ethnicities (Choueiti, Pieper, \& Smith, 2016).

This thesis will explore how the Latin American identity is depicted in promotional film posters by visualising the narratives that are repeatedly saturated through them. This exploration will be done to understand how western societies see the culture, to contrast it against cultural art and design research, that depicts how Latin Americans see themselves. The analysis will then serve as a foundation to critique three cinematic posters that depict stereotypical stories. Other narratives within the films will then be examined, in an attempt to find authentic stories that could resonate with Latin Americans through a cinematic poster. From the research and personal understanding of my Latin American culture, I will design a series of concepts for cinematic posters. These posters will depict narratives that I believe represent 
the Latin American identity in the cinematic universe as complex and multidimensional, dismantling age-old stereotypical expectations. 

METHODOLOGY 


\subsection{Introduction}

This section provides an in-depth description of the processes and methods followed throughout this thesis, and their relation to the research aims and objectives. All the methods used in this study appear within Qualitative Research. Creswell (2014), defines qualitative research as a methodology that explores and aims to understand a social or human problem, in which data is collected, analysed, and the researcher makes a final interpretation of it, in hopes to add to the importance of rendering the complexity of the situation. This research used a perspective lens, in "identifying the social, political, or historical context of the problem under study." (Creswell, 2014, p.176) which in this circumstance, is current visual representation of the Latin American identity.

My research is split into two main aspects, the gathering of information to understand the current social problem, while the second part aims to analyse it and respond to it through design processes, which in turn concludes this thesis.

\subsection{Research Question, Aims and Objectives:}

At the core of this research, the aim of it is to answer the question:

'How can film posters be designed to illustrate complex, multidimensional narratives of the Latin American identity in the 21st century?'

In answering this question I will:

1. Explore the current treatment of, and attitudes towards Latin Americans and their culture in film narratives.

A. Collect data and information through cultural research, and background research, to build links between Latin American culture, film narratives, and stereotypes.

B. Define the current treatment of Latin Americans and their culture in film posters.

C. Gain Appreciation for the contemporary art and graphic design style in Latin America.

2. Express the visual language of Latin American culture through film posters in an elaborate manner. 
A. Reflect on knowledge gained, and start re-appropriating previously disproportionate promotional film posters.

B. Gather feedback from stakeholders on their perspective of the cultural significance of the poster, its designed qualities, and cinematography references, for comparison from the original promotional poster, to the newly redesigned posters.

C. Reflect on feedback and research, to develop final versions of the culturally aware poster, based on research findings and critiques received.

\subsection{Research Approach}

\section{Qualitative Research}

Silverman (2017), believes that methods should not rule us, but serve us. What Silverman (2017) argues is that a choice of methods should not be predetermined; your methods should benefit your study and facilitate space for new knowledge. This qualitative approach, has given me the freedom to develop my work as I go, and has allowed me to create a structure that was beneficial to this research.

Qualitative research uses a perspective lens on the content at hand. This lens allows the researcher to orientate questions towards issues within marginalised groups, and see the problem through their eyes, therefore finding a solution that benefits them directly (Creswell, 2014). According to Creswell this approach also gives the researcher liberty to position themselves in the study, which was an essential aspect because I, as a Latin American, researching Latin American misrepresentation, would have my own bias to consider, but also explore. My background and knowledge of Latin American culture became an asset that needed to be acknowledged in this setting, giving the research further context.

\subsection{Methods}

\section{Literature Review}

Jesson, Matheson, \& Lacey (2011) argue that "A literature review is a written appraisal of what is already known" (p. 10). This literature review gives an insight into different fields of study and how they overlap and relate to each other, also creating a lens with which to view my research though. 
The literature review, as according to Creswell (2014), determines the scope of the research and the range. This is how my literature review has been produced, with the intent of unearthing the importance of this misrepresentation from a variety of perspectives and fields.

\section{Visual Content Analysis}

Denzin \& Lincoln (2005) deduce that many social phenomena must be analysed through visual terms to recognise an issue, problem or concept. This process allows researchers to interpret the results within its social, cultural, and political context. Therefore, a visual content analysis was conducted to define the visual treatment of Latin Americans and their culture in film posters. This study was done according to the specification of Rose (2007), but also informed by the writings of Saldana (2009).

\section{Case Study}

Simons (2009) defines a case study as an in-depth exploration of the multiple perspectives of a unique project by looking at its complexity and uniqueness in a real-life context. Therefore, a case study was done to gain an in depth appreciation for contemporary art and graphic design in Latin America. A case study focuses on an individual case, or situation to understand the broader context it sits within. This statement is vital because of two points:

1. Within the study, three countries will be used to explore Latin American art and design. The investigation is done to construct a deep understanding of Latin American culture.

2. According to Denzin \& Lincoln (2005), the knowledge gained from a case study is the attention paid to the influence of social, political, and cultural issues, therefore, not only was graphic design explored, but also art history.

\section{Design Process}

Design is a way of thinking, that results in an object, system, artifact or design outcome. As stated by Stone (2010), all of this is the design process which leads to applied creativity. There are many ways to 
tackle the design process, but the method used within this research follows the steps of; discover, define, develop, and deliver (Stone, 2010). This process is, of course, loose, and interpreted differently by many. However, I go about it by conducting background research (discover), taking that new found knowledge and creating 1-3 concepts that approach different aspects of my research (define). I then analyse said concepts and create a new output (develop) which I then receive feedback on, to create a final design (deliver).

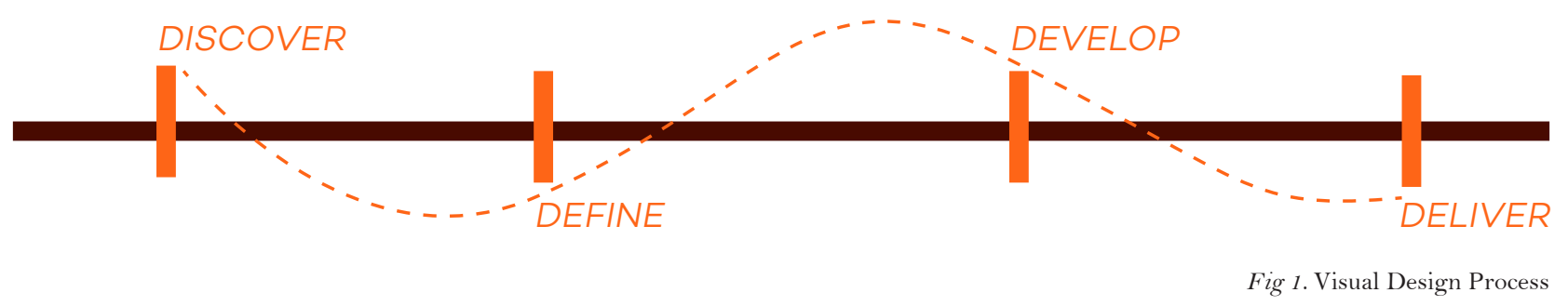

Interviews

Unstructured interviews gave me the freedom and flexibility to understand participants perspective at an in-depth and personal level. As stated by Kumar (2014), an unstructured interview is useful in the sense of creating an open and non-restrictive space to ask questions, and dig deeper into the research topic. It is constructed in a format that is relevant to the situation and conducted with wording that will be understandable and convenient to participants. This format was critical to this research to get accurate responses about the film posters presented and the freedom it gave participants to be honest. These interviews were conducted following VUW's Human Ethics Committee specifications, with their approval.

\subsection{Conclusion}

This research aims to approach film culture and Latin American misrepresentation from a different lens that reflected my approach to this as a Latin American designer. Therefore, the use of qualitative research and methods allowed this study to flourish and be explorative in a context that was not restrictive. The design approach investigates these issues in an interdisciplinary manner. 



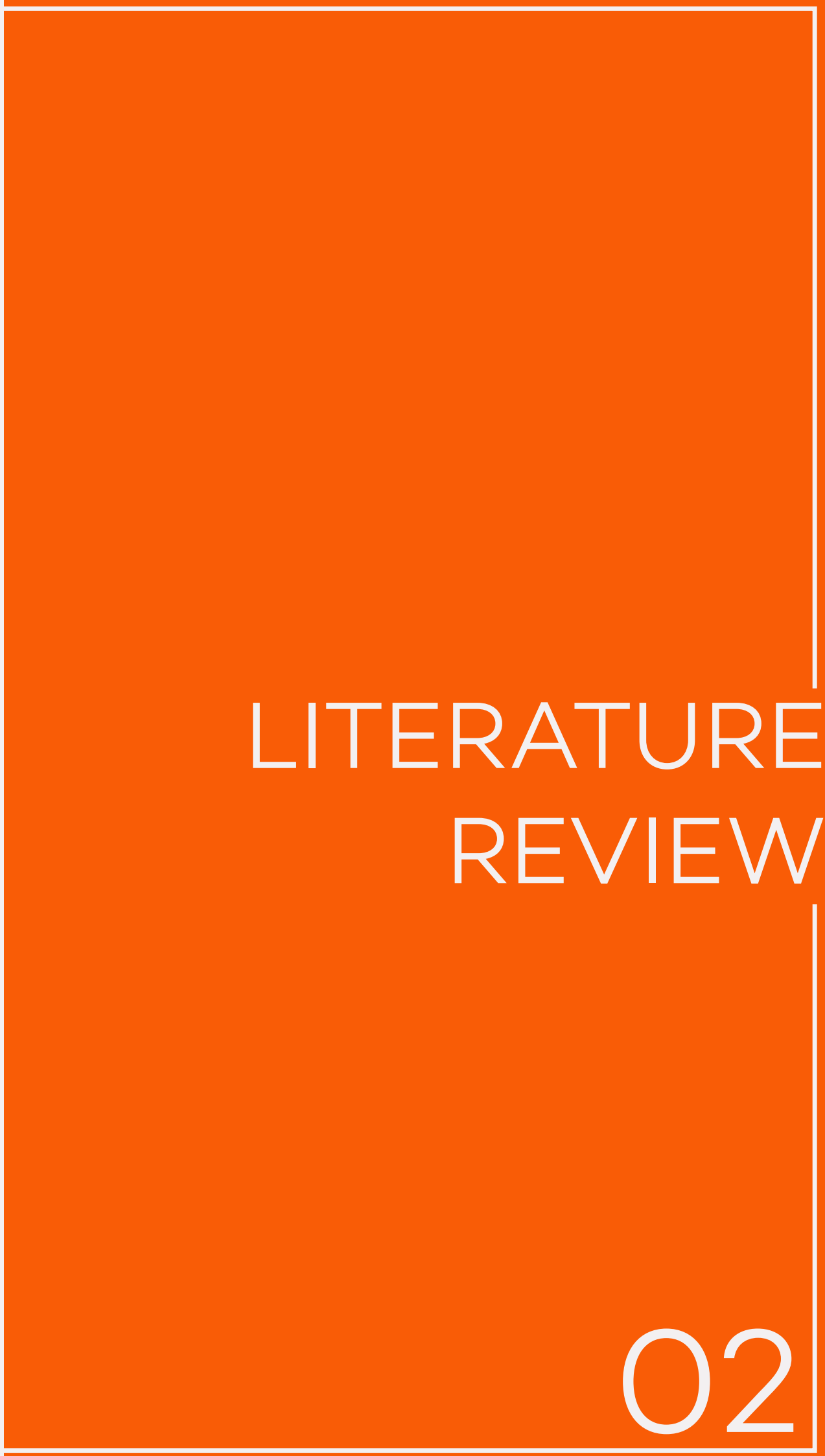




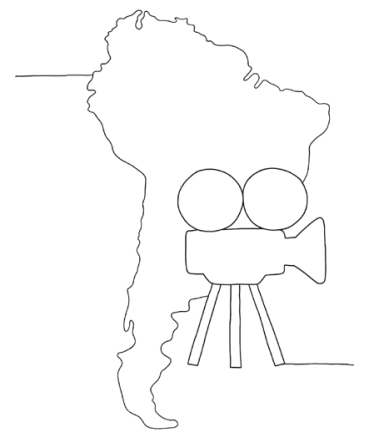

This literature review will develop an understanding, and cover essential aspects of: cinematic narratives within promotional film posters, the history behind them, and their current uses and standing. The study will then explore the Latin American artistic background and identity. To then identify and study the current Latin American representation in film narrative, to lastly analyse the current overall public perception of the culture. This investigation aims to grasp the basic knowledge behind all of these aspects and pinpoint the information that is crucial to the fields of design, film and culture, to build connections between these three areas, and their importance to this study.

\subsection{A Well-Designed Film Poster}

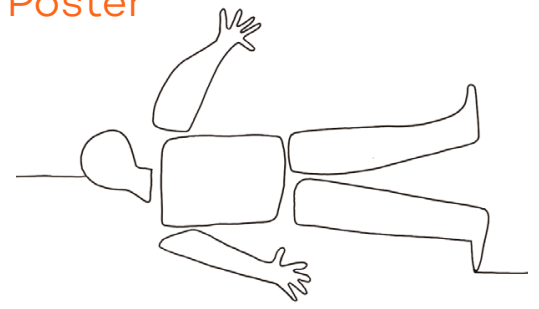

Until the early 1980s, the first contact audiences had with a film was through seeing its poster (Burke, Graham, \& Lawson, 2017). This led to an undeniable frenzy around them because of the content that could be interpreted from a single static image. The purpose of a film poster at its roots was to be an idea and small indication of what to expect from the Film itself (Burke, Graham, \& Lawson, 2017). Designing something like this was a long process that took time and practice. Leslie Combemale, an expert in the field of animation, says in the documentary $24 \times 36$ (2017), that there is more to designing film posters than people believe, it takes education, creativity and repetition, in an attempt to create a concept that could represent an entire narrative.

Effective poster design in a film can add layers of relevance and importance to the story. A designer who plays a substantial part in 
this domain is Saul Bass. Considered a pioneer of the genre, Bass transformed, and shaped the design field of film posters (Bass \& Kirkham, 2011). It can be seen how Saul Bass revolutionised the field, in the 1959 film, The Anatomy of a Murder which soon became a classic of cinema. To this day, it can be instantly recognised by its posters and title sequences. Bass uses a bright orange as a backdrop for an illustration of a dissected body, which symbolises the body of evidence dissected in the court of Law within the film narrative (Bass \& Kirkham, 2011). As highlighted by Bass, a compilation of work integrated into a film has the potential to be the main features, and reference point to a film. They can give context, add depth, and intrigue the audience into watching a movie. (Bass \& Kirkham, 2011).

More recently, promotional film posters have become part of the modern approach to film marketing, which has been characterised as the "Saturation Strategy" (King, 2002). The saturation strategy involves using multiple media to make awareness of a film virtually unavoidable, since promotional material allows audiences to grasp the content of the film, and build appeal (Bolls, \& Eastman, 2000). This leads to a basic formula commonly seen now in most mainstream film posters which consist of; a photographic image, a reviewers quote, any prizes won in film festivals, and mention of the star cast, quite often displayed as floating heads in the poster (Lambrecht, 2012). Most studios now will place $\$ 15-\$ 35$ million on creating a campaign around their films, especially those films with a large fanbase. Studios will try dozens of art and design concepts, before picking only a few for the marketing of it (Marich, 2005). Poster Artists like David Byrd (Burke, Graham, \& Lawson, 2017) believe that creating film posters is becoming a dying art form. "The most difficult part of the movie poster industry is that $99 \%$ of what we do is thrown in the trash can" (Lucas, 2011, p.36). Technology created a shift in the industry, as it now has an essential role in the creation of film posters, drastically changing their objective and direction.

Design techniques have moved from being utilised to craft something that explores beauty, narrative, and art, to now being appropriated as a manipulation tool. Humans subconsciously decode certain aspects in a poster to determine what it is, and the narrative behind it $(\mathrm{Fu}, \mathrm{Li}, \mathrm{Li}$, \& Wei, 2015). Poster designers evoke emotions from their audience by using visual techniques to conditions audiences to interpret and define the film category. The problem with the uniform way of designing 
is that "advertising is supposed to cut through the clutter, not to blend in with it." (Shutt, 2003, pg.300). Shutt explains that producing promotional film posters should be about advertising something to the audience in a fresh, complicated, loud, and messy way. However, with all these new technological developments, Lee believes that the film posters created today, will not be celebrated or remembered as we do the posters created by the likes of Saul Bass (2016).

Technology has also affected the film poster by altering the medium in which the posters are understood. 24x36" posters are no longer the only manifestation of a film, online media and streaming platforms such as Netflix, now also require thumbnails and banners. This relatively new aspect of film posters has not been studied far since the field is still emerging. However, online writers such as Amat, Basilico, Chandrashekar, \& Jebara (2017) can already illustrate that the thumbnail you see of a film on Netflix, is directly related to what you have previously watched. Users will spend under 2 seconds looking at each thumbnail of a film before moving on, so within that time, Netflix will do whatever it takes to make users click. This formulaic approach has forced film poster designers to evolve alongside technology, creating what some consider further adverse effects.

Technological developments in the design field of Film, create an expectation of higher quantities of work, sequentially leading to a decrease in quality. This volume of production of not only posters, but also thumbnails, and banners encourages biases and prejudice in the design process. Sottek argues that some of Netflix's decisions of thumbnails is related to racial identity since different countries cycle through completely different thumbnails depending on the characters (2016). He argues that unconscious cultural bias plays a part in this. The Tv series Senses which has a culturally diverse cast, will depict a different character in the thumbnail depending on which country you are streaming from (2016). This fast-paced environment of productivity forces designers to more heavily rely on previously established stereotypes and film characteristics to capture viewers attention.

This section argues that cinematic posters have deformed from being celebrated art forms to systematic marketing schemes. Technology, public expectations, and the economy of Hollywood has forced designers to create posters that no longer can be considered artwork. 
Academic Lee outlines that posters of the likes of The Danish Girl, and Dirty Grandpa will never end up on anyone's wall in 20 years, unlike posters such as Scarface, Pulp Fiction, and Breakfast at Tiffany's (2016).

\subsection{Latin American Artistic Background}

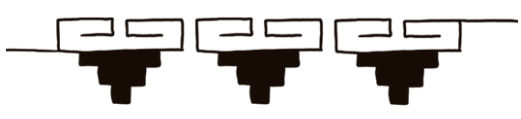

Latin America is a continent that is fueled by its diversity. Poet Pablo Neruda once described Latin America as the continent of hope. This is due to so many broken promises by the people for the people, while still maintaining a constant faith and perseverance in the face of social and political turmoil (Ryan, 2017). The continent is made up of 20 countries, and contains a mix of peoples from Asia, Africa, and Europe. It was a site of ancient civilisations and empires. It has the most significant number of surviving Native American groups in the world, the largest concentration of Africans outside of Africa, and Japanese outside Japan. The region is not just rich in tradition but the scene of exciting developments in modern and postmodern culture (Knapp, 2002).

While design as a practice only started to take shape in Latin America in the 1960s, there have been many components that have formed what it is today (Bonsiepe \& Cullars, 1991). The characteristics of Latin American design originates from visual narratives in preHispanics textiles, tapestries and paintings. Designers such as David Consuegra, still reproduce a lot of geometrical motifs, anthropomorphic and zoomorphic figures in his work (Caban, 2004). The continents design style also has a rich heritage traced back to the Aztecs, the Mayans and the Incas. According to Taborda, \& Wiedemann the work of graphic designers from Latin America tend to be characterised by free-flowing forms and shapes, reflecting the sense of free-flowing ideas and the impact that social issues have on design in Latin America (2008).

Latin Americans tend to use posters as a way to explore their social, political, and economic struggles. Lear (2014) states that historians since the mid-1980s have primarily moved to recognise the period between 1910 to 1940 in Mexico as a social and cultural revolution, and argues the immense impact and influence graphic design and art 
had over this. For example, in 1933, La Liga de Escritores y Artistas Revolucionarios (The League of Revolutionary Writers and Artists) was established to artistically speak on their current situation (Caban, 2004). The Cuban Poster Movement also shows the power of graphic and poster design, as a medium to spread social and political messages to a large number of people (Caban, 2004). These countries and many others in the continent have at one time or another used graphic design to fight against the hardships they faced.

Latin American design today is influenced by the political need to educate and inform the masses of current issues and messages of cultural identity, politics, oppression, resistance, and progress (Souter, 2018). The Mexican 'Muralist Movement' visualised the hope, pride and nationalism of the people on the aftermath of a revolution. Murals were the way Mexicans found of spreading visual messages. Two people that are influenced by this today are Latin American artists Os Gemeos ('The Twins' in Portuguese). The two brothers communicate silently to create colourful art on murals and street walls. Their bright, vibrant art shares a dream-world feel (Macdonald, 2014) that reflects their colorful culture. It becomes apparent that design started in Latin America as a means of political rebellion and has advanced with that, while also being influenced by international ideals, to become what it is today.

While Latin American design involves indigenous crafts, ceramics and intricate mural art, it is also slowly growing and learning where it fits within a global context. The twentieth century brought about a perception of the United States to be a place of modernity, formalism and intellect, simultaneously creating the image of Latin America to be a place of timelessness, realism, and passion. These characteristics led Latin American art to be perceived as unestablished and not validated due to its use of traditional craft (Perez-Barreiro, 2005). These views meant that very few Latin American artists were part of exhibitions outside of Latin America due to the fear of art galleries and museums appearing uncultivated. What this caused, was a lack of recognition and comprehension of Latin American art, allowing societies to keep to their old perceptions of the people from lack of international exposure.

Just like Latin American art, Latin American design has also been profoundly misconceived globally. 
Diego Vainesman, an Argentinian-born designer, once proposed a question to his American public (Fox, 1996)

"What do we in the U.S. know about Latin American and Caribbean people and activities? We know they play soccer. We know they have military coups. We know they take siestas. And we know they mostly speak Spanish, which we remember taking in high school. Just as we would not expect to really know the great cities of the world by traveling only through Epcot Centre recreations of Paris, Rome, and Tokyo, so we should not expect to know much about Latin American and Caribbean design just by contact with Spanish-language ads in the subway." (Fox, 1996, p.2)

Vainesman and many other Latino designers who were trying to break the mold were the ones who spoke for their culture and history and allowed for further acceptance and appreciation to appear in the rest of the world.

\subsection{Stereotypes in Film and their physiological implications}

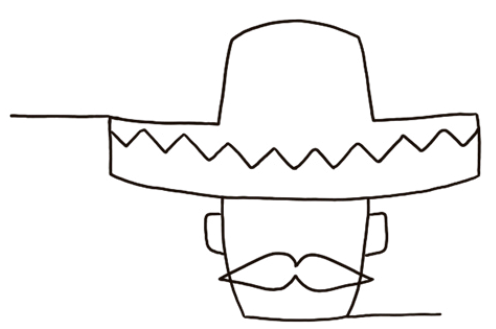

Humans beings stereotype as a way of categorising visual information in their minds. While this is harmless and necessary to comprehend the world around us, in this review the term that will be targeted is, "The act of making judgments and assigning negative qualities to other individuals or groups" (Berg, 2002, p.14). This stereotyping consists of three things; category making, ethnocentrism, and prejudice (Berg, 2002). The potential issue with this mindset is that it takes a large group of complicated people, simplifies and strips them down to shallow images, removing any redeeming qualities the people have, to emphasise the few flaws they may or may not acquire. For example, DePyssler and Vargas argue that all Latinos represented in Film are considered to be loud, Catholic, poor, uneducated and passionate, they all also must speak Spanish, and be part of a big family (1998). Which in itself is an assumption and judgement made. 
These assumptions made about the culture only grew when Latin Americans started migrating to other parts of the globe, creating the title 'Hispanic'. Initially, this was a way to unify them, but it soon became their status and identity badge (Olivarez, 1998). 'Hispanic' has now become a too broad a title, which has prevented a sense of self-development to build between these different types of people, and hindered others abilities to differentiate and judge those who only have their ethnicity in common. Stereotypes reflect reality from a not very refined, single point of view. As Katzew (2011) explores in his text, stereotyping as enforced as this, can hinder one's sense of self and cause problems for young people when growing up. When people do not see themselves enough in Film and Television, it can lead to thinking of oneself as unimportant and worthless (Katzew, 2011). These are only some of the effects that formed from so many different and varying characteristics condensed down into the title of 'Hispanic', which is what makes these assumptions dangerous.

As stereotypical characteristics became more apparent through time, patterns become evident. Berg (2002), states that there are six central Latin American stereotypes in Film. "El Bandido", 'The Harlot", 'The Male Buffon", "The Female Clown", "The Latin Lover", and "The Dark Lady". These stereotypes are not only seen in the golden age of Hollywood but are still commonly used storytelling conventions, applied to narratives in film today (Berg, 2002).

Above the six central stereotypes of Latin Americans, the most enduring stereotype is 'Tropicalism' (Guzman \& Valdivia, 2004). This refers to the unswerving attributes of bright colours, rhythmic music, brown skin, and females with red lips, seductive clothing and curvaceous bodies. A stereotype often explored through the likes of Carmen Miranda and Ricky Martin (Guzman \& Valdivia, 2004). Tropicalism is deeply rooted in societies ideals, making it no longer seem to be a stereotype. When considering the psychological impacts on those Latin Americans that do not have brown skin, or enjoy dancing to rhythmic music, the damage that is caused by these assumptions is identifiable.

Katzew (2011) assesses biased images by exploring in her text the "Schema Theory". The theory speculates that children, who do not have real-life exposures to culturally different people, and minority groups, rely on television and Film to gather cultural and ethnic 
information about them (Katzew, 2011).

The issue of misinterpretation is that it can shape public opinions (DePyssler, \& Vargas, 1998). Gordon, Rivadeneyra, \& Ward (2007) support this statement by exploring the power that television and Film have over young 'adults' education. They hold proof of why breaking these stereotypes are relevant, by exploring its abilities to shape all viewers knowledge of culture and their perspective towards it. A film can often act as an agent of socialisation, which brings to light how powerful cinema is, and while the Schema Theory represents the adverse effects of this, it also proves that positive effects are possible when culture is addressed correctly.

These stereotypical images create negative physiological feelings towards oneself (Saucier, 2010). These assumptions arise from the lack of directors, writers, and producers with no deep cultural understanding of varying groups. Erigha (2015), claims that "biased images can influence social behaviour towards members of marginalised groups, impacting public perceptions of racial/ethnic minorities”. (Erigha, 2015, pp. 85-86) bringing to light the importance of breaking down and dismantling the white, male, hegemony of American civic myth and culture which created these stereotypical assumptions in the first place.

\subsection{The Public's Perception}

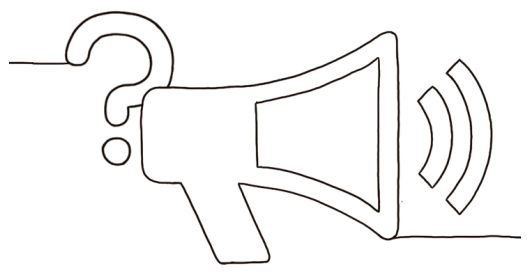

Having an industry that is still so profoundly exclusive and uniform makes cultural representation lacking and underdeveloped. Lee \& Priester (2014) are a part of developing the knowledge that films have a social and cultural responsibility to the public, and that viewing films that explore different cultures and ethnicities can help our societies to understand each other better and coexist. Mass media, films, social institutions and legal systems are extensively intertwined, since media content shapes people's thoughts, and peoples thoughts shape legal systems (Bender, 2003). In recent years the media has seen politicians, 
like American President Donald Trump, encourage stereotypes, and negative connotations toward Latin Americans. In Trump's Presidential Announcement Speech (Time Staff, 2015) He states that

"When Mexico sends its people, 'they're not sending their best. They're not sending you. They're sending people that have lots of problems, and they're bringing those problems with them. They're bringing drugs. They're bringing crime. They're rapists.”

While Trump affirms Berg's (2002) stereotypes with many of his statements, it puts the film industry in an awkward position, should they be casting the exact people politicians rally against in their campaigns? Films predating World War One defined all Latin Americans as male bandits, whose sole purpose was to murder and destroy (Woll, 1939). Through the years, instead of banishing these stereotypes, they grew to seep into every media aspect the masses produce and consume. The underdeveloped view of these type of people is direct evidence of the implications of having such exclusivity in the film industry. Brook (2016) argues that these Hollywood studios might fear to offend a regressive part of the population by casting "immigrants" as main characters in big blockbusters. Cathy Schulman, an American Film producer, also enforces this by stating that there is a decrease in cultural opportunities in film when there is a crescendo of financial risk (USC Annenberg, 2016). This statement explores the idea that Hollywood is always hesitant to explore minority cultures in fear of appealing to fewer people, and offending those in power.

Online authors like Castillo (2018), and Machado (2018), identify that the lack of advertisement on Latin American centered narratives, affects the general awareness of the film. Ladybird, the 2017 Oscar-nominated film, was a success in the mainstream media, a movie depicting the coming of age of a young girl battling with a problematic motherdaughter relation. This plotline sounded very familiar to many cinema fans that had watched critically acclaimed 2002 film, Real Women Have Curves which depicts a very similar storyline, but this time portrayed in a Latin American setting, with a Latin American cast. Authors like Rodriguez (2018) shine a light to those similarities and questions why Real Women Have Curves did not receive the Oscar buzz Ladybird did. Two films with almost identical plots, reviews, and messages, but the lack of media around it, means Real Women Have Curves did not receive 
the same attention as the more traditionally western Film Ladybird did. This argument brings to light why promotional material is so crucial in the success of a film.

\subsection{Conclusion}

This literature review highlighted the fields this thesis has at its centre. It explores the critical aspects within those fields, to give perspective into the 'why', while also giving the research its foundation. In this process, it firstly explored the significance of the film poster to stress how meaningful it is in building a connection between the masses and the Film itself. Then, Latin American art and design history was explored to create a window into the Latin American identity. Latin American stereotypes were explored to identify what this research will be fighting against, and finally, the public perception was recognised and defined to grasp why this issue is relevant and must be acknowledged. Latin Americans have been misinterpreted in the mainstream media for decades, and the lack of thought that goes into creating a film poster allows designers to rely on those traditional and old interpretations of the culture, which is no longer acceptable. 



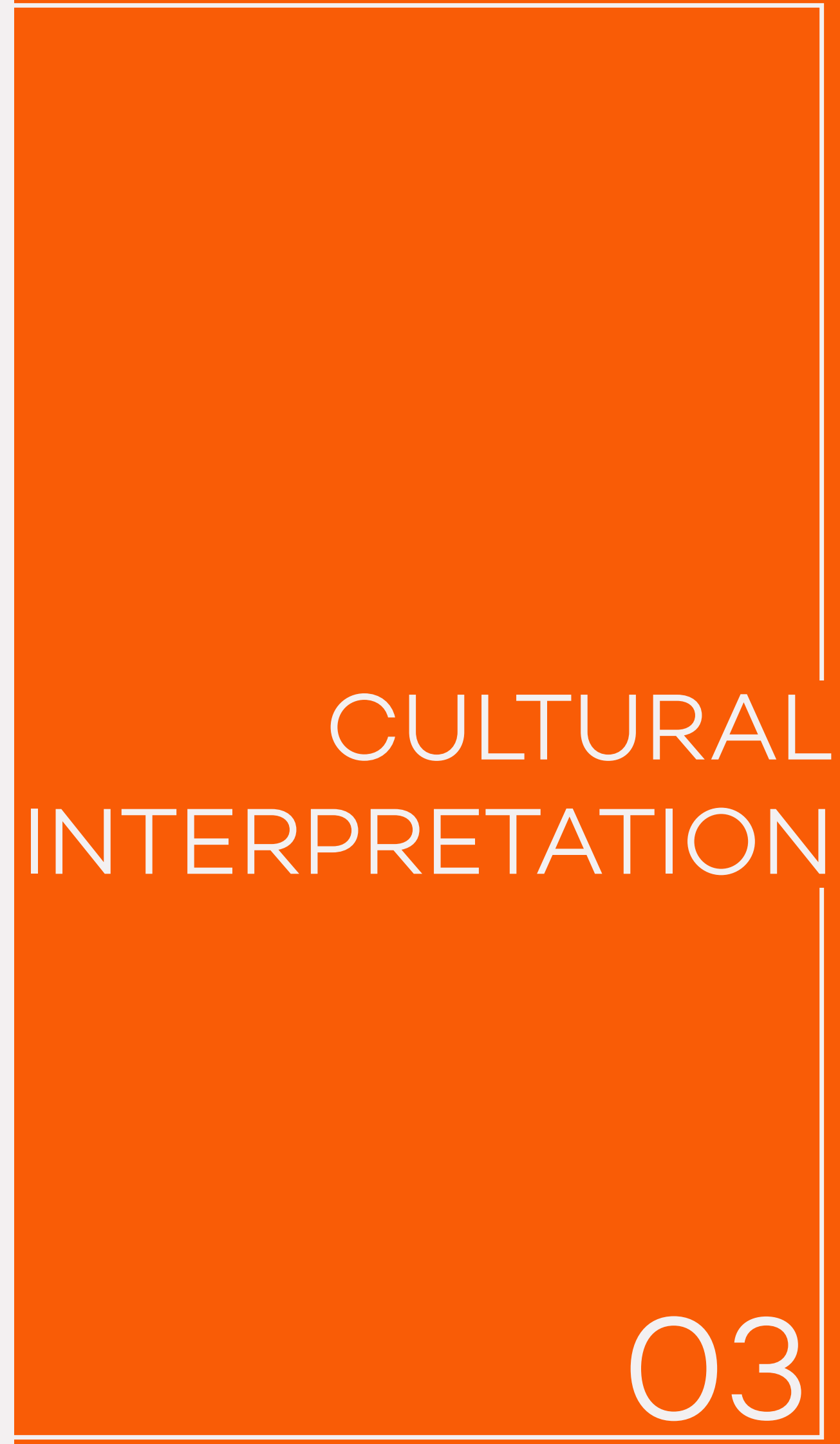




\subsection{Introduction}

In this section, cinematic posters will be analysed to understand how Latin Americans have been visually depicted in the last three decades. This analysis will be conducted to understand the visual message that is understood by western societies about Latin American culture. McKee (2003) defines the importance of such an analysis by the fact that as human beings we use visual stimuli to understand those who are different to us. We interpret reality by the visual information our brains receive - therefore that information has to be as close to the truth as possible.

The criteria for the posters to be selected were as follows; they had to either contain a Latin American Actor/Actress, or explore some form of Latin American culture/story within the poster, and have been released to the public from 1990 to 2019. One hundred and twenty film posters were selected for the study, and this amount was suitable to fit multiple films from the 1990s, 2000s, and 2010s, but also include multiple genres and films with both Latin American men and women. All of these elements were considered to ensure a well-rounded representation of Latin Americans in film posters over the last three decades.

\subsection{Visual Coding}

Once the posters were determined, the process of coding then started. I followed the process that, according to Saldana (2009), is called 'structural coding', which is an inquiry to a dataset that relates to a specific research question. In this case, 'What has been the visual treatment of Latin Americans in promotional cinematic posters over the last three decades?'.

The one hundred and twenty cinematic posters were initially coded to break down all visual or physiological elements within them. This process involved creating codes related to multiple aspects that ranged from the colour palettes used, costumes, the film title, characters facial expressions, any text used, and accessories. This process produced over 50 initial codes. 


\begin{tabular}{|c|c|}
\hline BROWN SKIN & 120 POSTERS \\
\hline FEMALE & 68 POSTERS \\
\hline RED & 52 POSTERS \\
\hline MALE & 48 POSTERS \\
\hline MENACING FACE & 48 POSTERS \\
\hline WEAPON & 33 POSTERS \\
\hline GUN & 31 POSTERS \\
\hline ANGLO HERO & 26 POSTERS \\
\hline LONG HAIR & 26 POSTERS \\
\hline VILLAIN & 25 POSTERS \\
\hline REVEALING CLOTHES & 24 POSTERS \\
\hline SEXUALISED & 21 POSTERS \\
\hline SECONDARY & 19 POSTERS \\
\hline MORE THAN ONE & 15 POSTERS \\
\hline FACIAL HAIR & 14 POSTERS \\
\hline EXPLOSIONS & 13 POSTERS \\
\hline RED CLOTHING & 12 POSTERS \\
\hline SUNGLASSES & 8 POSTERS \\
\hline DARKNESS & 8 POSTERS \\
\hline ETHNIC & 8 POSTERS \\
\hline HIGH HEELS & 7 POSTERS \\
\hline YELLOW & 7 POSTERS \\
\hline RED LIPS & 7 POSTERS \\
\hline 'THE OTHER' & 7 POSTERS \\
\hline TROPICAL & 6 POSTERS \\
\hline FLOWERS & 5 POSTERS \\
\hline LATIN LOVER & 5 POSTERS \\
\hline MESSY HAIR & 4 POSTERS \\
\hline GUITARS & 4 POSTERS \\
\hline ORANGE & 3 POSTERS \\
\hline MONEY & 3 POSTERS \\
\hline THIEF & 3 POSTERS \\
\hline SUITS & 3 POSTERS \\
\hline RELIGIOUS SYMBOL & 3 POSTERS \\
\hline ANIMALS & 2 POSTERS \\
\hline MEXICAN REFERENCE & 2 POSTERS \\
\hline INAPPROPRIATE & 2 POSTERS \\
\hline 'REVENGE' & 1 POSTERS \\
\hline OLD WEST & 1 POSTERS \\
\hline
\end{tabular}


APPEARED IN

\begin{tabular}{|lr|}
\hline SYMBOLS & 1 POSTERS \\
\hline EXOTIC & 1 POSTERS \\
\hline MALE BUFFOON & 1 POSTERS \\
\hline THE MAID & 1 POSTERS \\
\hline THE DRIVER & 1 POSTERS \\
\hline TATTOOS & 1 POSTERS \\
\hline STEREOTYPICAL SLOGAN & 1 POSTERS \\
\hline TRAVELERS & 1 POSTERS \\
\hline ROUGH & \\
\hline FAMILY & \\
\hline DRUGS & \\
\hline & \\
\hline & \\
\hline & \\
\hline & \\
\hline & \\
\hline
\end{tabular}


Nevertheless, within the second cycle coding, the codes were then homogenized and narrowed down to 36 codes. Now within these codes, patterns started to appear, alongside striking connections between the posters.

\subsection{Patterns}

The most consistent patterns that appeared were that: women appear more often than men, however, when they do appear, the men tend to be utilising weapons (mostly guns, but swords in timepieces). The men also tend to have longer hair and facial hair than any other Anglo male in the poster. There was also a pattern of women often being sexualised, either by their facial expressions, positioning, but predominantly by their revealing, tight clothes, or ethnic costumes. All the Latin Americans had darker skin than their Anglo counterparts and very often seen with a menacing facial expression. This representation is problematic since studies of facial expressions prove that there is a high cross-cultural agreement in how the masses interpret facial expressions (Hwang \& Matsumoto, 2011).

Beyond the dominant patterns that appeared, some codes were not consistent throughout, but still essential and robust features which I believe relevant to mention. I found that in 7 posters, the Latin American character was shown wearing sunglasses, which appears to have been used to give the character a more mysterious and arguably malicious appearance. There were also only 15 posters that presented more than one Latin American actor, which reinforces the idea that beyond being misrepresented, Latin Americans are also underrepresented. Lastly, 14 posters displayed symbols that are often stereotypically related to Latin Americans, and this happened sporadically throughout the years, these symbols included drugs, money, guitars, animals, and cleaning supplies.

\subsection{Themes}

From the patterns produced, a visual interpretation of stereotypes can be understood, and constant elements can be interpreted. This leads the research to identity overarching themes. 


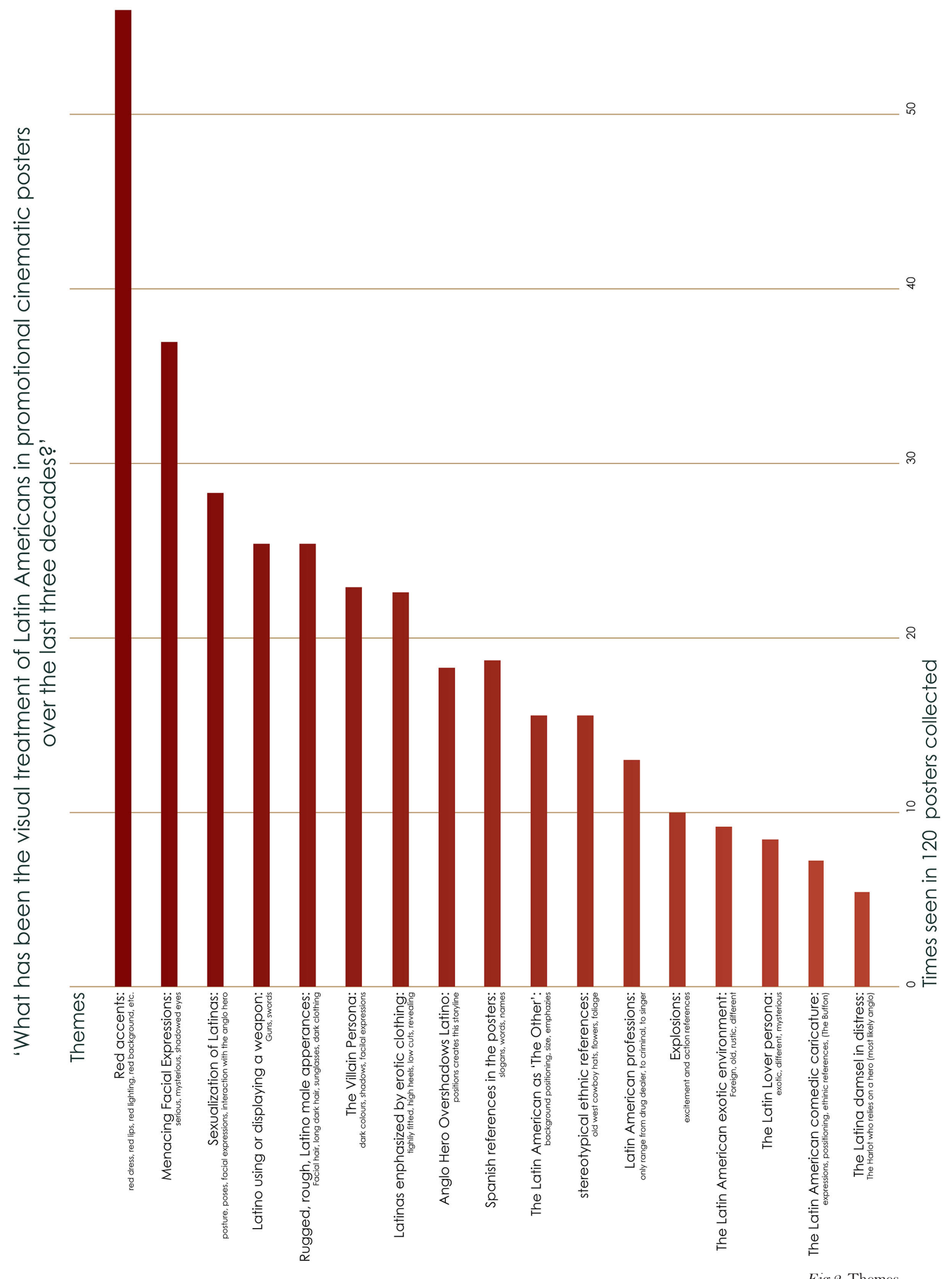

Fig 2. Themes 
As seen in the above image, the following themes are:

- Red Accents

- Menacing Facial Expressions

- The Villain Persona

- Latino Using or Displaying Weapon

- Anglo Hero Overshadows Latin American

- Spanish Reference in Poster

- Sexualization of Latinas

- Rugged/Rough Latino Appearance

- The Latin American Other

- The Latina Damsel in Distress

- Ethnic References

- Latin American Professions

- Explosions

- The Latin Lover Persona

- The Latin Exotic Environment

- The Latin American Comedic Caricature

Some of these themes overlap throughout the decades and the posters, but most impressive of all is the fact that out of the one hundred and twenty posters collected, based on my criteria, only thirteen posters did not present any of the themes explored, those cinematic posters were for the films;

- Anaconda (1997)

- The Sisterhood of Traveling the Pants (2005)

- Rent (2005)

- Things We Lost in the Fire (2007)

- The Sisterhood of Traveling the Pants 2 (2008)

- The Place Beyond the Pines (2012)

- As Luck Would have it (2012)

- What to Expect When You're Expecting (2012)

- The Promise (2016)

- Dear Eleanor (2016)

- Pitch Perfect 3 (2017)

- Everybody Knows (2018)

- Life Itself(2018) 
From these themes, an analysis of whether or not the visual treatment of Latin Americans had developed through these three decades was then conducted, to understand whether or not this is a recurring problem. Since there was a different quantity of posters from each decade, the analysis was done by selecting five posters from the beginning of each decade, and the end of each decade, this leading to ten posters from each decade to be analysed. 


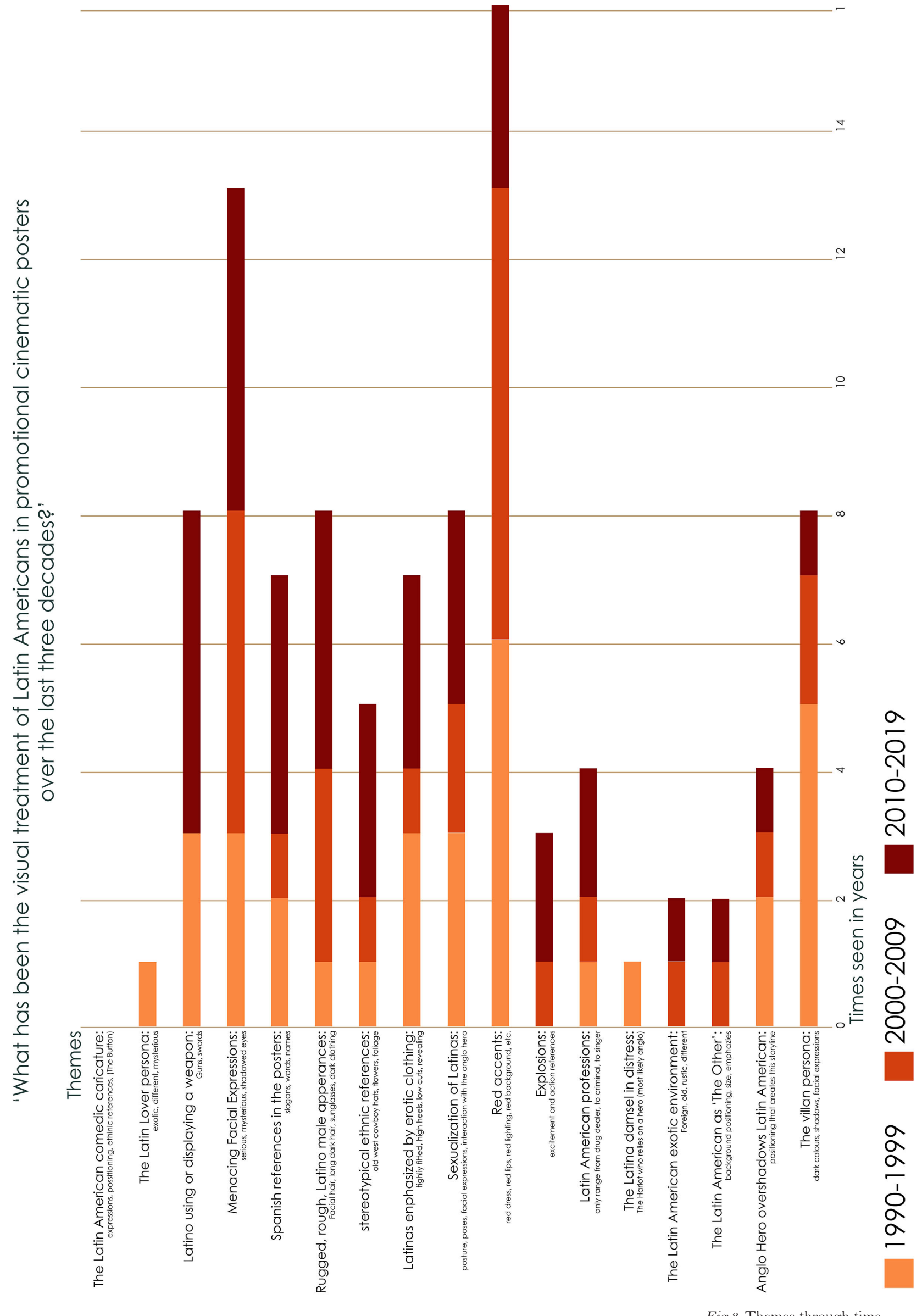

Fig 3. Themes through time 
From analysing the themes of the thirty posters, I expected to see a decrease in themes presented as the posters moved from the early 1990 s to the late 2010s. Nevertheless, What the analysis showed was that the Latin American representation had been consistently the same throughout this time. In some cases, themes have been seen more predominantly in this decade, then the previous two. For example, 'Latinos using or displaying a weapon' the characteristics of the Latino with a 'Menacing Facial Expression' and the use of 'Spanish references in the Poster'. However, most troubling was the continuous and steady objectification of the Latina body. The few positive outcomes were the slow decrease of displaying Latin Americans as the villain of the story, and the lack of sexualising Male Latin Americans as a 'Latin Lover'.

I use these charts not to emphasise the numbers, but to put into perspective the lack of change towards the portrayal of Latin Americans throughout the last three decades. The view of what Latin Americans are like and their governing characteristics have not changed since the early 1990s. 


\subsection{Analysis}

In further investigating the one hundred and twenty posters, an analysis was conducted based on, chronology, genre, and colour.

\section{Chronological Analysis}

When analysing the cinematic posters by year, the most compelling element was that similar themes kept appearing with the same frequency through the decades. Themes including the use of weapons by Latin Americans, red costumes, revealing clothes and facial hair by men kept appearing at a constant pace, which means that in 30 years the same visual techniques were being used to form the representation of Latin Americans in film posters. 


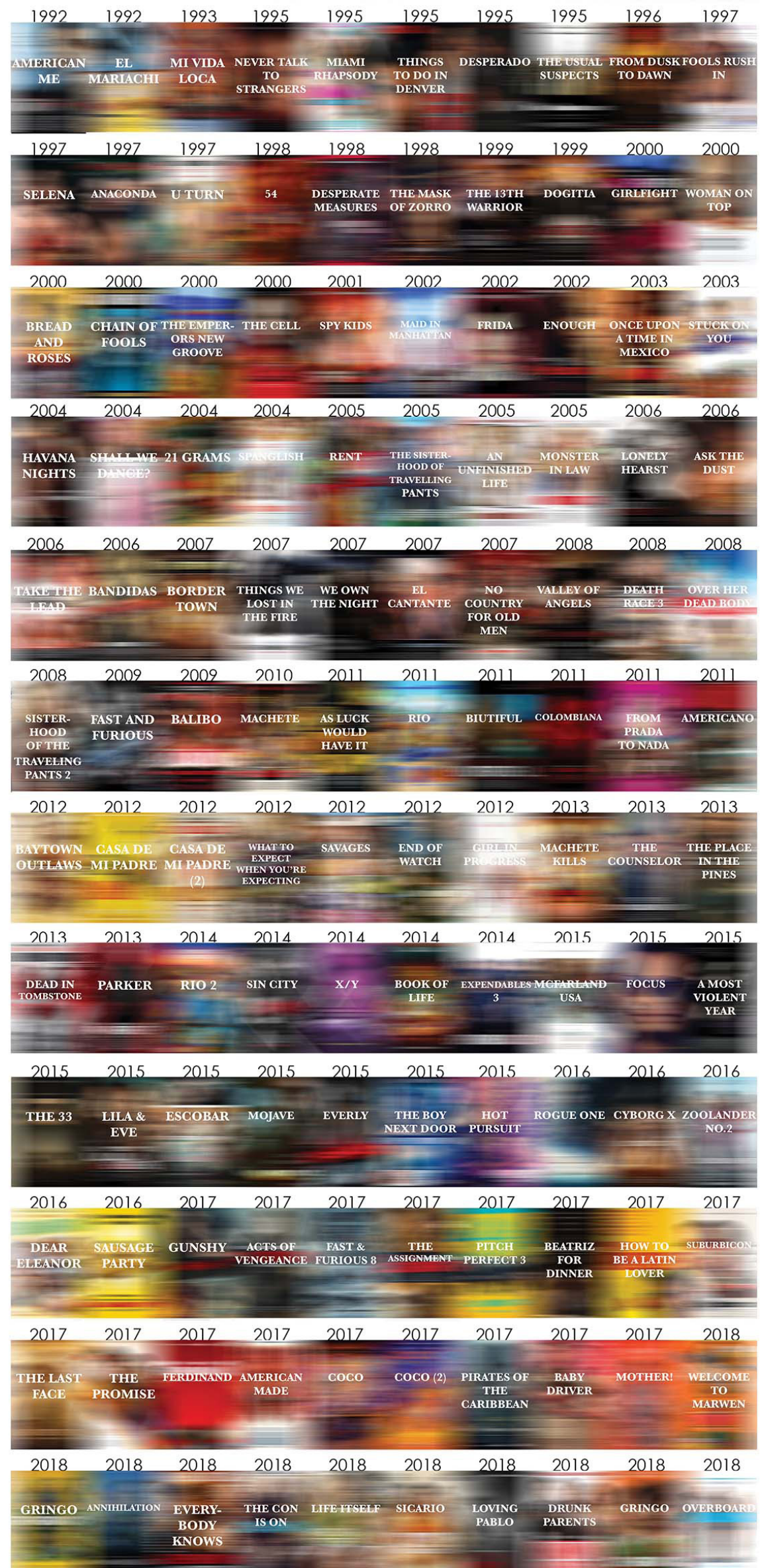

Fig 4. Chronological Visual 
In terms of colour design, these posters show that when Latin Americans are involved, there is a predominant lean towards warmer colours. Browns, reds, oranges and yellows were forefront colours, followed by blacks and blues, and lastly neutral shades of white, and $\tan$. Also remembering that there is always an undeniable affiliation of colours to the genre and style of the film. In those cases, it could be seen that the Latin American character was wearing red costumes, red lipsticks, or warm coloured accents on the posters. 

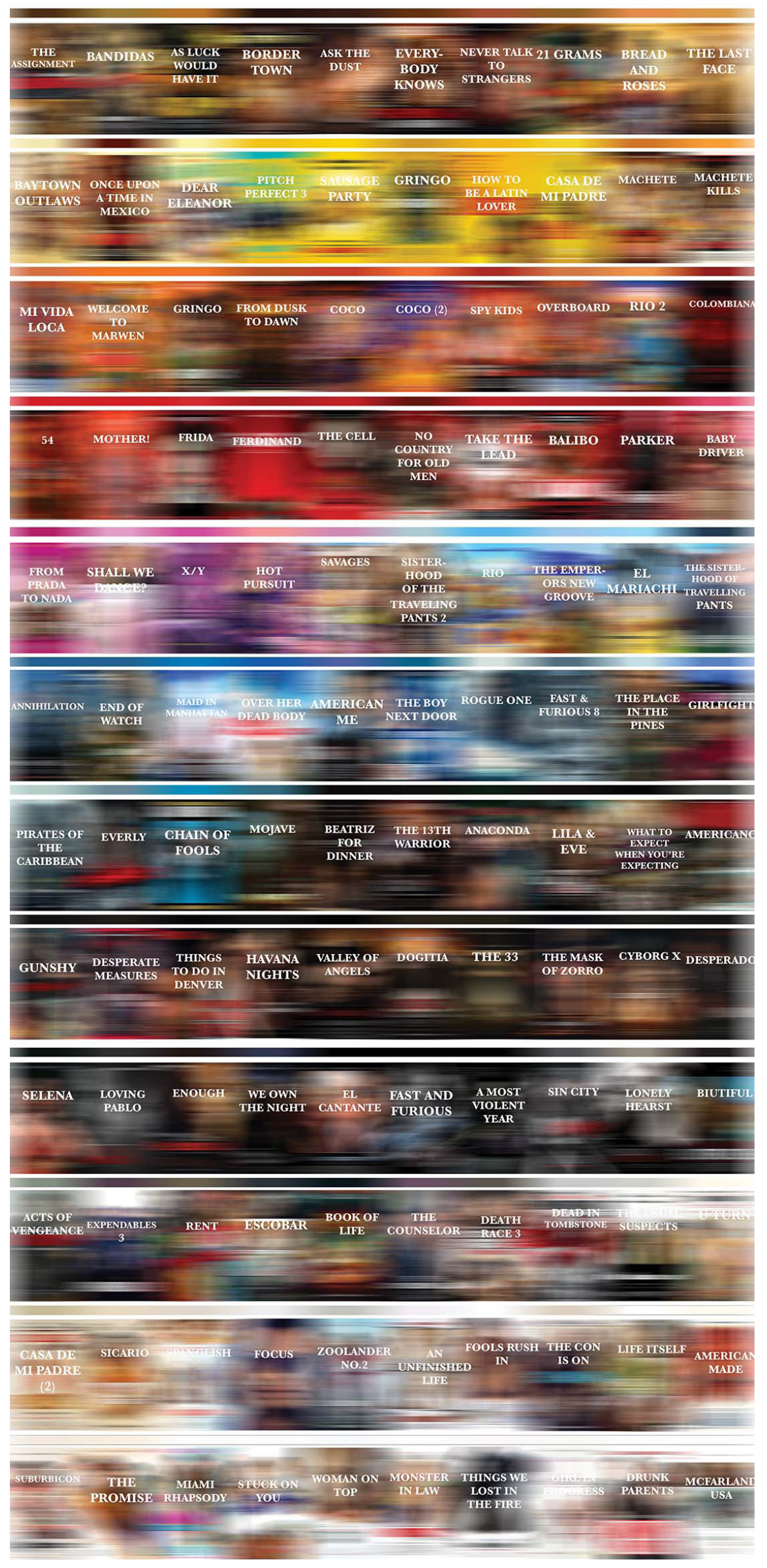

Fig 5. Colour Visual 
When separating the posters according to their genres, the IMDB database was visited, but I also relied on my interpretation of their visual identity. It became apparent that Latin Americans appear far more in action and drama films, rather than comedic and family films. What is also apparent is how often visual elements are used to establish the Latin American as the 'villain' of the story. In the promotional poster of Suburbicon, the dominant colour composition is neutral, while Oscar Issac, a Latino actor, is displayed in a hue of red. Also shown with facial hair, and a menacing expression. Standard visual identifiers that scholar Berg's (2002) recognises as critical features of 'El Bandido', and societies' Other'. 


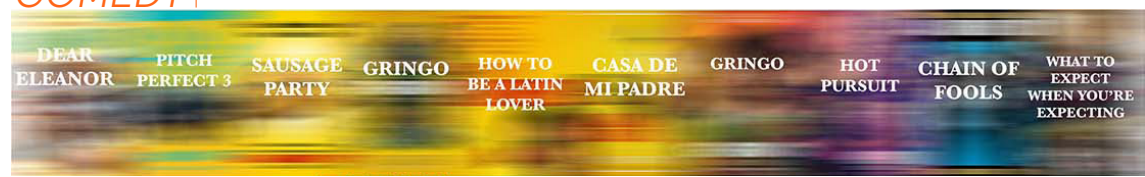

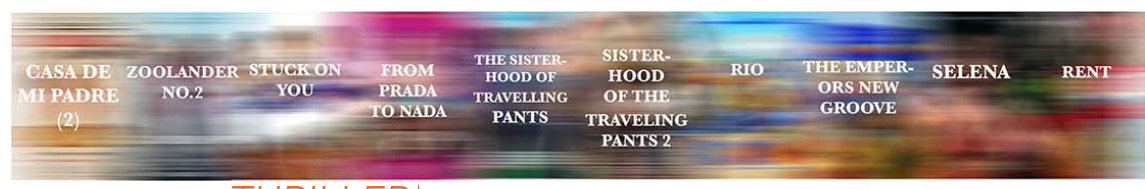

\section{THRILLER}

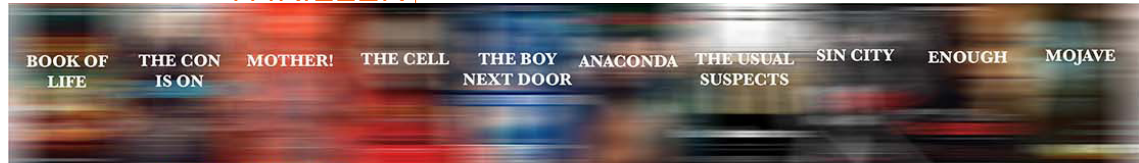

\section{ROMANCE}
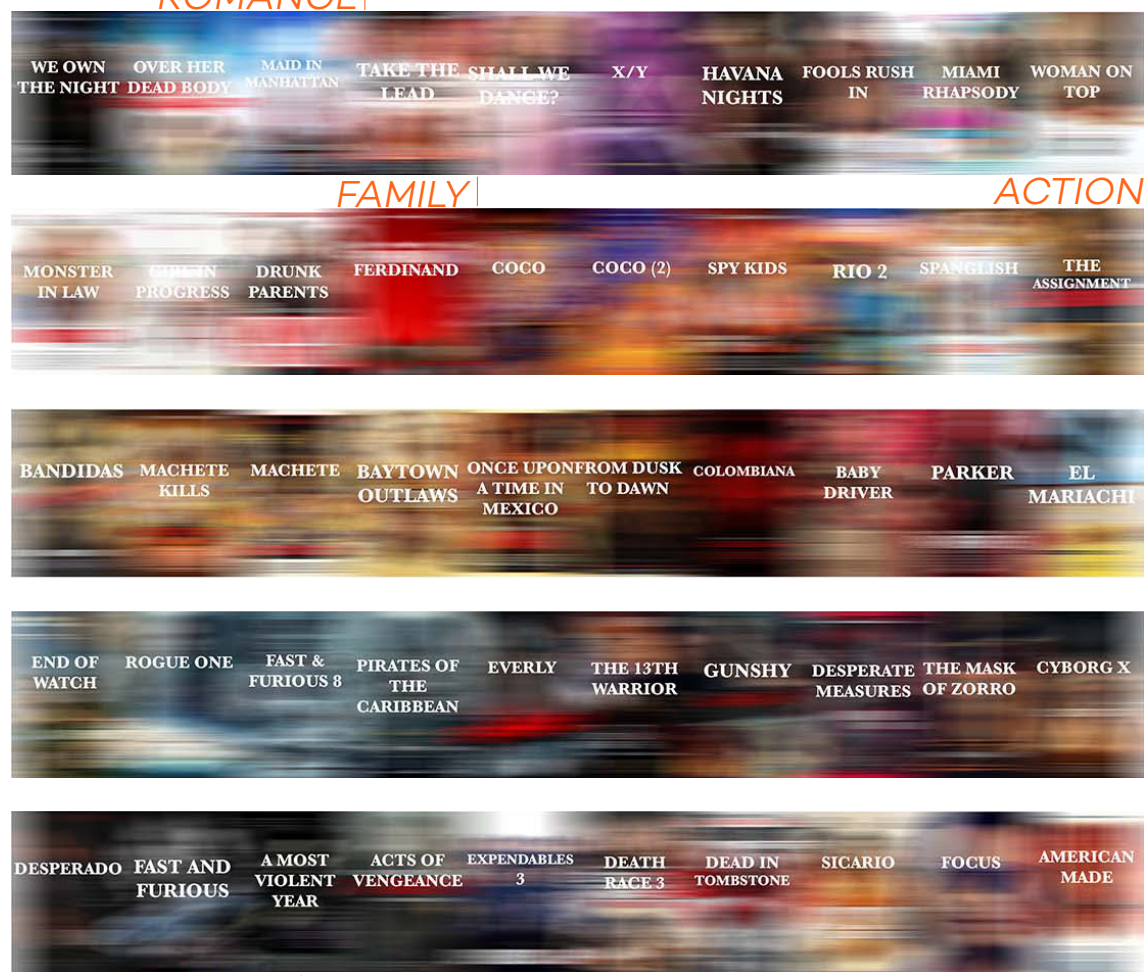

DRAMAI
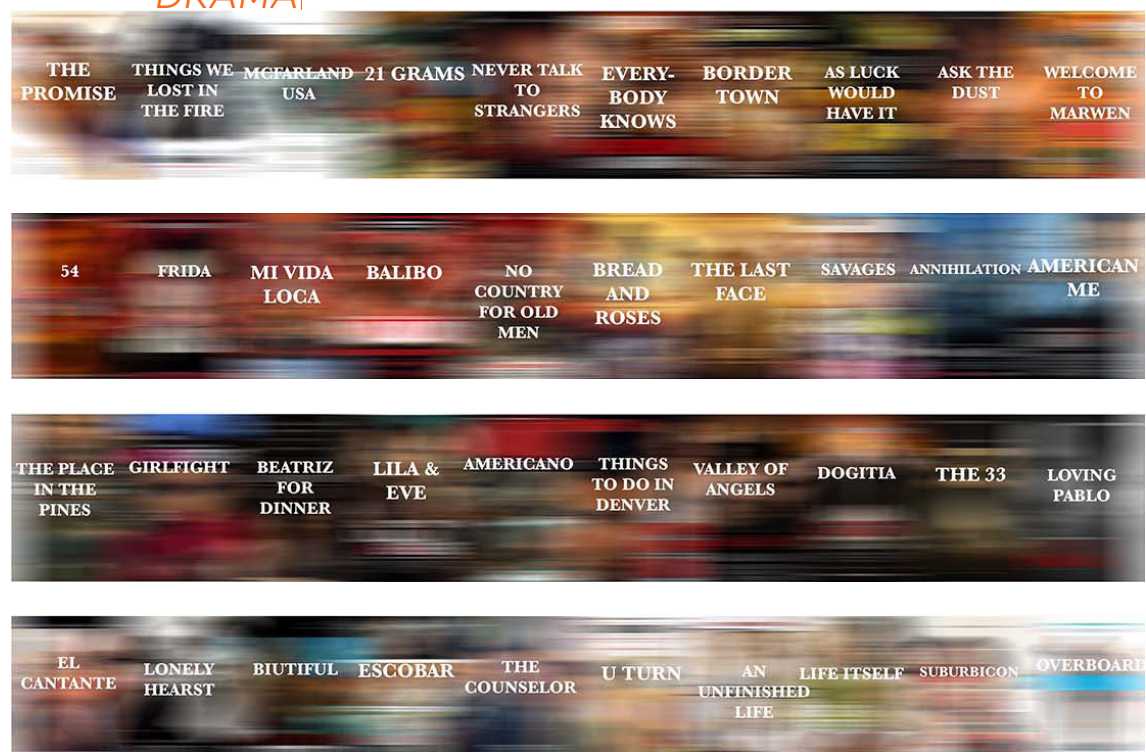

Fig 6. Genre Visual-2 


\subsection{Conclusion}

The purpose of this content analysis was to solidify a hypothesis that current visual images in film posters rely on formulaic processes of representing Latin Americans. These processes were established at the beginning of cinema, and as shown through the analysis, have not shifted since. This analysis has identified the visual manifestation of those stereotypes and seen their progress through the last three decades. With the knowledge of these factors, they will be bypassed in this thesis while attempting to display Latin American narratives and identity in promotional film posters. 



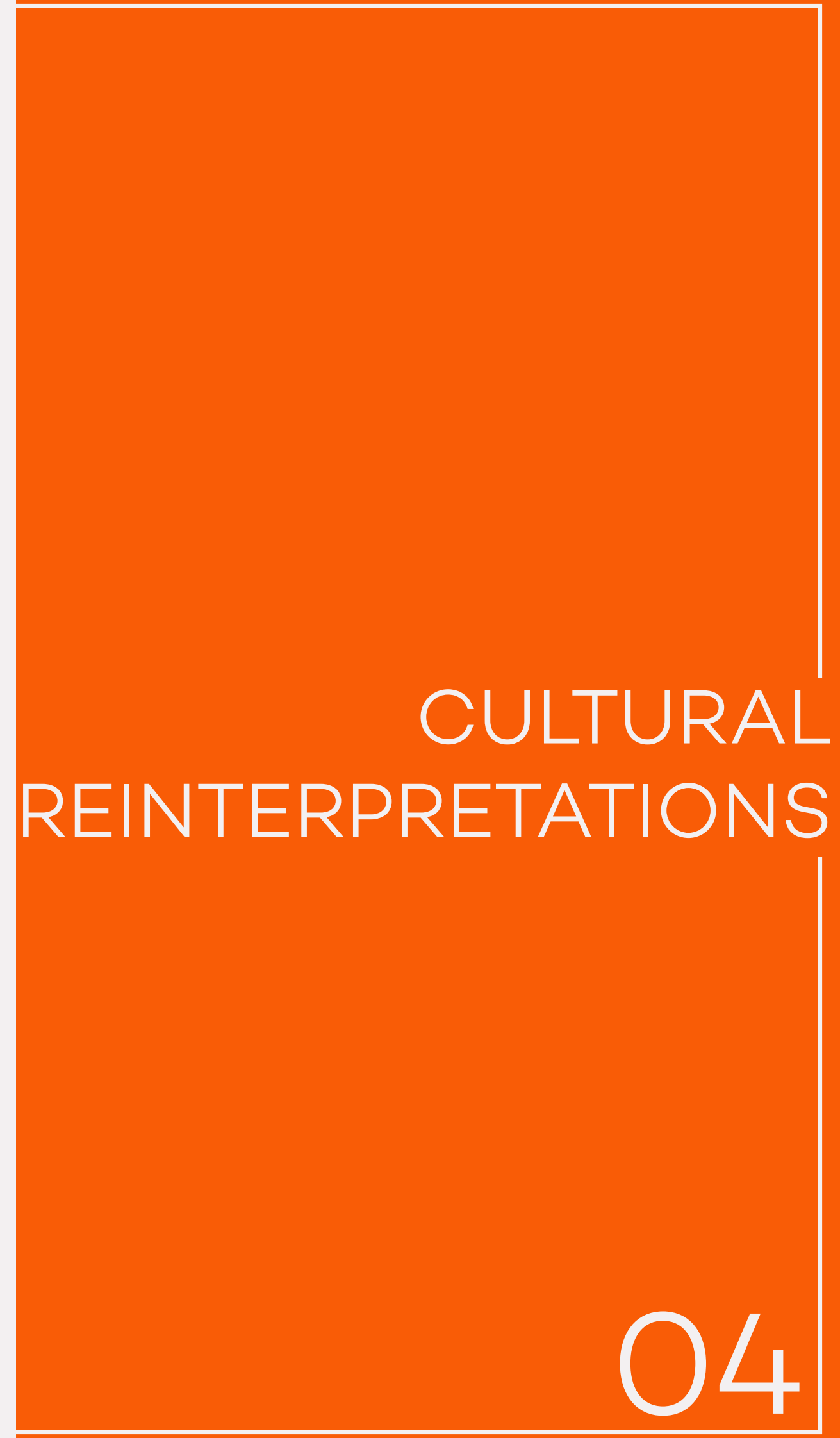




\section{4. .O Introduction}

Latin American art is influential and provoking, and it gives context to the reality around itself. The visual arts history of Latin America is directly related to social and political issues that happened through its history but also consists of an unswerving narrative to the people of the area.

Latin America is a place where, historically, many cultures have come face to face and found ways to form bonds. In this continent of twenty countries, there is an array of diversity within their narratives, folklore, history, and customs. Designer Gonzalo Fargas, states that in graphic design, creativity and ideas formed behind it are all the same throughout the area. In every Latin American piece of design, it is possible to trace some aspects back to the cultural roots and place of origin, which reinforces the idea that all the countries form together to share the same concerns, problems, fears, qualities and energy (Taborda \& Wiedemann, 2008).

It was only in the mid 20th century that Latin American graphic design began to form its identity. Latin America was colonised mainly by Portugal and Spain. In an attempt to maintain control not only over the countries within the continent but also on cultures within it, Portugal and Spain for a long time determined what should be read and consumed by their people (Taborda \& Wiedemann, 2008). Therefore, creating a bubble of what the Latin American people were allowed to believe and think. This means that within the design discipline, Latin America is still forming and developing its young identity.

Xavier Bermudez argues that purpose, pride, dignity and elegance are the legacies left behind to the people by their Latin American ancestors. Which leads to the continents graphic design to be overflowing with a vibrant and robust spirit, while it tells its narratives through images, and letters. However, most of all, it is always colours that make their designs stand out. "The designs taste of colours, smells of the arts, of fertile soil, and are observed from the heart. They remind us of the sweet treats in our food markets, our liquors and regional dishes" (Taborda \& Wiedemann, 2008, p. 8-9) 


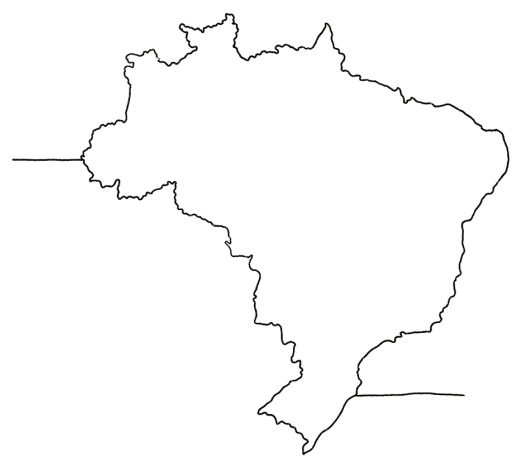

For Brazilian designers, there is a mix of modern, and third world influences from the northern hemisphere (Caban, 2004). Making Brazil a country that is continually attempting to balance all the diversity it contains. Due to this fact, only some of the critical points in its history will be explored in this section.

Cubism plays a significant role in Latin American art. In the 1920's 'Tarsila do Amaral' became the most influential female Brazilian painter and a pioneer of the art style. After learning from the great European artists, Albert Gleizes and Fernand Leger, Tarsila brought back to Brazil her creative knowledge. She explored its potential in a Brazilian, and Latin American context. This experimentation made Tarsila one of the founders of the modernist movement in Brazil, Tarsila was always combining her local spirit and art, with the influences of cubism (Dennison \& Shaw, 2005).

The 1950 s brought a new art movement to the forefront, that starts to resonate strongly with the concept of social and politically influenced art. 'Grupo Frente' (Front Group) was a society of people who rebelled against traditional values of the outside art world and fought for their cultural narrative and histories to receive the artistic acknowledgment that it deserved (Dennison \& Shaw, 2005). This group reflected Brazil's interest in art and their desire to be part of a global art world.

The 1960's held exciting times for the country, aside from political and social turmoil, it was a flourishing time for graphic design. Brazil's Ad industries became known worldwide and were, to a certain degree, recognised within the design field by taking home some of the most potent design awards in the world. Some years later, the magazine 'Grafica' become a design aesthetic sought by many, a reference point for what design in the country should be (Taborda \& Wiedemann, 2008). Today, Brazilian designers explore themes ranging from civil 
disorder, labour work on the country, the Amazon forest, and any other art movement that can be influential from other continents (Phillips, 2008).

In the article 'Artistry in the Blood', Carolina Gold, an Anglo-Brazilian designer, explains that Brazil is a little bit of everything. It carries a tropical aesthetic and intense colours that seem to appeal to those outside of the country (Phillips, 2008). It encases perfectly the sense of something traditional within the borders of Brazil but is seen as exotic, fresh and different to those on the outskirts. Brazil is a stage for a global exchange of influences, meaning that they look within, just as often as they look to the outside. Gold argues that Brazil's part in European, Japanese and Eastern histories, influences the Brazilian culture. (Phillips, 2008).

In Brazil, design starts with art. Artistic expressions of Brazilian designers pull more towards life experiences and instincts rather than academic sources, and previous rules to follow (Phillips, 2008). From experience, this reflects on the nature of how Brazilians live their lives. The Campana brothers, who are Brazilian furniture designers, explain in an article that, "The challenge is to make a portrait of our poor, beautiful and culturally rich country." (Phillips, 2008).

\section{Designer}

Felipe Taborda / Brazil

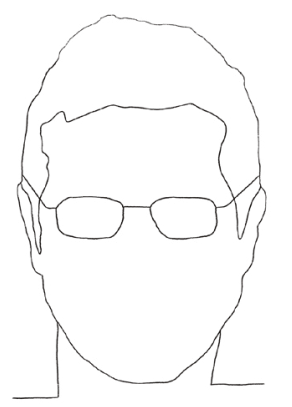

Taborda believes that its free-flowing forms and shapes can characterise Brazilian - and Latin American - design, he also believes the constant political and social changes in the country are continually affecting all creative channel, which includes graphic design (Samson, 2018).

Taborda is an exciting designer to analyse in terms of the efforts he has gone through to speak about Latin American design. His work and influence has been a part of books like 'Graphic Design for the 21st Century - 100 of the World's Best Graphic Designers', 'World Graphic Design', and 'The Anatomy of Design'. In 2008 he was a part 
of writing and publishing 'Latin American Graphic Design', the firstever compilation of historical and contemporary design from Latin America (Felipe Taborda Co-operation, n.d.). They are making him an advocate and defender of Latin American graphic design.

Taborda is part of the generation of designers who speak for their cultural background, embrace it, and protect it, which is crucial in the process of bringing not only Latin American culture, but every culture into the 21 st century. As beautiful and crucial is traditional art and folklore, culture needs to be explored through every art medium, including film design.

\subsection{Colombia}

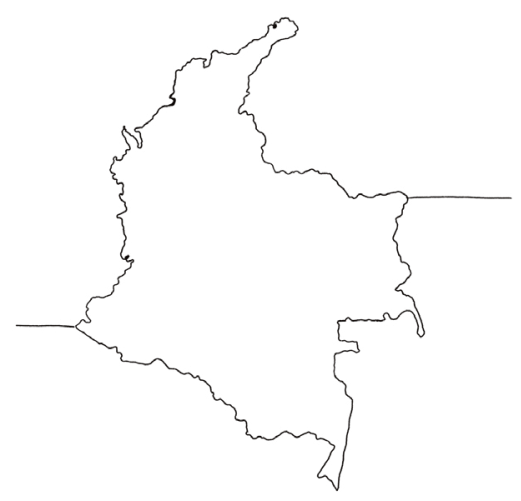

Like many other Latin American countries, Colombia's art history offers insights to not only their political and social history but also explores and adapts styles from Europe and North America to create their art. Their experiences with artistic artefact's date back to 3000 $\mathrm{BC}$, where archaeologists have found ceramics produced before any other country in South America. These pieces and all artefact's related to pre-Colonial times are found in the most famous museum of Colombia, Bogota's Museo del Oro (Don Quijote, n.d.).

Before many art styles reached the country, Colombian art from the 16th to the 18th century was heavily reliant on depicting Spanish Catholicism. It was then followed by many artists also being inspired by Baroque, and Rococo styles, even though the country has constant use of mixing indigenous, Spanish, and African cultures (Kline \& McGreevey, 2018).

Colombia's art history is also very closely related to its graphic design history. In Colombia, the big boost in graphic design happened in the first half of the 20th century when magazines like 'El Grafico', 'Pan', and 'Estampa' started exploring the possibilities within typography, colours, and photography. Another push towards the possibilities 
of graphic design for Colombia was within the creation of the international promotional character of Juan Valdez. The character was seen in all advertisements of the National Federation of Coffee Growers of Colombia' since 1959 (Taborda \& Wiedemann, 2008).

\section{Designer}

David Consuegra / Colombia

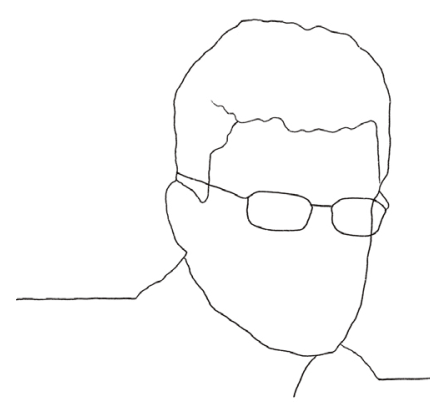

Consuegra states that Latin American nature is characterised by geometric motifs, anthropomorphic and zoomorphic figures. This fact gives Latin American designers inspiration to also construct their work by using geometrical shapes and figures, and the ability to change, adapt and abstract those shapes, leads these symbols to be incorporated into many design pieces seen within Latin American work (Caban, 2004).

Consuegra is Colombia's most famous graphic designer, who founded the country's first ever graphic design program in the University Jorge Tadeo Lozano. Consuegra is recognised internationally by the number of fantastic marks, symbols, and logos that he has created (Novin, n.d.).

Throughout Consuegra's career, he aimed to incorporate indigenous and international approaches and aesthetics to his work and visual communication in general. Consuegra believes that there is no distinct Colombian design. However, he argues that Latin American graphic design can always be distinguished and has a certain appeal and aesthetic that will always be recognisable.
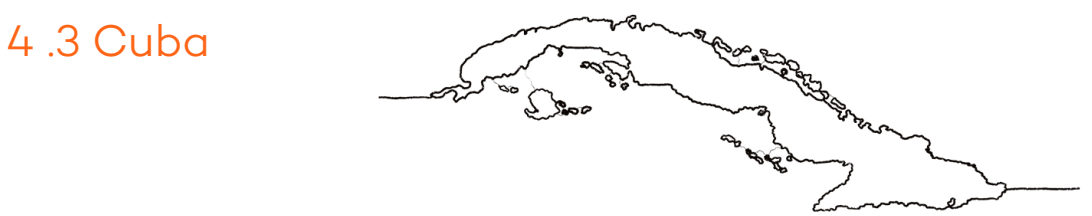

Beyond having a comprehensive cultural history, the country of Cuba has a long and entangled history with art. Much of Cuban art collects its references from Spanish descendants and Afro-Cuban culture, 
which also involves its indigenous histories (Fraunhar, 2005). While that is the fact, much of it is continuously developed and decided by popular culture throughout Cuba's history.

The impact of popular culture is seen in Cubas visual language through the understanding of the political/ social group 'Minorista' which was formed by intellectuals, artists, poets, journalists and attorneys, in the 1920s. The group protested against political issues, fought against corruption, and brought general awareness to the countries issues. Regular publishing showed this protest in magazines such as 'Social', by which they used art and literature to fight for freedom and their Civilian rights (Fraunhar, 2005).

Cuban artists collaborated with mainstream, and European art, while also exploring the rich narratives of African countries for inspiration, leading to the art movement which later became known as 'Afrocubanismo' (Fraunhar, 2005). This movements original concept was to embrace the varied, marginal, and non-dominant cultures within the country and the continent as a whole, which lead to stylistically expressive and diverse forms of art.

Within this movement it is difficult not to mention the work of art by Mario Carreno, 'Danza Afrocubana' the piece incorporates Afro-Cuban styles while also exploring European modernism, neoclassicism, abstract patterns, and cubism. 'Danza Afrocubana', is an example of developing art in Cuba and the influences from the outside world, but also the Latin American aesthetic and culture growing within the art scene (Fraunhar, 2005).

Cuban graphic design started to take shape in the 1960s when the Fidel Castro Revolution began. Poster design became a huge part of the countries visual language, ranging from Eladio Rivadulla posters that celebrate the victories of Castro, to government-issued posters that convey political messages. Beyond that, the Cuban Institute of Film always encouraged its national film posters to be artistic and creative, in an attempt to steer away from the American commercial styled film posters (Taborda \& Wiedemann, 2008). These reasons are part of the fact as to why Cuba is a leader in the design field within Latin American, despite its political and social problems, Cuban people were always encouraged to explore their cultural background. Graphic design in Cuba has been part of creating a visual cultural 
identity in the country, giving the nation a sense of unity (Taborda \& Wiedemann, 2008).

\section{Designer}

Pepe Menendez / Cuba

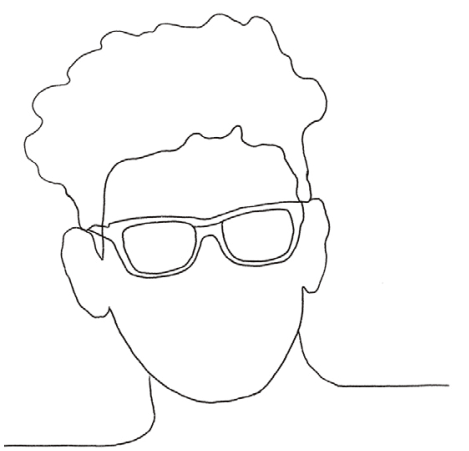

Menendez explains that Cuban graphic design is a convergence of Spain and Africa in one place, alongside Baroque forms and colours (Caban, 2004), it is the mixture of various cultures to create its own.

Menendez has built up his reputation by many exhibitions, and coordinating several national and international cultural events. He is a collector of Cuban posters from before his time, and gains his inspiration from those, portraying his cultural heritage through everything he designs (Taborda \& Wiedemann, 2008). Menendez has a passion for books and publishing, recently receiving the National Book Design Award in 2017 at the Havana Book Fair (Diaz, 2018). Menendez designs with the passion of a Latin American, which has allowed him to be an essential contributor to the visual language of Cuba.

\subsection{Conclusion}

This process has allowed me to understand where graphic design in Latin America comes from, and build a case around three countries and three designers to create a more specific view of the continents visual language.

Fargas, a Latin American designer, once stated that regardless of the differences each Latin American country shares, they all design in the same way. They share the same concerns, problems, fears, qualities and energy (Taborda \& Wiedemann, 2008). Which is why by analysing three designers I feel confident in saying that I now have a grasp on the essence and truth of Latin American graphic design, therefore its visual language also, which now allows me to discuss my findings; 
Latin America with its vast space and land, is also a very small, and niche place when it comes to graphic design. Regardless of the country, they have all shared similar histories, issues and victories. The outsiders who migrated or were brought to Latin America dispersed within the continent, meaning that all countries received similar artistic influences and occurrences within that. Throughout this case study, there were certain aspects of the designers' personalities that were intriguing, and elements they emphasise in their art that stood out. They all speak passionately about their origins and backgrounds and rely on instinct and their passions to drive their work. Most of them have studied outside of Latin America, but all have brought back their knowledge to help grow and develop Latin American graphic design.

These connections are a reflection of their Latin American ancestors who would study art abroad but come back with new styles and ways of creating art. In terms of their designs, they explore their culture in subtle ways. They bring nature, and modernism together through shapes, colours, collages and typography. Unlike common misconceptions, the colour red is not necessarily a leading player, but bright, neon and explosive colours do often take centre stage, reflecting the Latin American spirit and passion for life.

Overlapping shapes, motifs and symbols are often seen, and when photographs of people are a factor within the designs, they are often carefree, happy, unfiltered native Latin Americans. Lastly, a dominant aspect in the overarching designs is texture. Latin American graphic design tends to have depth and layers, the designers do not seem to shy away from crowded posters and visuals, relying on a mixture of features to convey their message, the designs are very rarely simplistic, but when they are, there is always that splash of colour. The design style is all done in a way that as Taborda (2008) says, creates a cultural identity unique to humankind. Latin American design speaks to creativity, culture, and Latin American people. Making it one of the richest, and most authentic visual languages the design world has ever seen. 



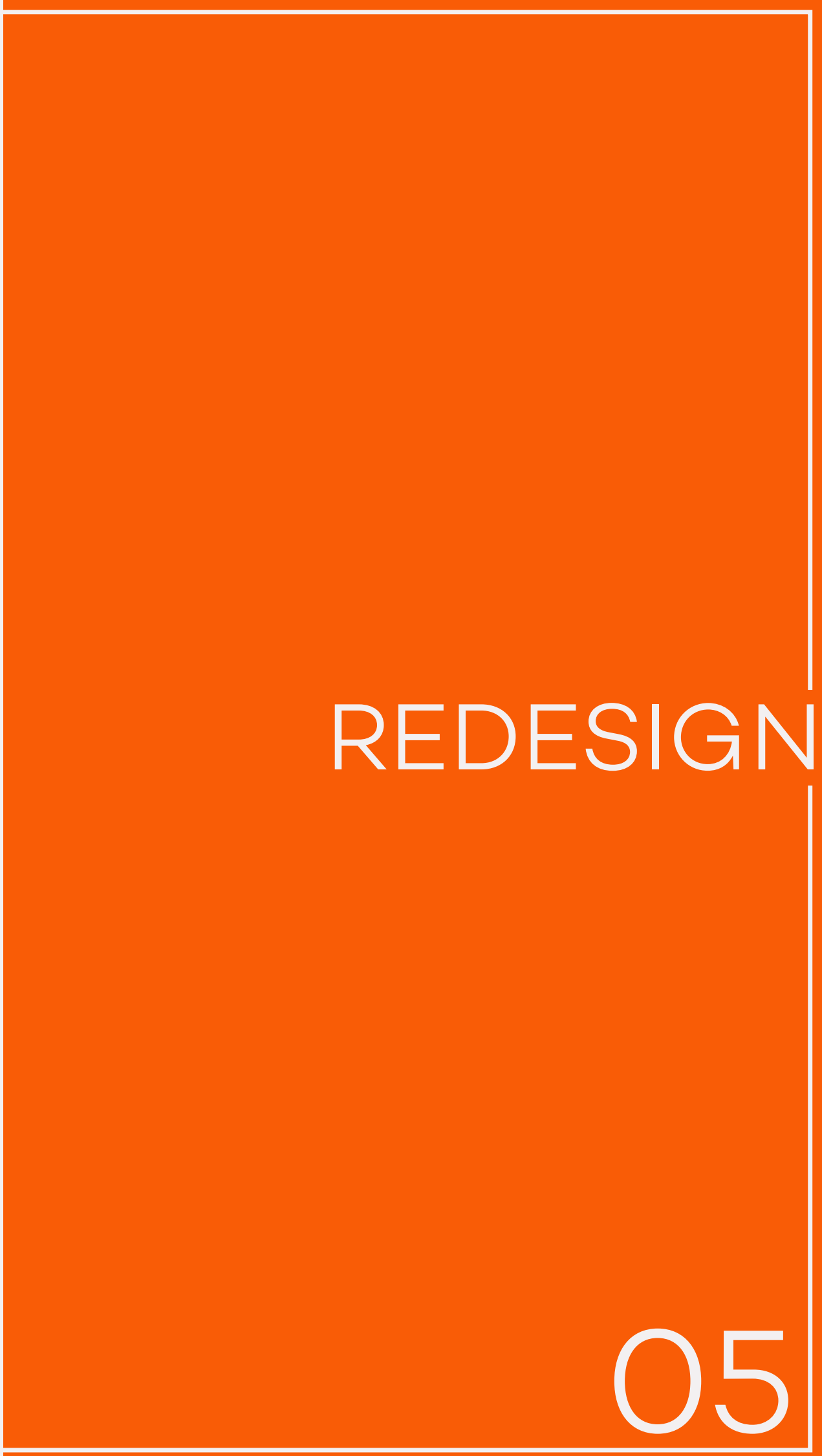


In this section, mainstream media film narratives will be investigated to understand how Latin Americans are represented in film. In doing so, the narrative of three films selected will be explored, to influence the creation of new poster concepts for each film. These films will be analysed based on the research presented in this thesis so far.

\section{Casa De Mi Padre}

This film can be described as a parody of the concept of popular telenovelas from Latin American countries. It is overly dramatic, sarcastic and 'low budget'. Will Ferrell presents this film as lighthearted fun. Nonetheless, very defined Latin American stereotypes are present and ridiculed. The plot of the film focuses on Armando (played by Will Ferrell), Raul (played by Diego Luna), and his fiancée Sonia (played by Genesis Rodriguez), who play out narratives of love affairs, family ties, and drug cartels.
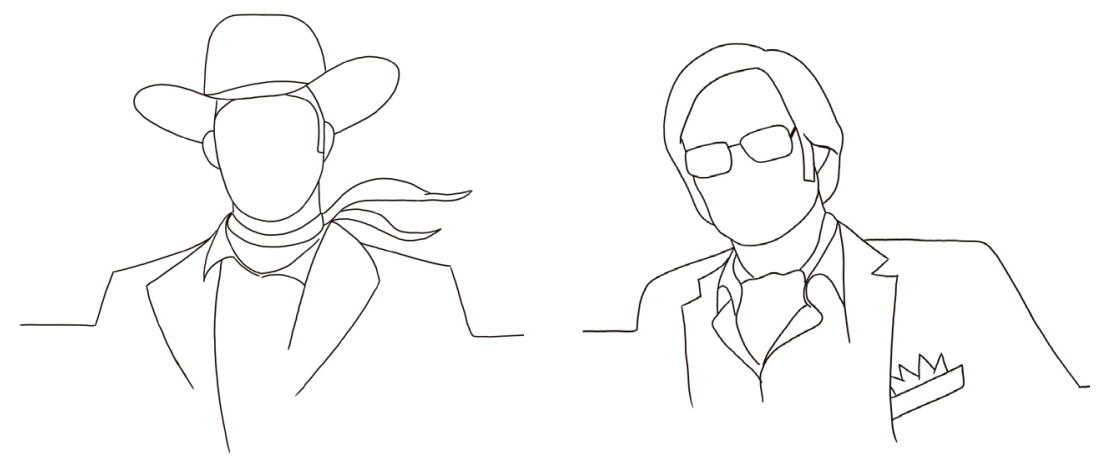

Two Male characters are established which can only be described as the 'Male Buffon' and 'El Bandido'. With strong links to Berg's (2002) description of the stereotypes, we see the former, Will Ferrell, sporting a cowboy hat, farm costume, and a bandana wrapped around his neck while Gael Garcia Bernal, the latter, is seen in a white suit, sunglasses, and long, slick hair.

The female Latin American stereotypes are also embodied through Genesis Rodriguez as the 'Damsel in Distress' whose personality in the film consists of being torn between the love of two men, and who is seen in tightly fitted dresses, flowers in her hair, and red lipstick. Again very closely matching the stereotype description by Berg (2002). The general objectification of women is also present in small ways in which they are portrayed. The men have somewhat more fleshed 
out personalities, while the women do not, and are often only referred to as 'The Woman', of 'His Woman', instead of utilizing their actual character names.

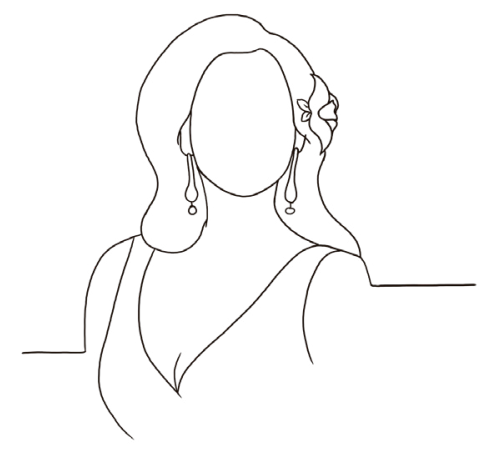

Stereotypical connotations are also displayed in the film by the use of dialogue. The use of derogative language can be seen through Mexican characters referred to as 'wetbacks', or a song that plays in the film stating that Mexican men do not know how to think. This is all placed as simple entertainment but contains negative connotations that affect the Latin American people.

\section{Gringo}

This film follows the narrative of American businessman Harold Soyinka. Who travels to Mexico where he is betrayed by his boss, and is forced to navigate situations of local drug wars, mercenaries, and dishonesty.

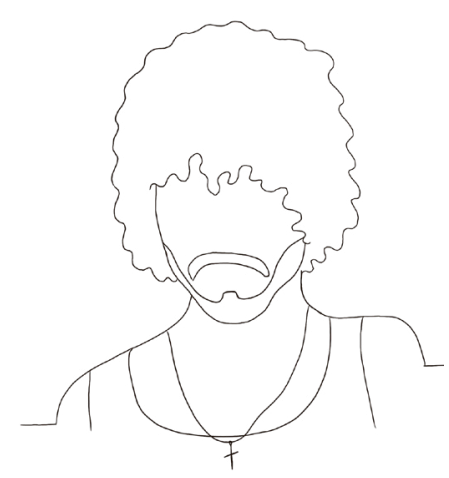

While this film does little to promote its Latin American actors on its primary film posters, they are still full of Mexican references, which heavily rely on stereotypes. Ronaldo and Ernesto, two of the few Latin American actors in the film, are the owners of a small motel, who have a minimal narrative. They rarely have any dialogue, and interact only with the Americans in the purpose of robbing their money. Like all of the other Latin American characters in the film, their motives are not explained, they have very few characteristics, and the ones that are present can be connected to the 'El Bandido' stereotype described by 
Berg (2002). Their visual appearance consists of long, dark, unruly hair, scuffed t-shirts and jeans, facial hair, and religious jewelery around their necks.

All of these factors build up to form a view that Mexico - therefore, Latin America - is dirty, poor, uneducated and rough.

\section{Colombiana}

Colombiana is a film about a woman who after seeing her parents murdered when she was nine years old, grows up intending to execute the same fate to those who committed the crime.

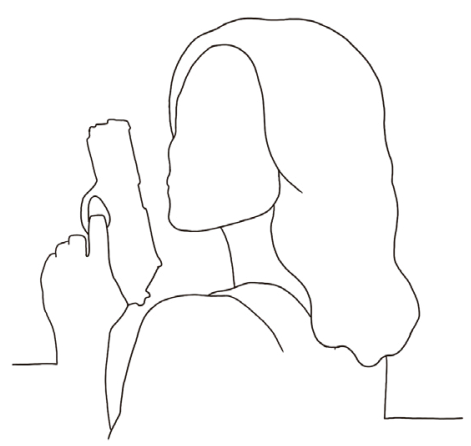

This film explores the narrative of family ties and the love between parents and their child. While this is a story that could resonate strongly not only with Latin Americans, but other communities, it is overshadowed by stereotypical implications that diminish the effect.

The film production had very little consideration towards Latin American culture. While the film is called Colombiana, there is nothing in the film that explores what it means to be Colombian, apart from the narrative that is built in the film poster that speaks to the idea that all Colombians are violent. Beyond this fact, no Colombians are cast as main characters in the film. Zoe Saldana is Latina. However, the supporting role of her Colombian uncle is portrayed by Cliff Curtis, a well-known Maori actor. Which creates an idea that being Latin American is a fantasy, not a reality. Therefore any brown-skinned person can represent a Latin American character.

This film belittled not only a country but an entire continent, in a way that encouraged Colombians to take action. At the time of the film release, an Colombian American organization began a campaign 
against the film, because of the use of stereotypes and lack of Latin American and Colombian substance.

The organisation 'PorColombia' explained at the time that their main issue was with the title of the film. They believed that, Colombia is only shown in a terrible light for a few minutes at the beginning of the film, with ripples into sequences outside of it that are only related to drugs and violence, but those few shots create a strong enough connection between the following events and the country of Colombian. PorColombia argues that the name was chosen because the stereotype sells, so, to fight this, their campaign consisted of modifying the cinematic poster (Carrasquillo, 2017). The original poster features Saldana with a gun between her hands and the tag line - "Vengeance is Beautiful" of which PorColombia removed the gun, to be replaced by flowers, and changed the tagline to "Colombia is Beautiful" (Carrasquillo, 2017).

The act of rebelling against not only the film but the cinematic poster speaks volumes to the concept that this affects people and how they see themselves. It also proves that Latin American communities want a different and complex representation of themselves in film narratives and their visual images.

\section{Conclusion}

The purpose of this section was to explore all of the negative narratives present in these films and identify the visual characteristics that were saturated in the narratives. This process allows for the opportunity to identify the stereotypical implications of those narratives, but also the cultural impact they may have on the general public. This process was a crucial step in the path to create visual narratives that do not depict the stereotypes explored here. 
5.1 Poster Redesign

Casa De Mi Padre Process 

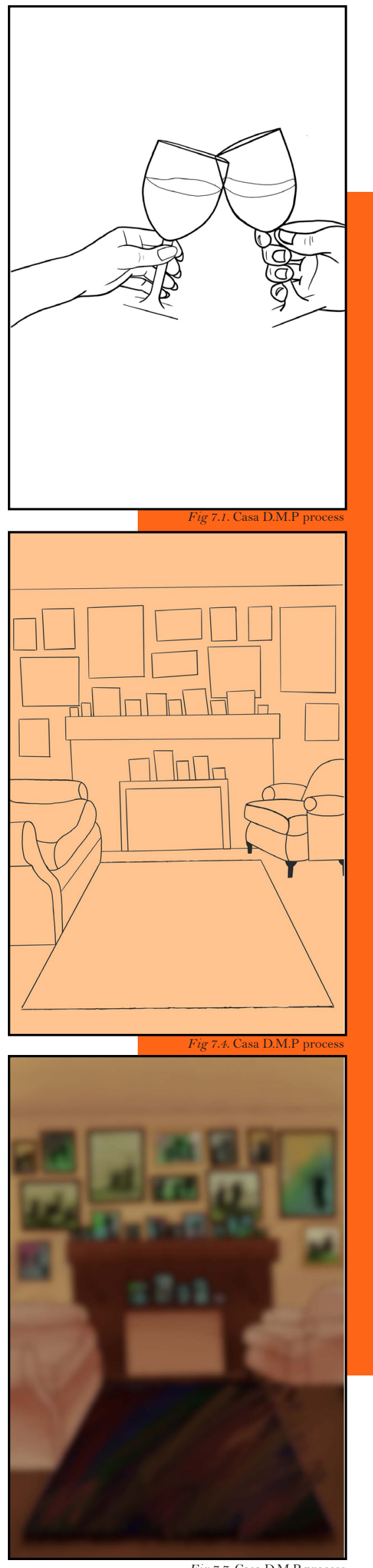

Fig 7.7. Casa D.M.P proces
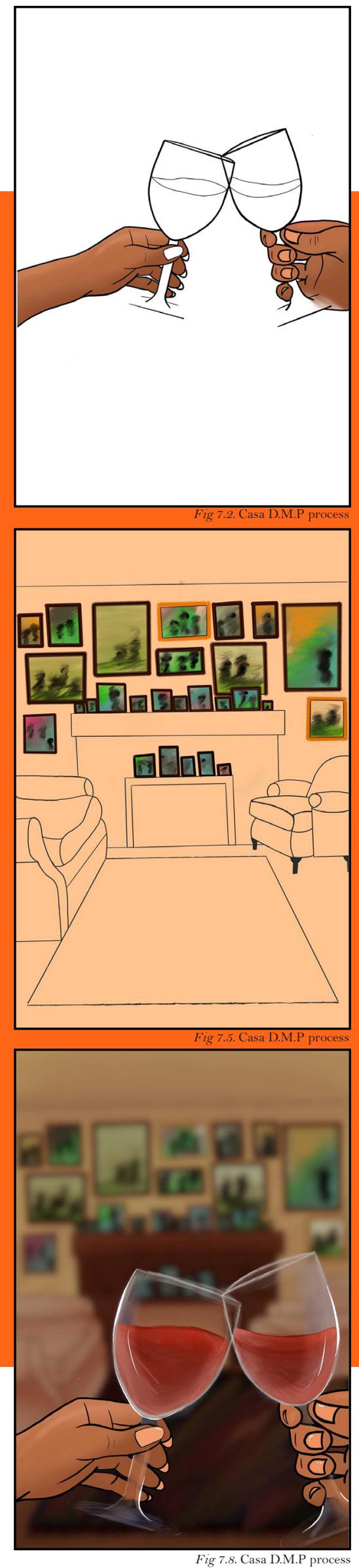
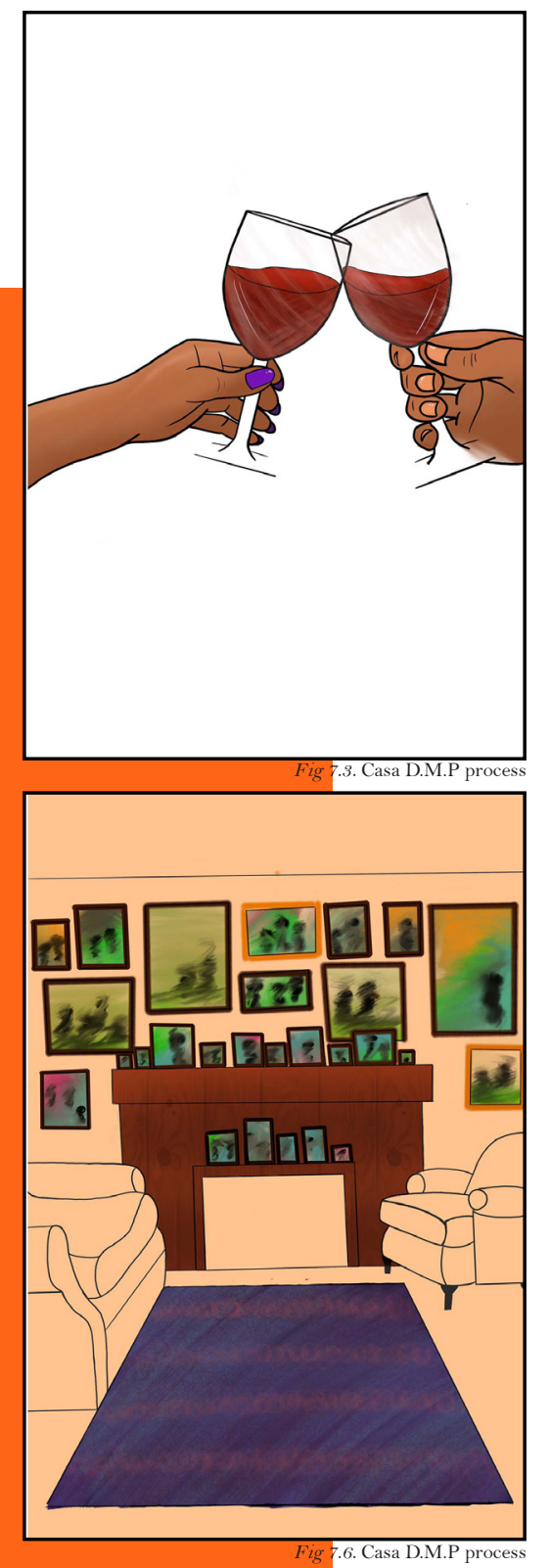
For the film Casa de mi Padre I tried to encompass the only Latin American variable that spoke to me as a Latin American, and my understanding of the culture, Which is the celebration of home and family.

The poster tries to bring forth an idea of wholesomeness, which can be seen in the background of the poster where couches and wall of family pictures are displayed, and by the toasting of wine glasses, a gesture often seen in a Latin American family gathering. The aesthetic of the poster also reflects information often found in traditional Mexican soap operas, which the film Casa de mi Padre ridiculed, while this poster tries to celebrate it as a massive part of the Mexican culture. It is emphasized by the colour schemes, fonts and the dramatic nature of the poster. 


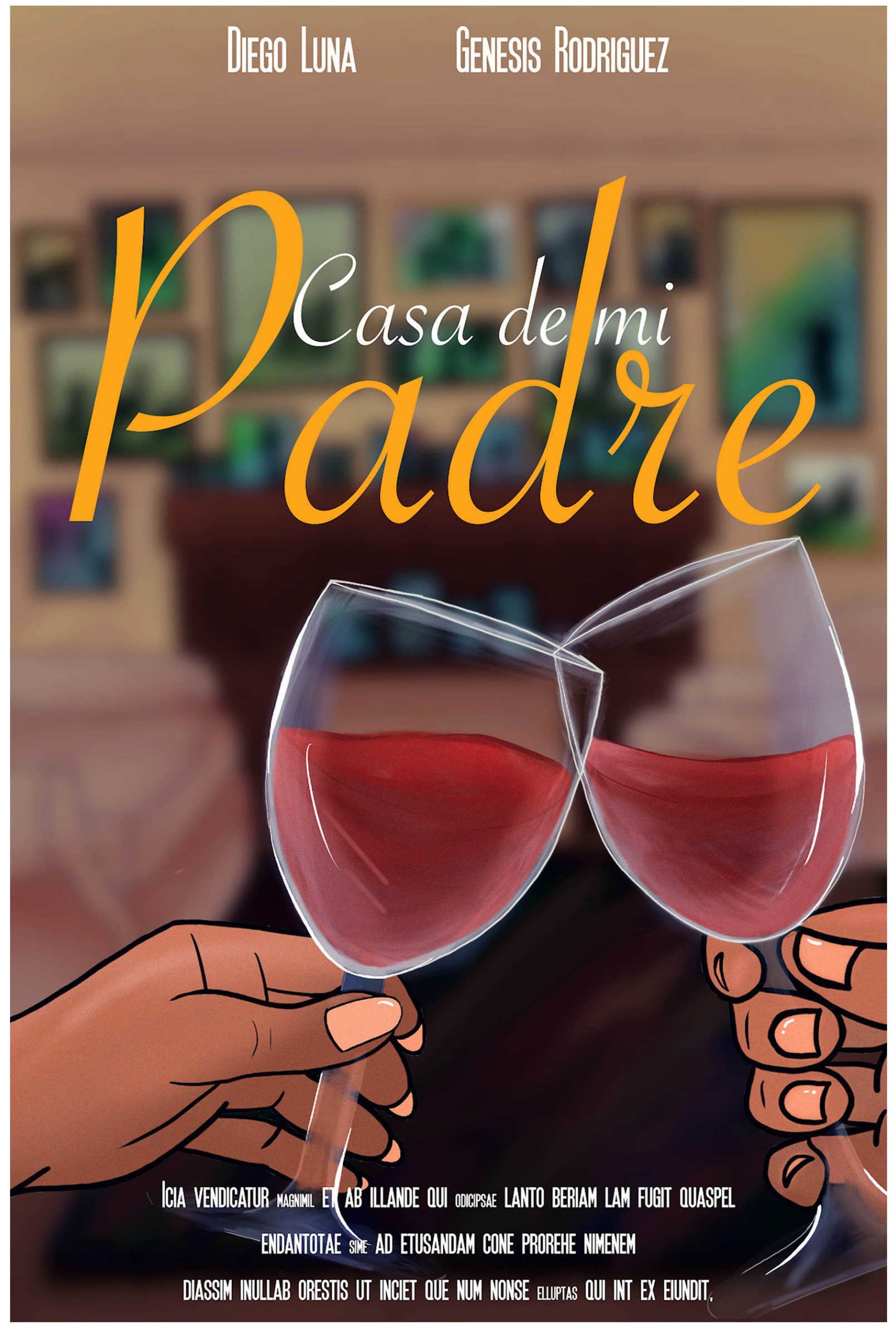

Fig 8. Casa D.M.P Poste 
Poster Redesign

Gringo Process 

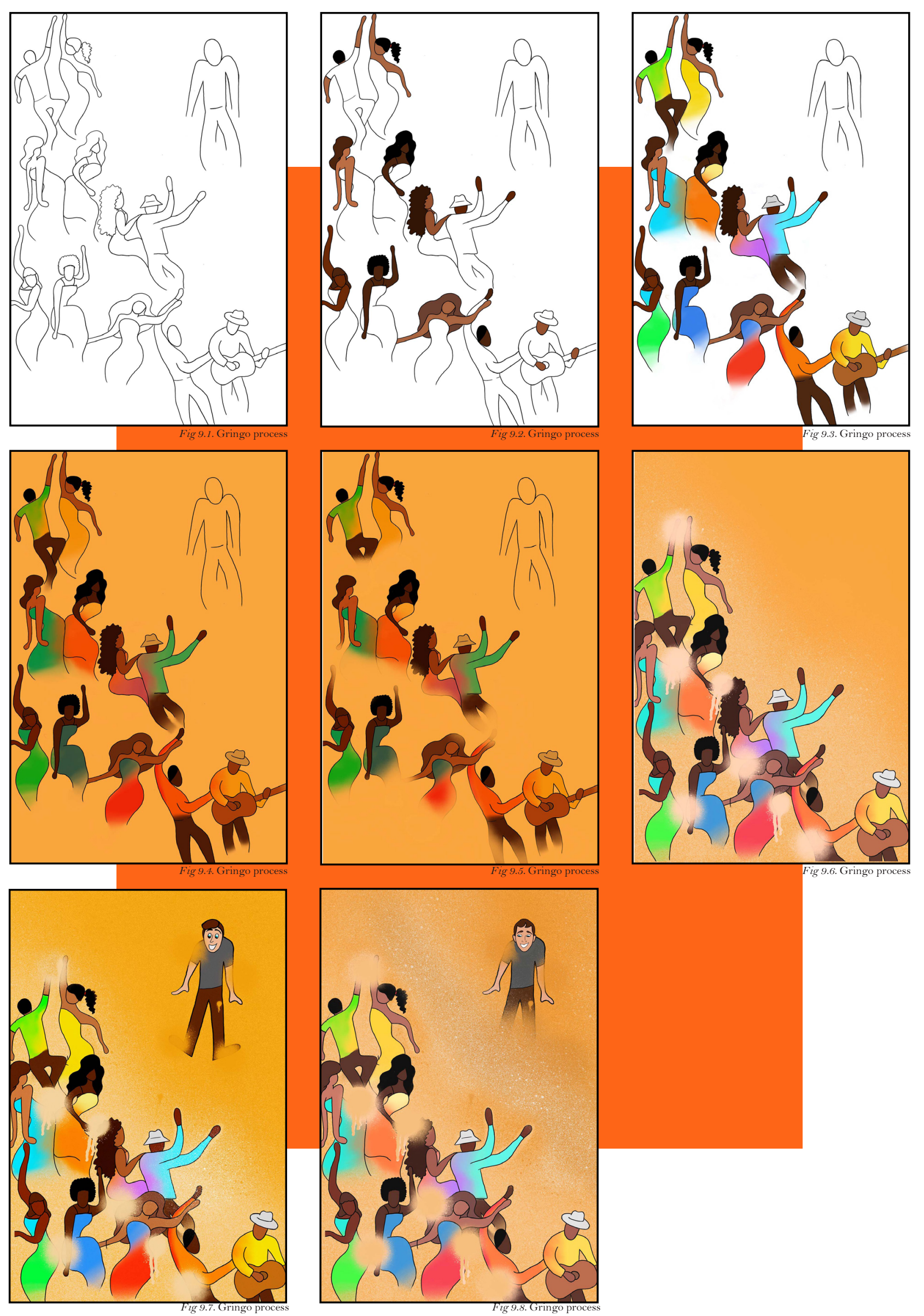


\section{Gringo}

This concept is for the film Gringo, released in 2018. Even though this film is set in Mexico, and the title brings up a term that many Latin Americans use for 'foreigners' the original cinematic poster does nothing to explore the culture or artistic lifestyle.

Therefore, for this concept I tried to explore further popular Latin American art styles and colour palettes, influenced by my previous work on the graphic design history of Latin America, I tried to capture some of the traditional stylistic approaches, while also embracing the passion for life that Latin Americans have.

Also playing more with the idea of the Gringo I wanted to visually show the space between a person and a different culture, but instead of showing a character that is shying away from it, or judging it, I wanted to display a character who could embrace new experiences, and people.

This poster is a celebration of the people of Mexico, and Latin America. Instead of displaying their flaws and relying on the stereotypes, it tries to put these people in a good light and saturate the colour and vibrancy of the culture and its people. 


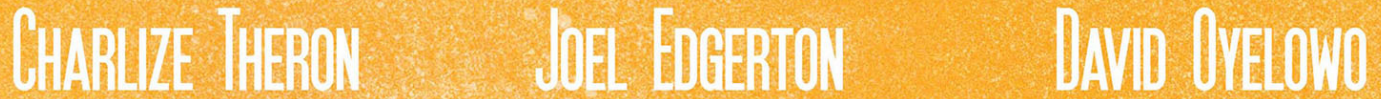

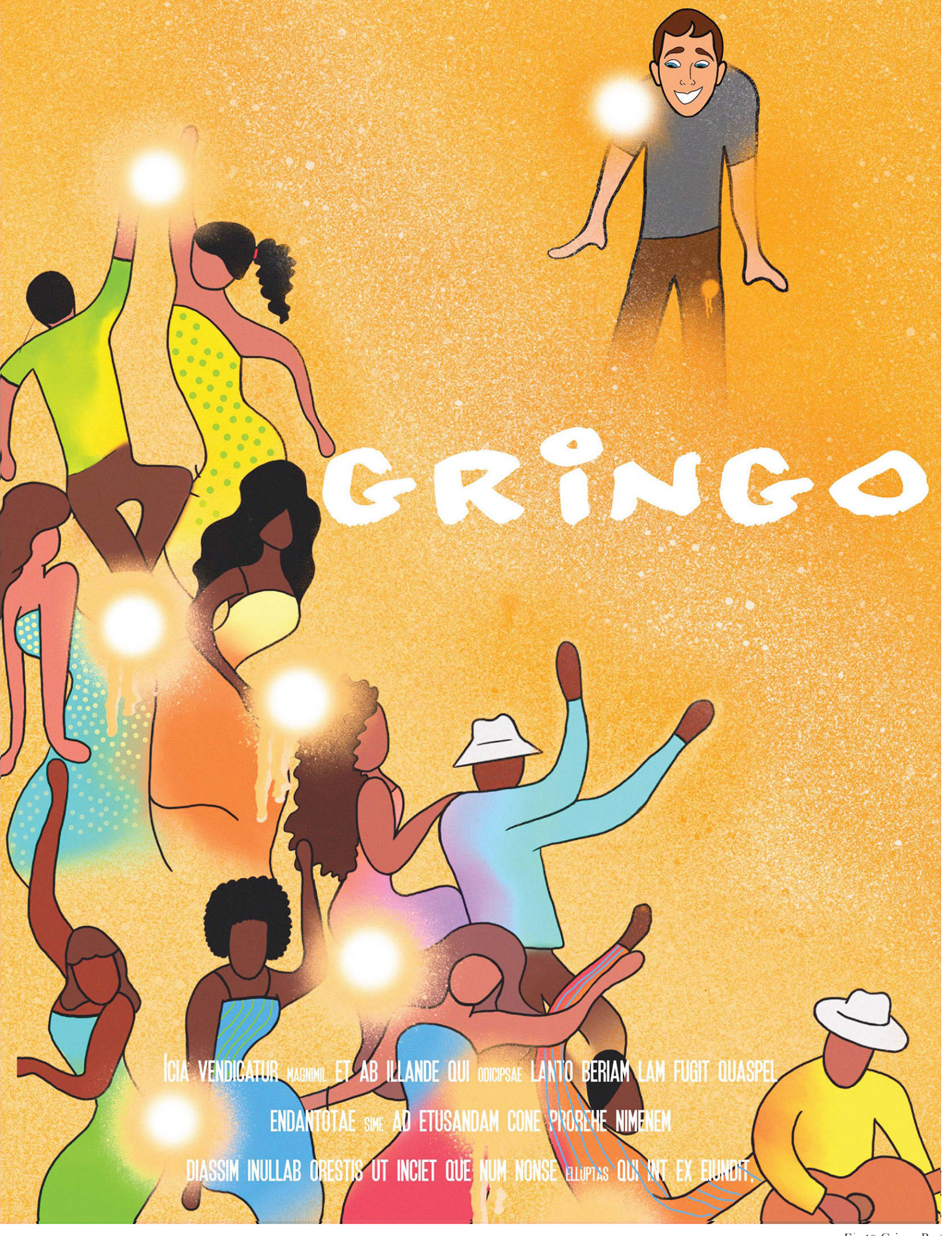


Poster Redesign

Colombiana Process 

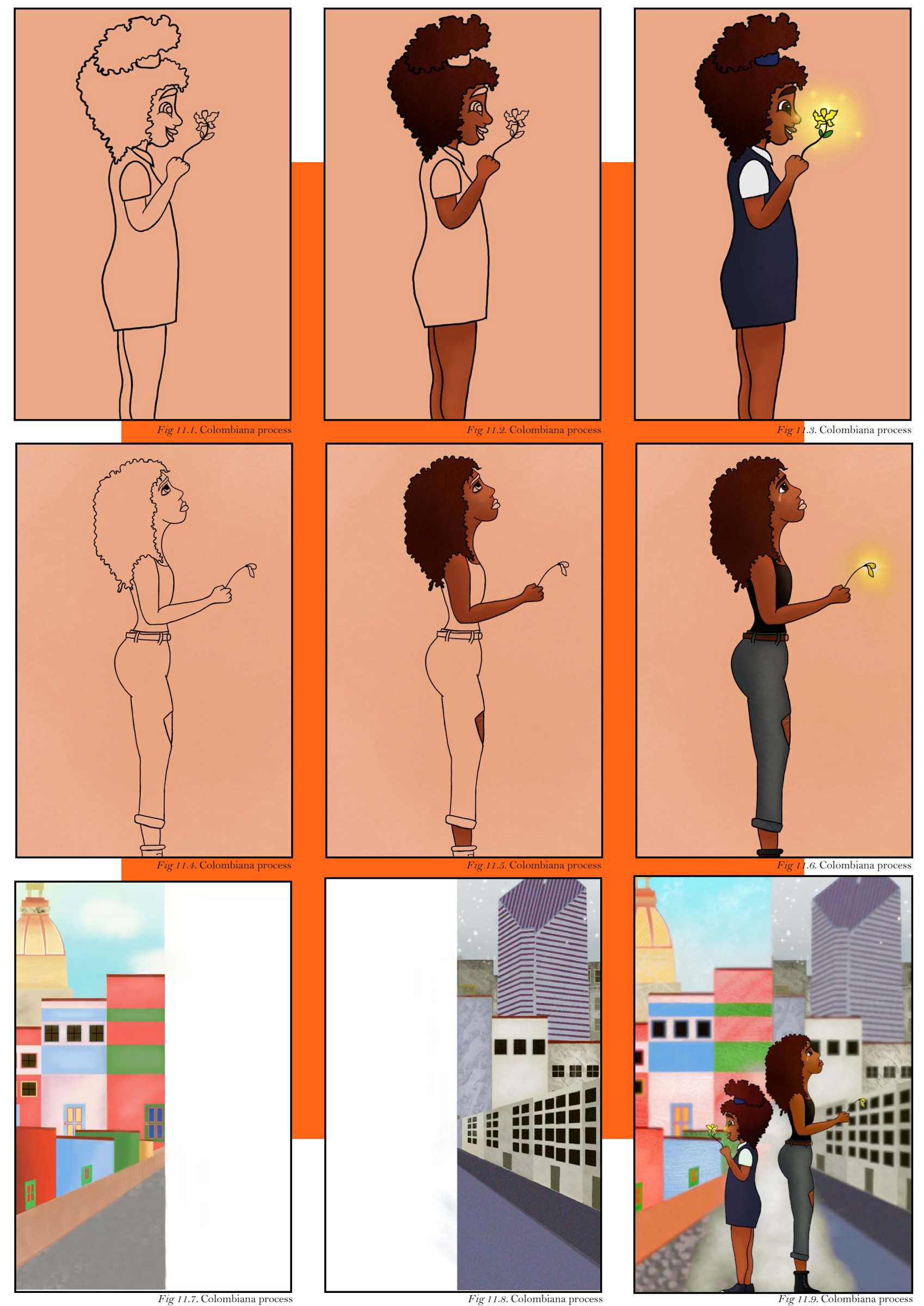
Here, I wanted to explore the narrative in the film Colombiana, directed by Olivier Megaton, starring Zoe Saldana, released in 2011.

The original theme and message of the cinematic poster of Colombiana were of tragedy, revenge, violence and danger. Emphasized by the main character holding a gun, the colour red, and also by the tag line - 'Revenge is Beautiful.'

However, in this poster concept the message conveyed is of family grief and pain, reflected by the flower she is holding (which is symbolic in the film), but also a message that resonates with the many Latin Americans who struggle to maintain a connection to their roots, reflected in the quote, 'Never forget where you come from' - which is the last thing her father ever says to her.

What I tried to capture here was the pain of growing up without parents, and being pulled out of everything familiar to a person, especially as a child becoming an adult. The back setting represents the difference between her home in Bogota, Colombia and her newfound home in Chicago, USA. This is seen by the colours used and the difference between the buildings, beyond that a more appropriate style was chosen to reflect her Colombian Heritage. Working around with aspects of street art which Colombia and Latin America are known for exploring. The physical appearance of the character has also been updated to reflect Latinas as a whole more accurately. Beyond a more accurate physical build, Afro-Latin culture is celebrated by the richness of the characters skin colour, and by not shying away from their hair texture. 


\section{NEVER FORGET WHERE YOU COME FROM}

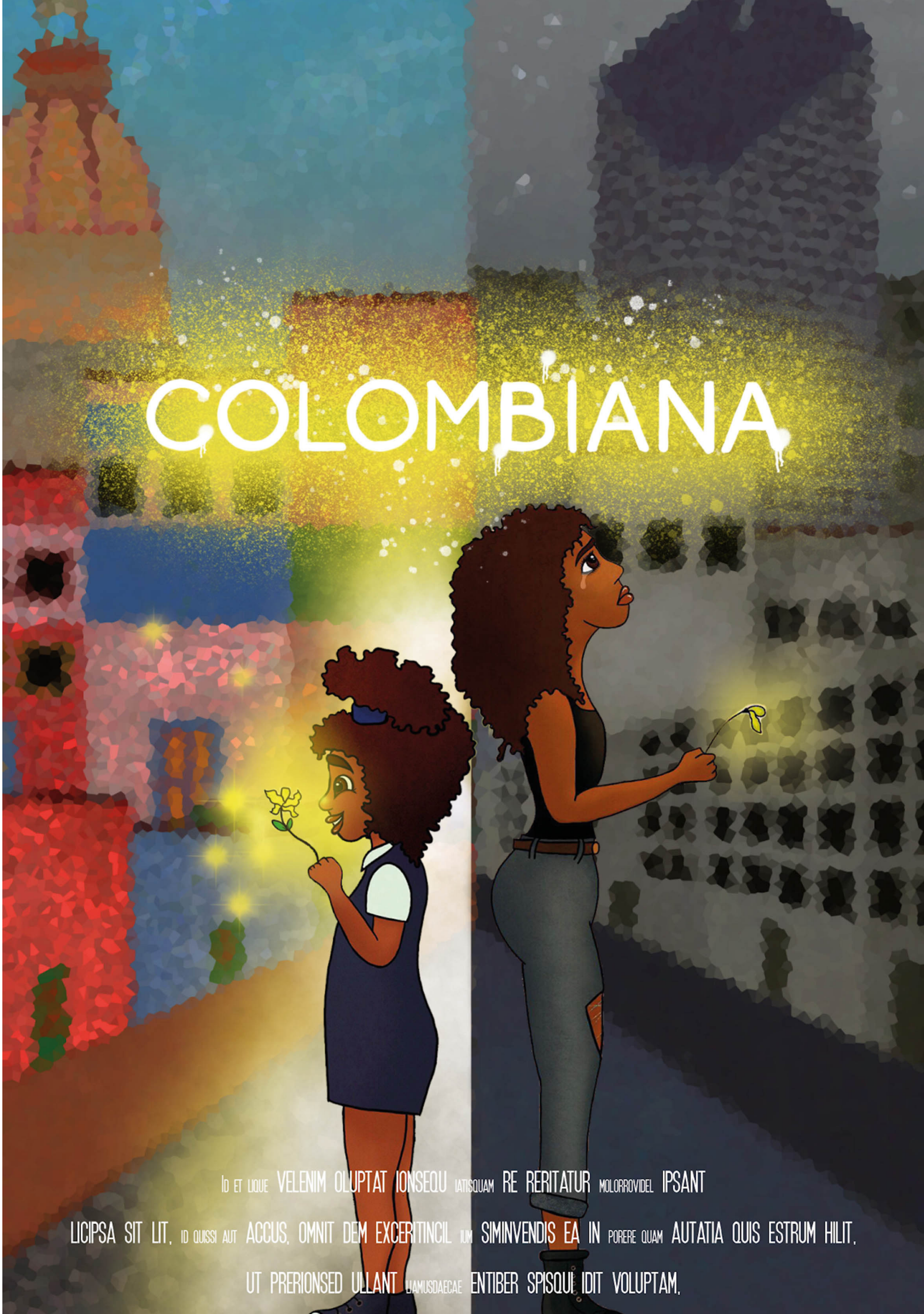

Fig 12. Colombiana Poster 


\section{5 .2 Poster Redesign Development}

Following the three promotional film poster concepts, I decided that in exploring the research and what the goal is within this thesis, the poster concept that allowed for more opportunities moving forward was that of Colombiana. This decision came about partially from the controversy it brought about at the time, but also by the narratives explored on the posters, which ignore many other possible narratives that can be seen in the film narrative.

Colombiana1 Development Process 

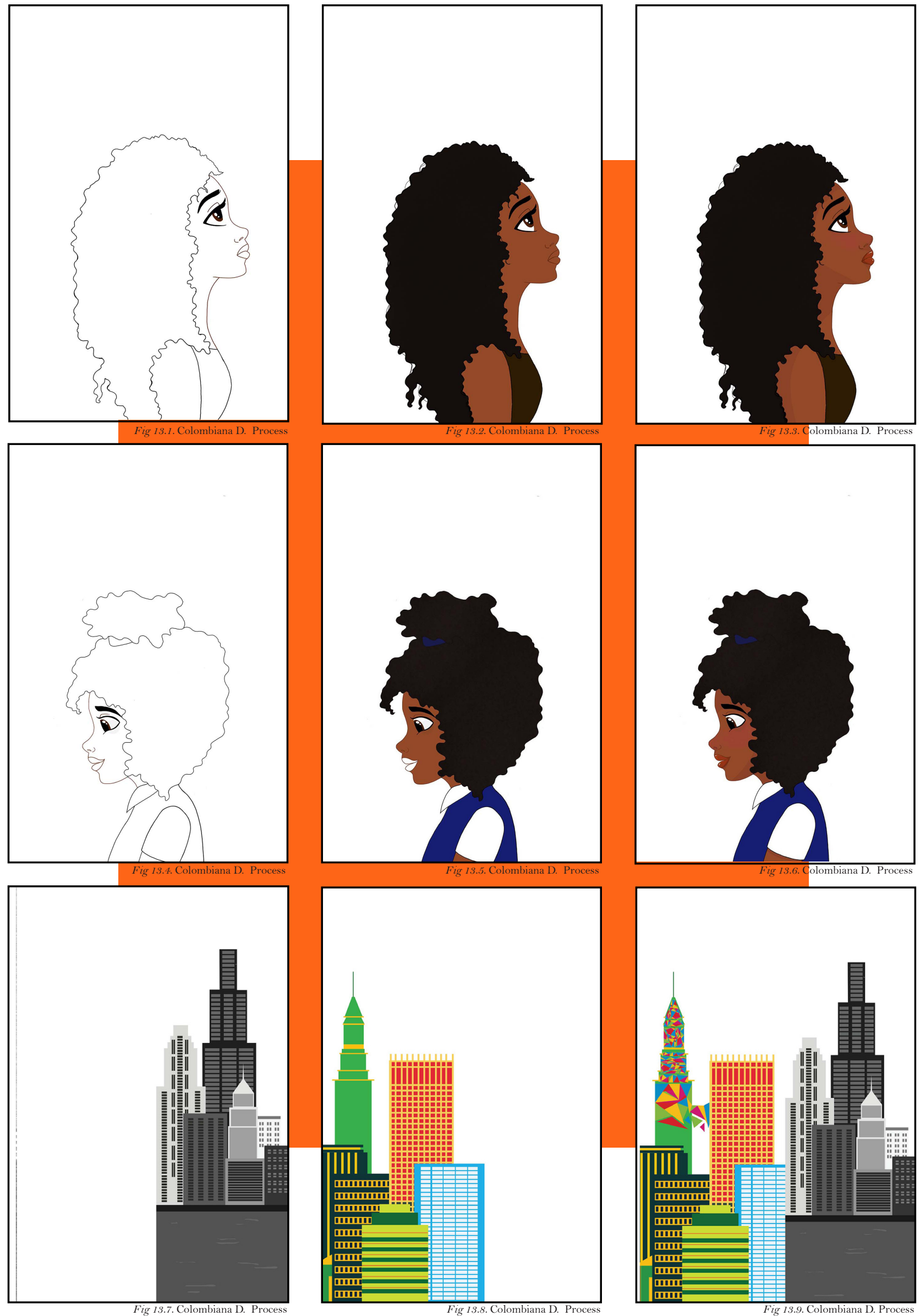


\section{Colombiana1}

This first development has a direct link to the concept in question. The aim was to deliver the narrative and message that was already there in a more complex and multi-dimensional way. With this development, the characters faces are more central to the narrative, with a focus on the emotions that are conveyed. The city landscape is also more carefully explored, and aspects of Latin American graphic design in terms of colours, patterns and motifs are also beginning to be seen and established. 


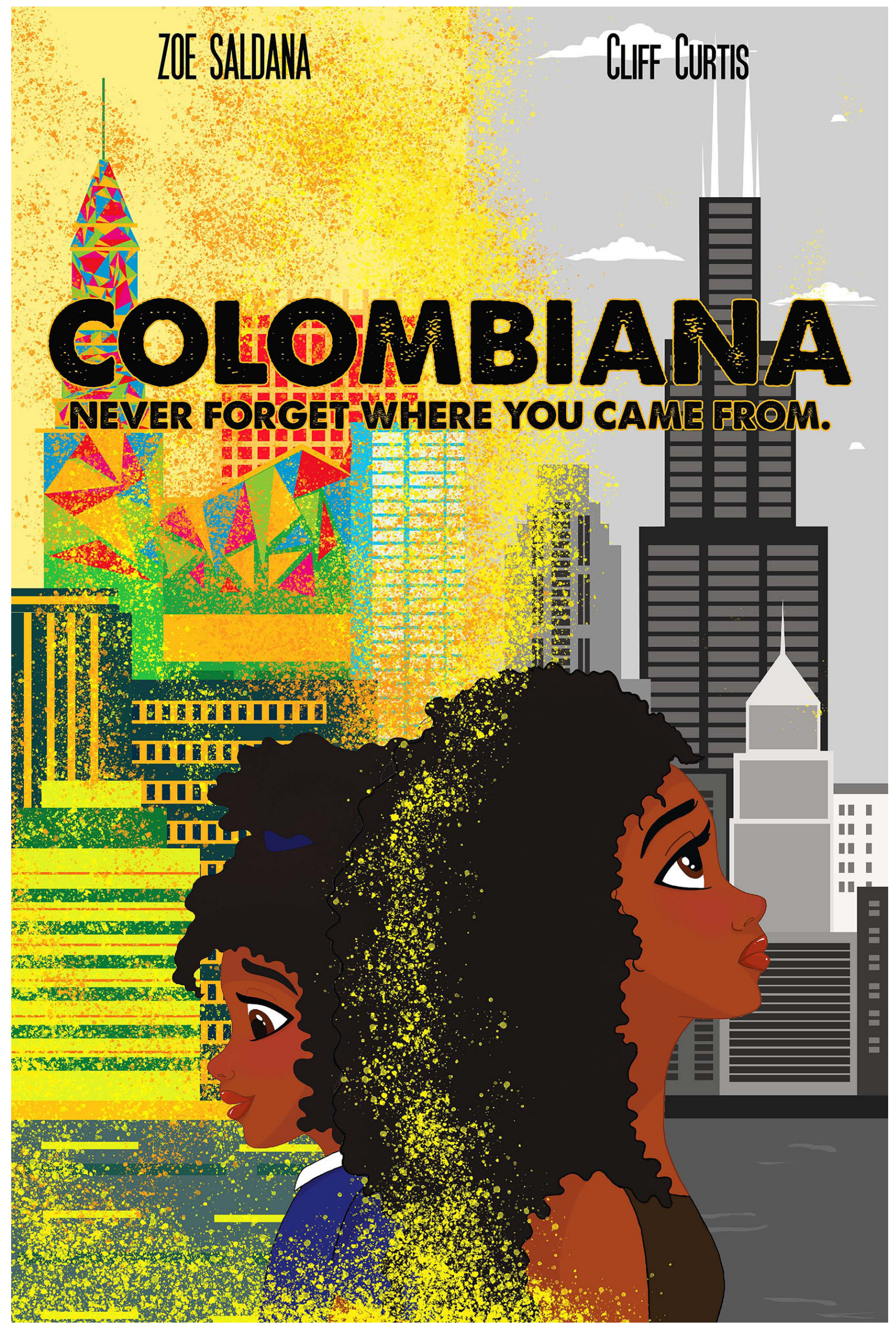


Poster Redesign Development

Colombiana2 Development Process 

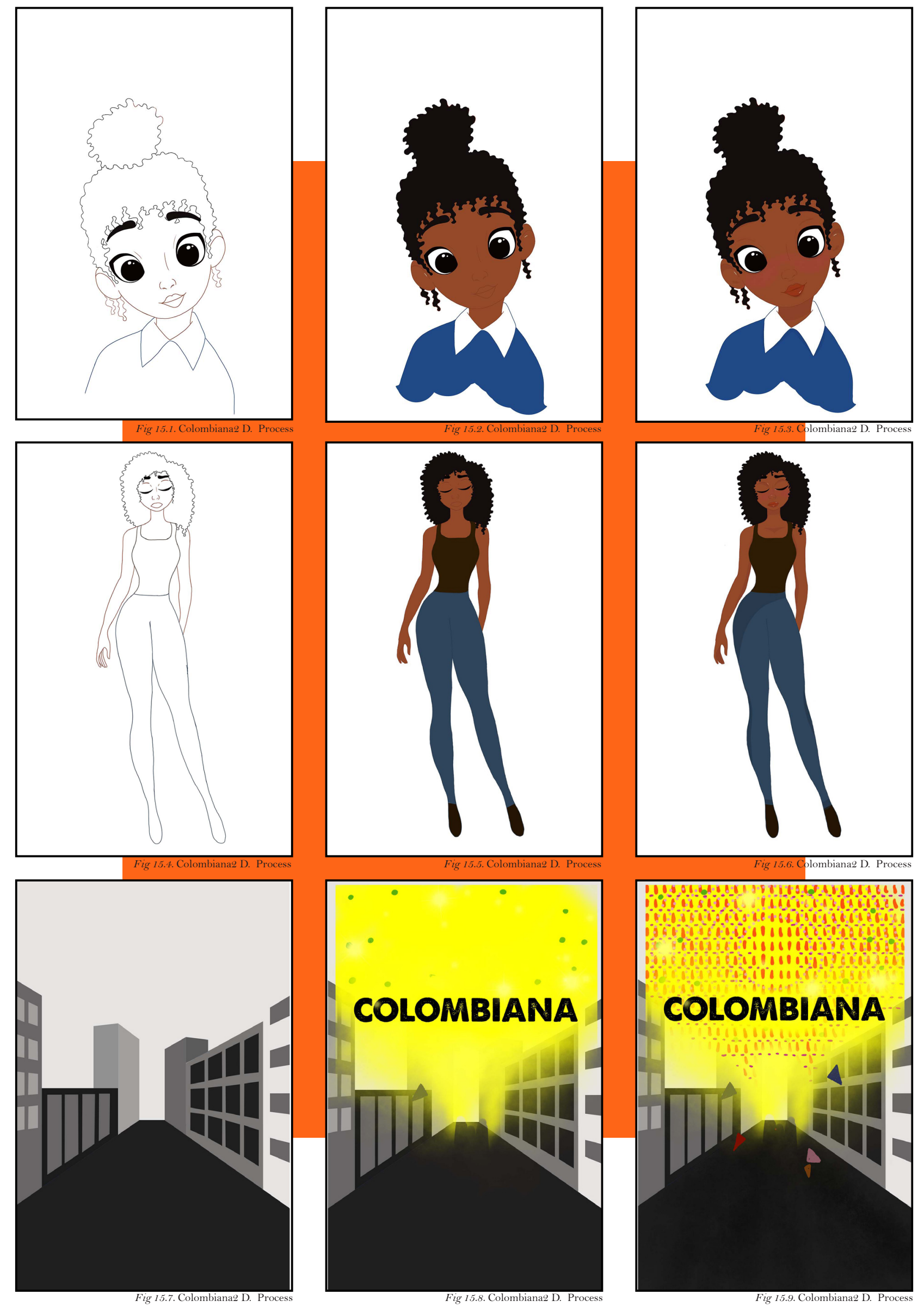

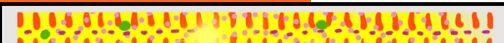

-

-

- orio

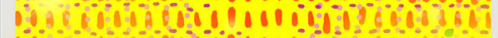

COLOMBIANA 


\section{Colombiana2}

A secondary poster within that campaign was also developed, giving another viewpoint and perspective of the main characters past. Here attempting to put on display the vibrancy of the characters childhood in a less literal sense, and also creating the narrative of the character's loneliness without the cultural heritage. 


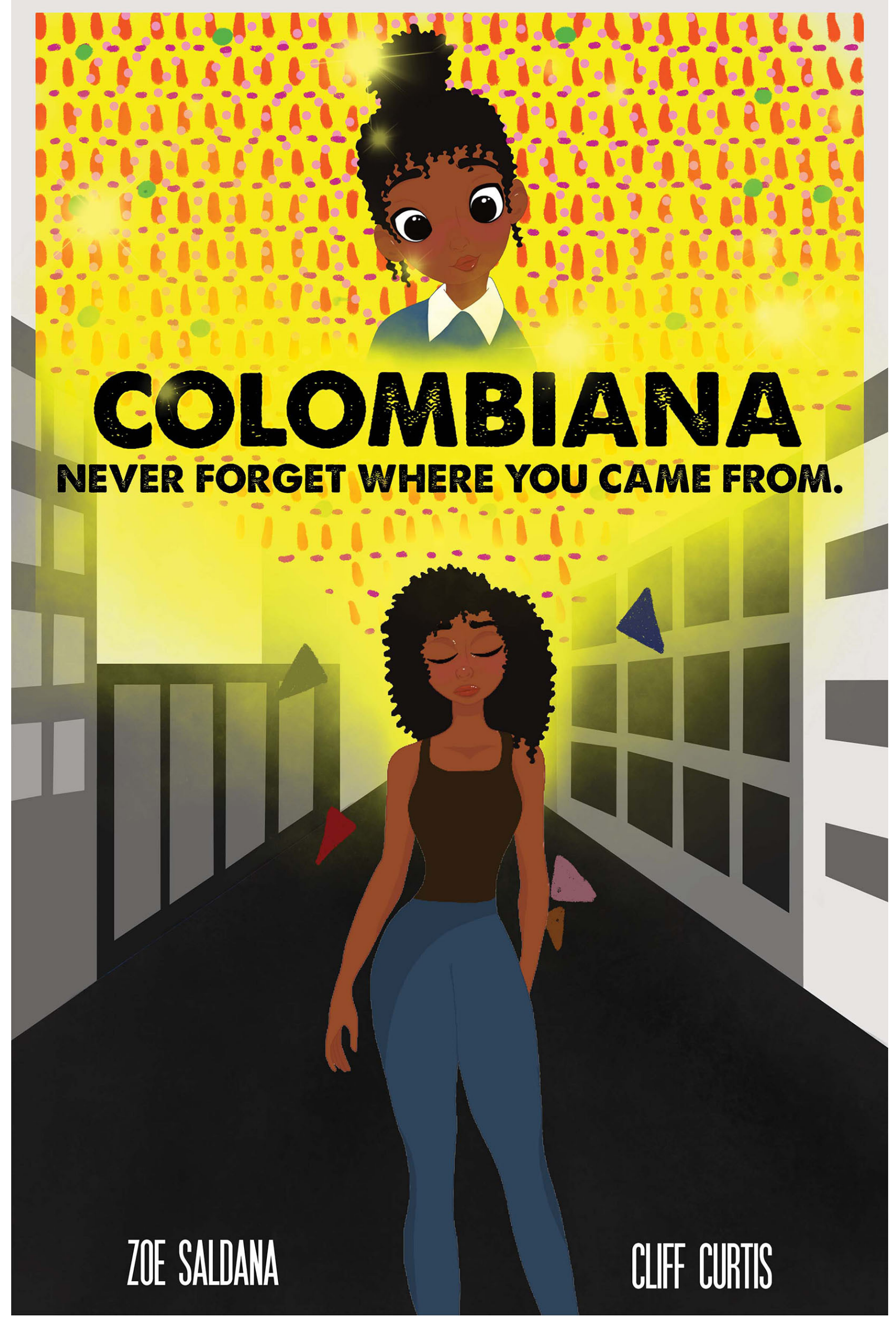

Fig 16. Colombiana2 Poster 
Poster Redesign Development

Colombiana3 Development Process 

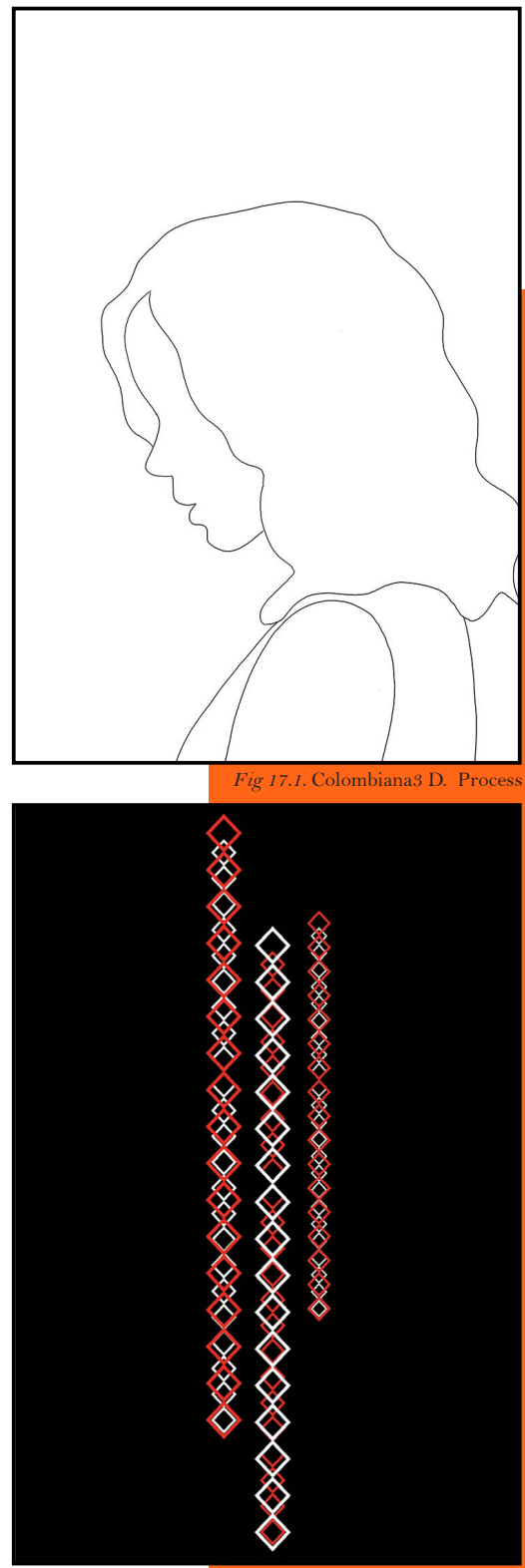

Fig 17.4. Colombianas D. Proces

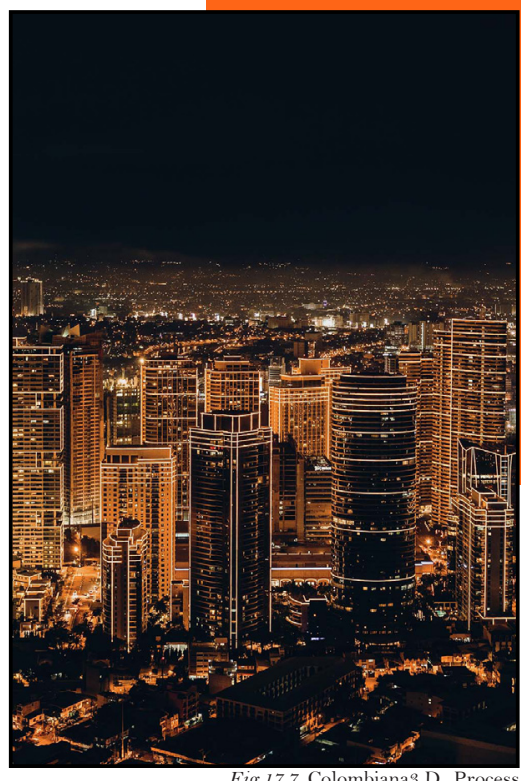

Fig 17.7. Colombianas D. Proces
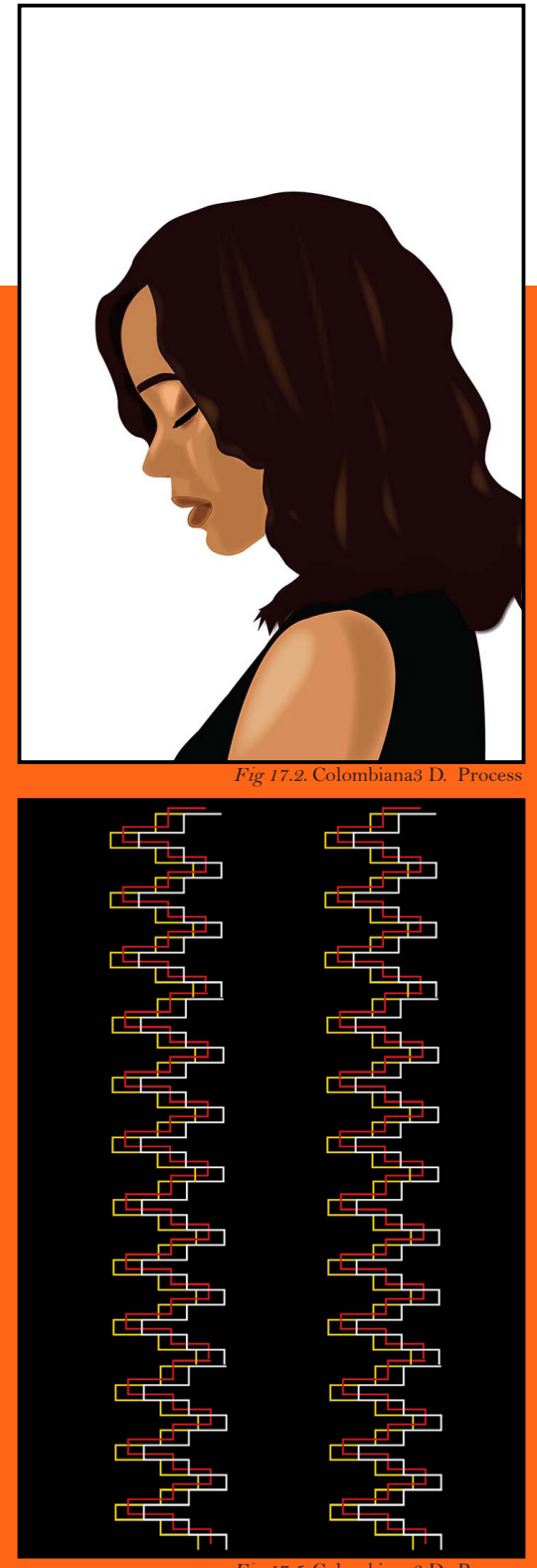

Fig 17.5. Colombiann3 D. Process

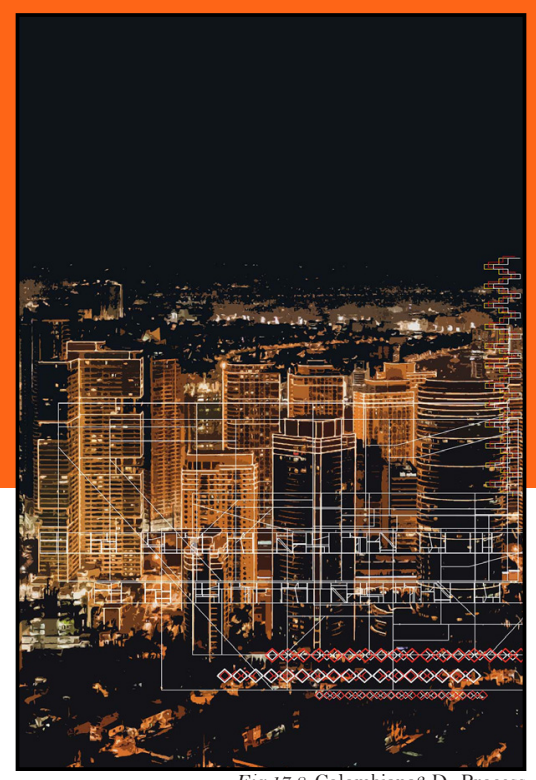

Fig 17.8. Colombiana3 D. Process
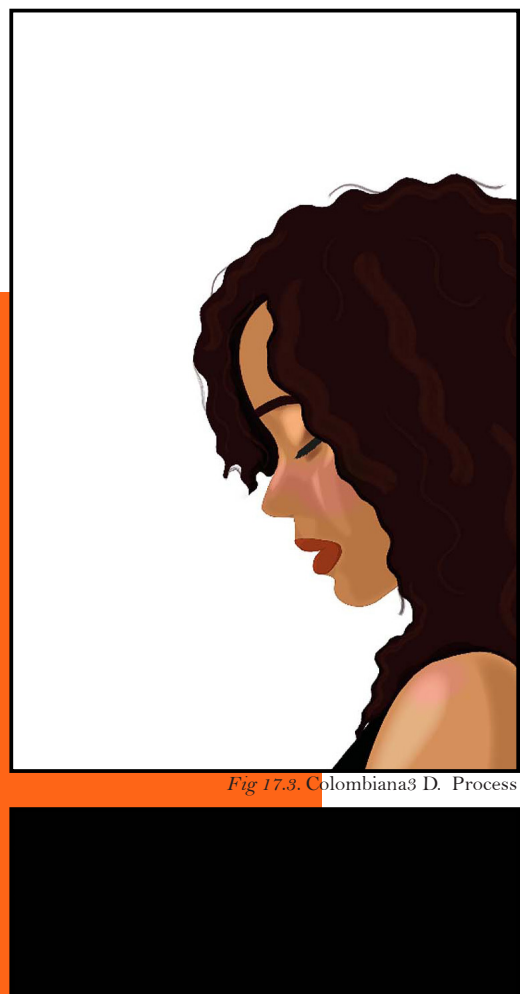

\# 每

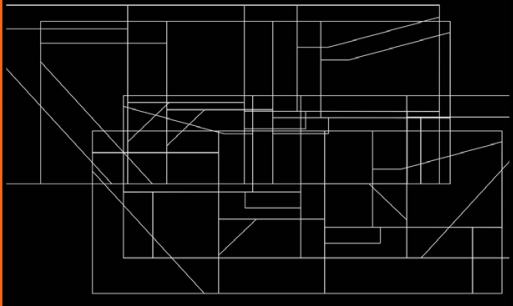

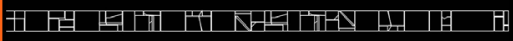
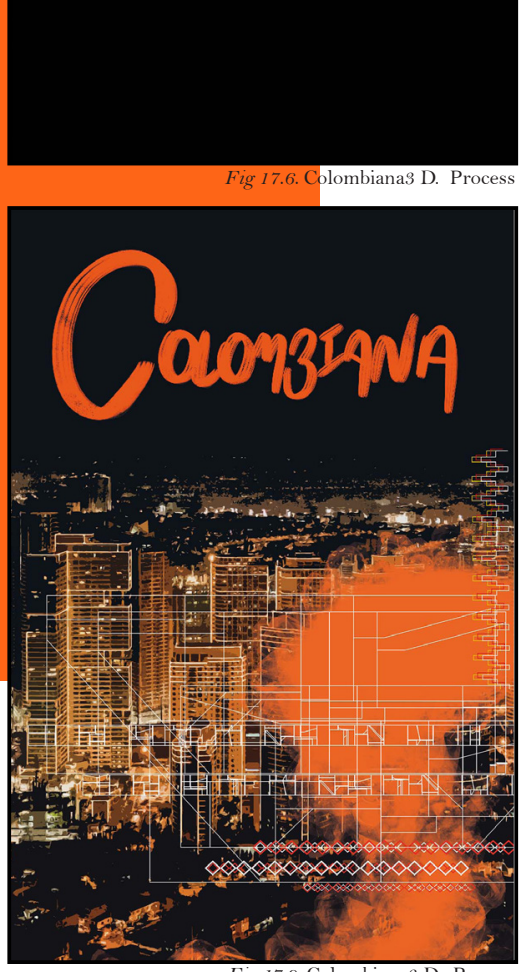

Fig 17.9. Colombianas D. Proces 


\section{Colombiana3}

My second developed iteration takes a more direct link to the original poster. Here, the layout is similar to the original, but critical elements were modified and explored differently. In this development, I have also started using some abstractions of traditional Colombian patterns, that shape itself around the poster's character. Another key element here is the tile, which I have hand drawn to aesthetically fit a longestablished style that reflects the street art history of Colombia and Latin America as a whole. It brings in the narrative of adding your mark to the world around you. 


\section{IDE SADAMA}

QLIFF CUTRTS
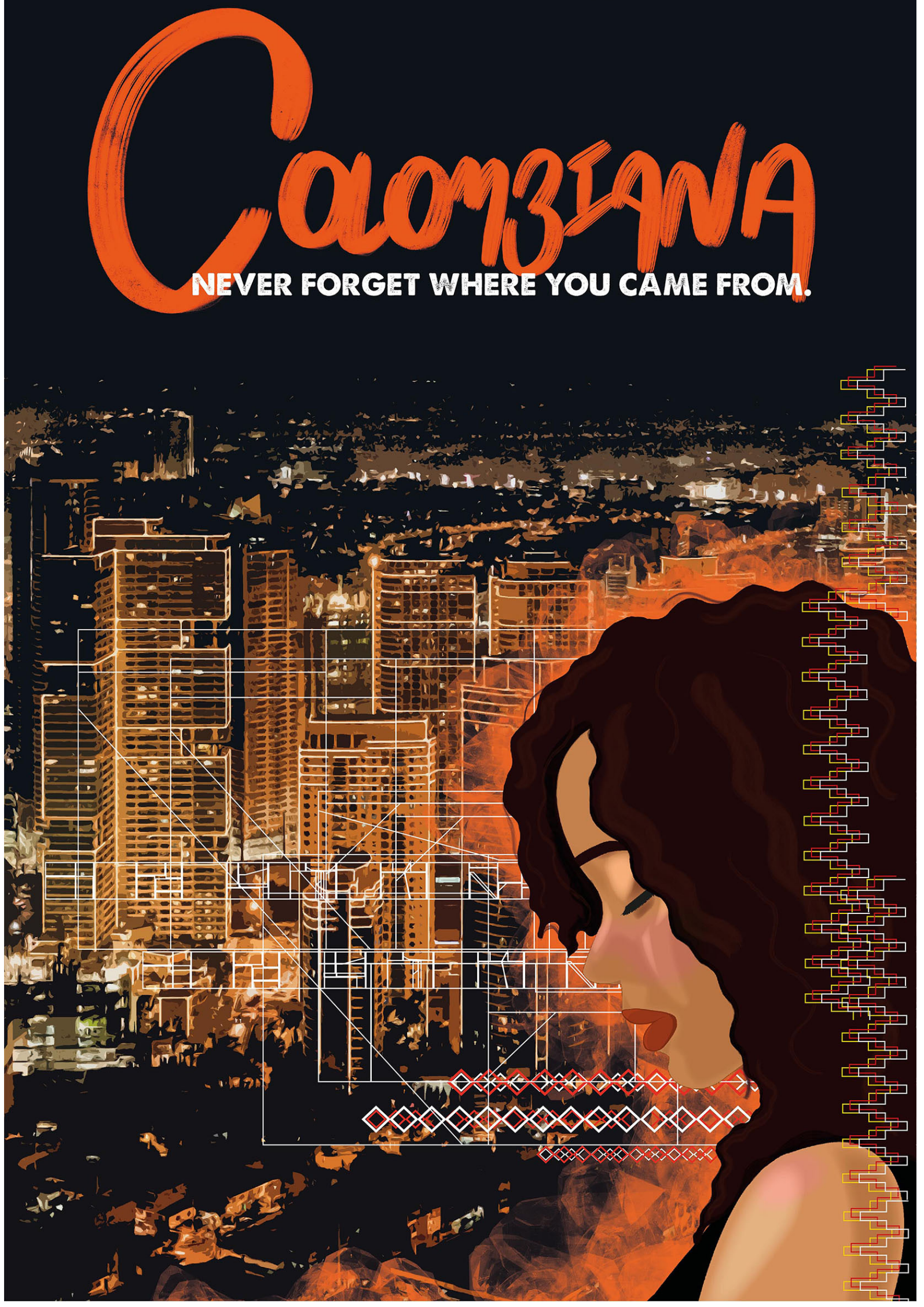

Fig 18. Colombianas Poste 
Poster Redesign Development

Colombiana4 Development Process 


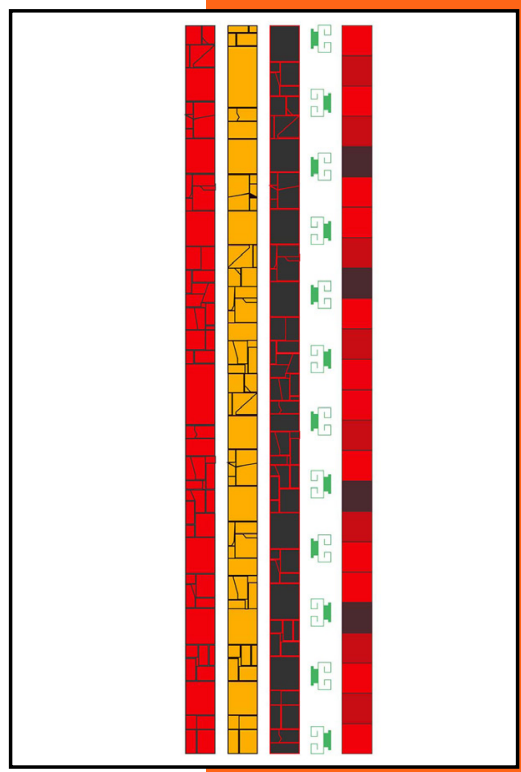

Fig 19.1. Colombiana4 D. Proces

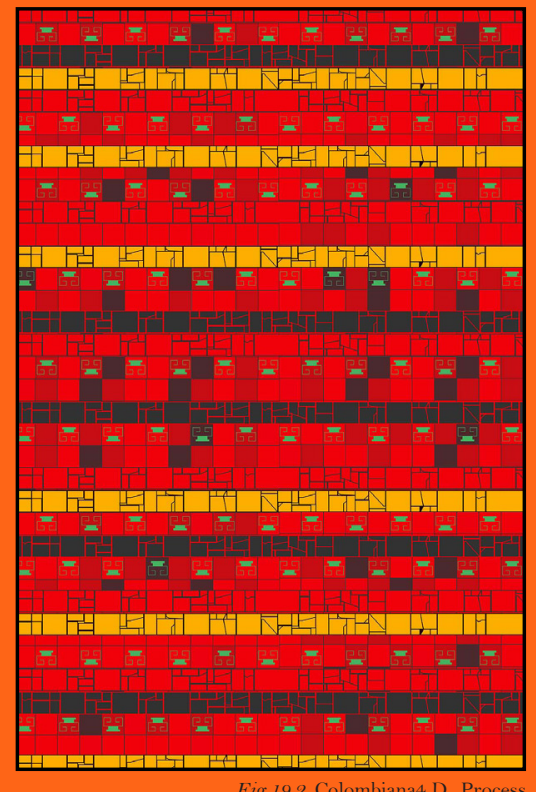

Fig 19.2. Colombiana4 D. Process

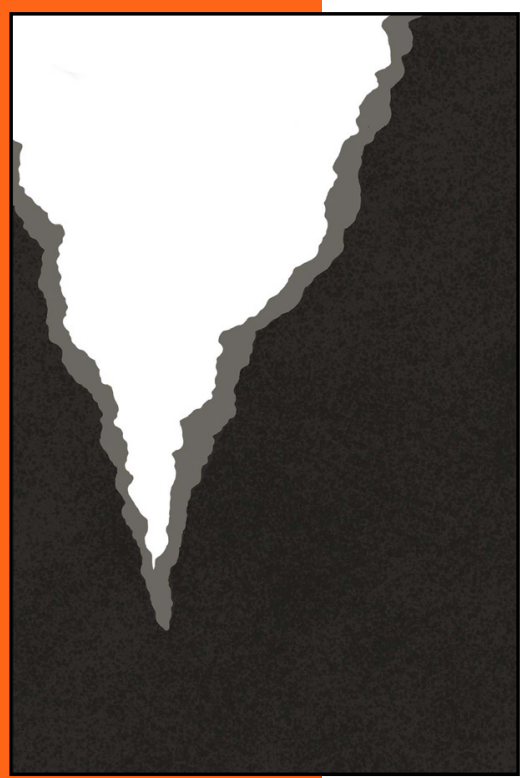

Fig 19.3. Colombiana4 D. Process 


\section{Colombiana4}

My final iteration takes its shape as an abstract interpretation. The narrative of characters has been removed to focus solely on a more dramatic interpretation of the story. It speaks to the concept that if you strip away the surface facade, your cultural background and heritage is always there. The patterns are inspired by a mix of traditional Latin American patterns and colours. Also incorporated is again the hand-drawn title, this is done to create a more personal and active connection to the narrative. 


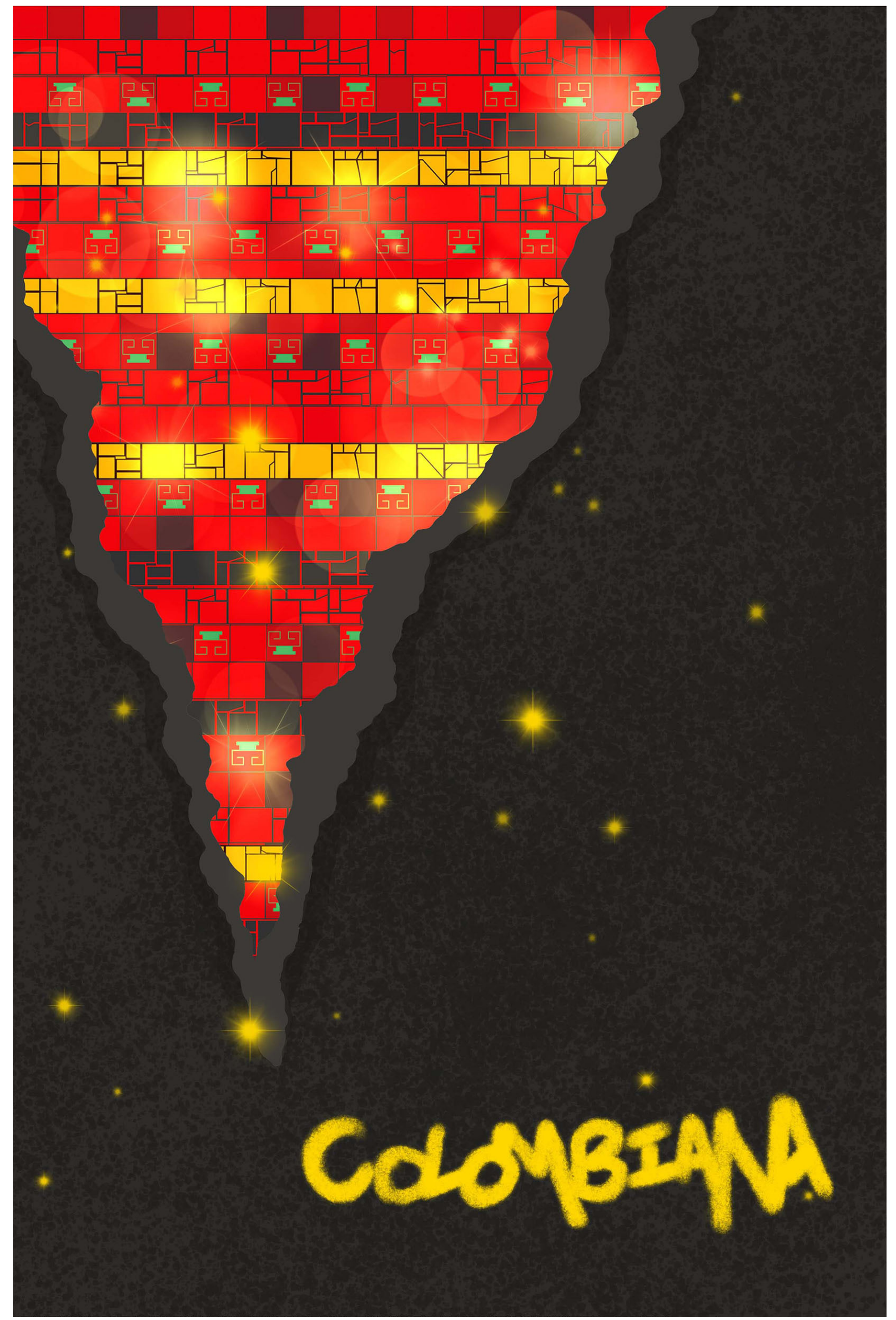

Fig 20. Colombiana4 Poster 


\subsection{Expert Feedback}

\section{Introduction}

In search of feedback, three experts of different backgrounds gave their critical perspectives on the film poster concepts presented in this thesis. This search was done through semi-structured interviews, that also allowed the expert to lead the conversation. Context and questions about the poster concepts were shared with the experts, to guide the conversation.

The following section will analyse the feedback given by the experts, focusing on the messages, implications, and themes of the posters.

The first expert (EX1) is a writer and a visual effects artist who has worked on many major feature films for studios including Disney Animation, Sony Imageworks and Weta Digital. This expert was approached not only for the successful career they have achieved within the film industry but also because of their passion for the importance of being culturally aware in the industry. As someone who understands how the film industry functions, and believes there are aspects within that industry that need to evolve, this interview was an opportunity to gain a perspective on how to communicate a storyline through a single image.

The second expert (EX2) specialises in Latin American literature and culture. They are a university lecturer who centres their teachings around Hispanic culture, the Spanish language, and the national identities and cultures of the Latin American world. EX2 was a valuable source of information who understands the history of Latin American culture and the issues we have faced. They understood the characteristics that do not embody our culture and could give the perspective of someone who understands the characteristics that I am attempting to portray visually.

The third and final expert (EX3) is centred on the field of graphics and communication design and had focused their career so far in the study and practise of visual layouts for print and Online media. They were able to advise on the ways that images should be visually composed for a viewer to understand its narrative and the compositions that allow content to be presented in the best way possible. 
Across the three interviews, there were common themes explored, from different standpoints, which means that all three experts analysed similar aspects of the posters from their perspective and point of view. However, there were also some big themes that came from the interviews individually. All of these themes will be explored in the process of creating final poster concepts.

\section{Narrative}

The poster narrative to me was one of the most valuable aspects to discuss. How the experts interpreted the narrative is a crucial factor in visually removing stereotypes. Beyond that, also identifying which aspects of the posters were creating the narratives I wished to present, and which were not fulfilling the requirements.

\section{Environmental Narrative}

In the 'Colombiana1' poster, the city landscape in the background was discussed. EX1 stated that this background, and the transition between cities told a narrative of this character having a

vibrant childhood, against the other environment which felt sterile in comparison. EX2, however, argued that too much vibrancy on one side of the poster, could also create the perception that all of Latin America is colourful, which creates another potential stereotype. Stating, “This transition is enough, going from one place to another”. EX3 expressed that "It feels like a coming of age movie, but those are not quite the right words". This came from the narrative that the character grew up in a bright and colourful childhood, only to find herself in sad adulthood. The narrative interpreted from this transition was that the city landscape played a crucial role in allowing the viewer to get a sense of where the film is set and what the narrative will be.

EX2 supported the use of the city landscape in the background, but also advised to use as realistic an image as possible, and believed that the approach would be to highlight the apparent differences between the two countries without adding any connotation to it. They also suggested I "Just take the woman out...it is far less insulting than having a half-naked woman in the poster". With the main takeaway being to focus on environment, colours, and typography. EX1 expressed that what was successful about this narrative was being able to see the two different worlds. Presenting it as actual places and cities allows the 
viewer to understand that this character is stuck between two worlds, making the narrative more concrete. An interesting point that was also made by EX3 was that the 'Colombiana2 Poster' was missing the context that 'Colombiana 1' poster had, without the landmarks of two very distinct cities, it loses that cultural narrative.

\section{Character Narrative}

EX2 also spoke about how the representation of characters can influence the narrative. In speaking of 'Colombiana1' and 'Colombiana2' poster, they expressed that, "It is better without the faces. It relies less on a stereotype and a caricature. If you use any drawing you will have to isolate them; you will have to make some caricature, supposed to if you used an actual picture, which is already stereotypes because this is an American product". The abstraction of two very much different places, speaks well to the narrative that is attempting to come across. However, EX3 established that considering what I am trying to portray, the use of a character in the poster is essential for a few reasons; The fact that Latin Americans hardly see themselves in a positive light in a poster would entice them to seek out the film. While also for the rest of the public, being able to connect with a character is a selling point in seeing that this could be a real, human, story, and lastly, a lot of a film posters narrative comes from the facial expressions of the characters. These are contradicting viewpoints which will be addressed in the subsequent development.

In terms of removing stereotypical narratives, EX3 spoke of the context they received from the posters. People all around the world can share similar problems, and just because of your ethnicity, it does not mean that your problems are based on guns and violence. They believed that these posters are "about representing the Latin American culture as it is, and that is just regular people living their lives." These posters can show the perspective of Colombian and Latin American people and relate them to people of all cultures, creating inclusivity in our communities. Nonetheless, the expert also touched on their lack of Latin American cultural understanding, saying that in the 'Colombiana2' poster, "There's nothing that really stands out to me as being Colombian other than the name, if this is going to be produced for the masses to see then there will be others like me that don't know the culture and won't see whatever connections there may be." What is crucial about this is the understanding that the use of 
cultural references really could be an interesting point when presented to the masses.

\section{Genre Narrative}

As a whole, the experts had a positive reaction to these poster concepts. They believed these posters are about representing a culture that is often overlooked, but also just about presenting people as real humans, who suffer from similar problems. EX1 advised that since these posters are so different from the original, they fall within a whole new genre since they are trying to steer Latin Americans away from being portrayed against a severe background. While the original poster is immediately identifiable as 'Action/violence' the experts advised that the new poster concepts did not. EX3 argued that the narrative they gathered from the 'Colombiana 1' poster was that of a movie about a regular woman from Colombia attempting to make her way through the world as it comes at her, whereas, the original poster only gave them the narrative of guns and violence. Therefore, their understanding of the genre changed.

They also stated that the fact that they look so different from the original proves that they are succeeding in changing the rhetoric. EX3 stated that "It has gone from a movie about guns and violence to a movie that's just about a regular girl in Colombia trying to make her way through the world as she sees it”. EX1 posed the question of, what are the intentions for these posters? Whether they want to inspire people to think something explicitly or are they trying to capture a feeling or general emotion from an audience to influence them towards watching the film?

\section{Subsequent Narrative}

The 'Colombiana4' poster was a contrast to the rest considering its lack of characters. EX3 critiqued that this would not work as a leading poster, but, that it would be interesting to develop it as a teaser poster, to intrigue the audience, or as part of a series of posters which tell a story. Since "As a standalone, it would need to give us a lot more to be used as the main poster." The expert explained that film posters tend to be far more successful when it includes the main character, to create a human bond with and understand that perspective. Overall they advised it to be an exciting concept to develop further, saying it 
has got enough qualities there to make the masses stop and look. EX1 also took this as an opportunity to express that they would watch this film, from seeing this poster. They highlighted the fact that the masses are not accustomed to seeing mainstream posters such as this, but that does not mean it could not be successful. These posters lean further towards artistic instead of formulaic and basic. EX1 stated that posters like these, could easily become what the masses are accustomed to seeing, and replace the current mainstream posters in production.

\section{Poster Aesthetic and Design Style}

A subject area that is very dominant within film poster design is the overall aesthetic and design style. EX 1 was able to identify and create expectations of the film based on the styles they saw. The 'Colombiana 1' and 'Colombiana2' posters, reflect a style commonly seen in the 1980s, which was an aesthetic pioneered by Spike Lee, which marked his career. While the 'Colombiana3' poster three felt adapted from a darker, noir aesthetic, contrasting against the Colombiana4' poster four, which has a more abstract, 'art house' aesthetic. Each poster does indeed have a different aesthetic. From the interviews, it was clear to me that to seek out a specific film style, can be another factor in creating a narrative, and an understanding and interest in the poster.

\section{Illustrations}

All experts also touched on the fact that regardless of the presented posters being concepts, the style in which I designed them affects how the viewers interpret it. EX1 explained that the illustrations of the 'Colombiana1' and 'Colombiana2' posters present a 'cute' aspect that I had not intended to show. This type of illustration can be associated with animation for children, and the concept is disjointed from the genre of the film. With the expert saying that they "Would be very surprised if I saw this poster and the film was about her family being killed". EX2 advised that this type of illustration and artistic mean "gives it an undertone of 'Disney' princess", which again is a damaging way to portray people of particular cultures, whilst EX3 also mentioned that these illustrations change the genre of the film in a drastic way that can be confusing for audiences when the film has absolutely no connections to the poster. Similar issues were brought on by EX2 in terms of the design style in the 'Colombiana3' poster, for different reasons. The expert advised that she is depicted as being 
too perfect, shown with a "porcelain face" which would not be the case. Again, the style in which the poster presents its characters, affects audiences deeply in terms of what their assumptions about the character become. So, in an attempt to stay further away from negative stereotypes, they stated that potentially removing her from the foreground would be a step in the right direction.

\section{Composition}

Another way in which the design style affected the interpretation of the posters was the composition and how that can allow for some ease in 'reading' the posters.

In terms of the 'Colombiana1' poster, EX3 believed the layout has a good flow, especially in the way there was almost a line drawn by the two characters eyes and heights. With the composition, the expert argued that there should be another layer on the right hand of the poster (the black and white side) to keep the left-hand side from being too overpowering, so more detail on that side would create a more balanced poster. In terms of the 'Colombiana2' poster, the expert believed that the top half on the poster was further developed than the bottom half. They explained that it has the layers in the background to make it seem dynamic and eye-catching, and advised to keep in mind that successful poster compositions should always strive to have three layers as it "Gives it the depth needed to catch your eye if you saw it walking down the street".

With the 'Colombiana4' poster, EX1 explained that. "Aesthetically it's just exciting, the patterns and colours make me interested in the image". The composition was also seen in a positive light, in which it moves the eye around the image and creates a compelling contrast. The tear down the side was a good indication that there are two different worlds, and in some sense, there is always something else beneath the surface. The expert also saw the aesthetic of the poster as something related to a Saul Bass aesthetic, and way of creating, by using abstract but straightforward methods of depicting stories, making it a successful design. Nonetheless, this poster does not give enough context for the audience to understand the narrative. 


\section{Symbolism}

Cultural symbolism is an aspect of the design style, which I subconsciously integrated into the posters. However, EX3 identified it in the 'Colombiana3' poster through the lines and patterns on display but wished there was more of it, and in continuing this poster to focus more on the cultural symbolism that I could pull through. The overall style of the film poster felt very 'chic' to the expert and the contrast of the limited colour palette, was helping in that department. Out of the selection of poster, the style of this was the one the expert recommended exploring further. EX2 also commented on the use of capitalising the ' $\mathrm{c}$ ' in Colombiana, and the expert explained this is often not done in most Latin American countries.

The colour was also an essential aspect of the posters, EX2 explored that with the 'Colombiana4' poster, the use of colours and typography was subtle but very interesting. With the expert expressing that using the colours of the Colombian flag is valid, and the use of typography can speak volumes on representation. Describing this typography as soft, leaning more towards an authentic Colombia and less towards the violence, the original poster attempted to show. EX3 also expressed an interest in this concept by discussing that it has excellent contrast and a structured colour palette. In saying that, "It has got the really strong top left corner and it is not trying to compete for attention from anything else. The colour files down into a point which takes your eye naturally down to the title and the dark aren't just a big unbroken space, and it has a layer of the sparkles over the top to break up the darkness".

\section{Representation}

It was not to my surprise that the topic of cultural representation came up more prominently in my interview with EX2. We spoke at length about the representation of Latina women, with the expert being able to point out many aspects in the poster concepts that were still negative representations.

How designers portray the Latin American female body, plays an essential role in depicting our people. The expert spoke about how the body was drawn in the 'Colombiana2' poster and advised to remove the connotation of being 'curvy'. Also diving deep into the character's 
characteristics, they spoke about the curly hair of the character, and about "making a feature of the hair" and to consider that not all Latin Americans have that textured hair. In terms of the first two posters, the expert spoke of the potential idea of not needing to embody Latin American people at all, to try and avoid negative connotations in general. However, they also advised that "if you just use her head, that is not very sexualised, it does not show anything". They were explaining that displaying the character's body could potentially lead to negative stereotypes. The expert also warned caution, as the current display of 'makeup' in the character of my posters is still an American interpretation of what Latin American women look like in real life. Overall, in representing an entire ethnicity of women through an illustration of one, takes a deep level of detail and attention, as even elements that can be considered positive, will still lead to stereotypical implications.

\section{Subheadings}

EX2 also discussed the slogan used. The slogan is something that I have taken very highly into consideration. They also saw this as something essential to observe, and the original spoke of violence which created a connection from that, to beauty, but also insinuated the beauty of the character in the poster. They advised that I could potentially still use the original slogan if the visuals broke those primary connections. So, steering away from the idea of violence with the connection to the name Colombiana encourages the removal of this negative stereotype. While, the slogan used in the new poster concepts embraced the message of family and cultural roots. 


\section{Final Comparisons}

A final subject that all interviews touched upon were the differences in narratives between the original poster, and the concepts that I created. Generally speaking, EX1 regarded the posters to be "more interesting posters than the original". In thinking about the contrast between the different film posters, we spoke about the expectations that the industry has in making a film poster. What is seen in the original film poster became the norm, whilst this made the film industry believe it is therefore what people want to see, the expert believes that we could have also gone down a path in which what we regularly saw was steered more towards what I tried to recreate in the 'Colombiana4' concept.

"Film impacts peoples world-views, and people that have not thought very deeply about it, do not want to accept that" EX1 expressed that in her experience, film it is one of the things that impact our societies the most. The expert believed that it is easy to fall into the perspective that watching and making films is all-just for "entertainment" and neglect the educational importance of it in favour of being frivolous and detached from the realities we face.

EX3 also spoke about what they saw as 'wrong' about the original poster. The narrative that the expert saw was of an attractive and 'sexy' woman, and criticized the use of her cultural background to create negative connotations that Colombians are violent. The first thing that captures audiences about the poster is her body, thus creating even more negative stereotypes about Latin American women. According to the expert, whatever happens in the film has an American approach, therefore is a stereotypical depiction of Colombia. This statement is something I will fight against to prove that regardless of the country of origin of the film if Latin Americans are participating in communicating our narratives, they will not be stereotypical depictions.

EX1 also spoke about how things are easier said than done, and a project like this forces people to see that regardless of how much the film industry speaks on being aligned to a liberal and politically correct way of thinking, there is usually a lack of evidence and action to hold up those statements. The conclusion that I was left with from the expert was that "One thing needs to lead the other, so if how 
film posters are advertised is made better, maybe the people making films will realise the content could also be made better... if you could redesign an advertising campaign and prove that it would still be successful, then somehow a change could take place."

\subsection{Final Posters Development}

Following from this, I produced three developed film poster concepts. These poster concepts took into consideration all the aspects of the posters that were received well and developed aspects that required more thought. These posters will then once more be shared with the experts for final feedback. 
Colombiana Final Poster Design 1 Process
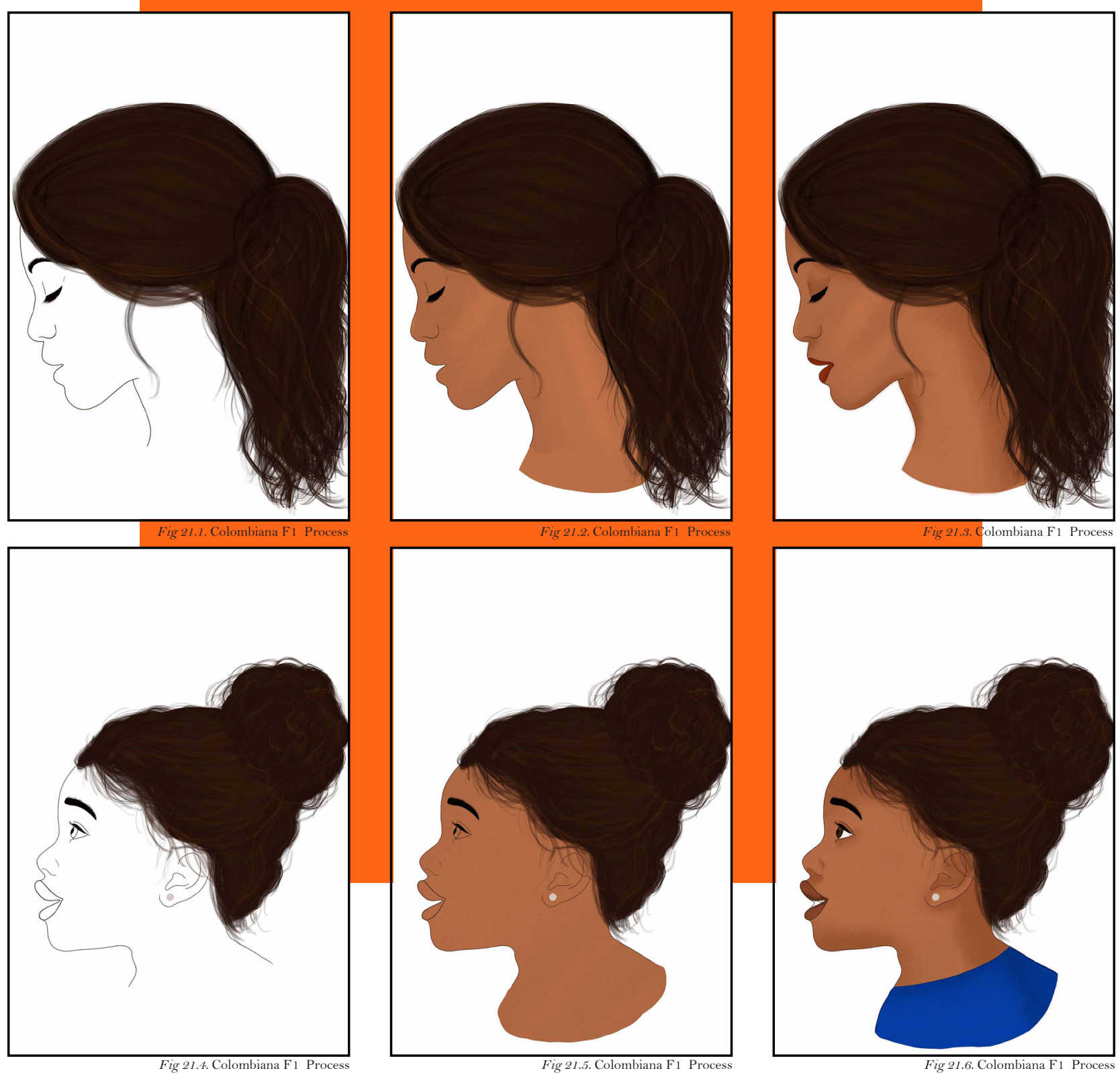


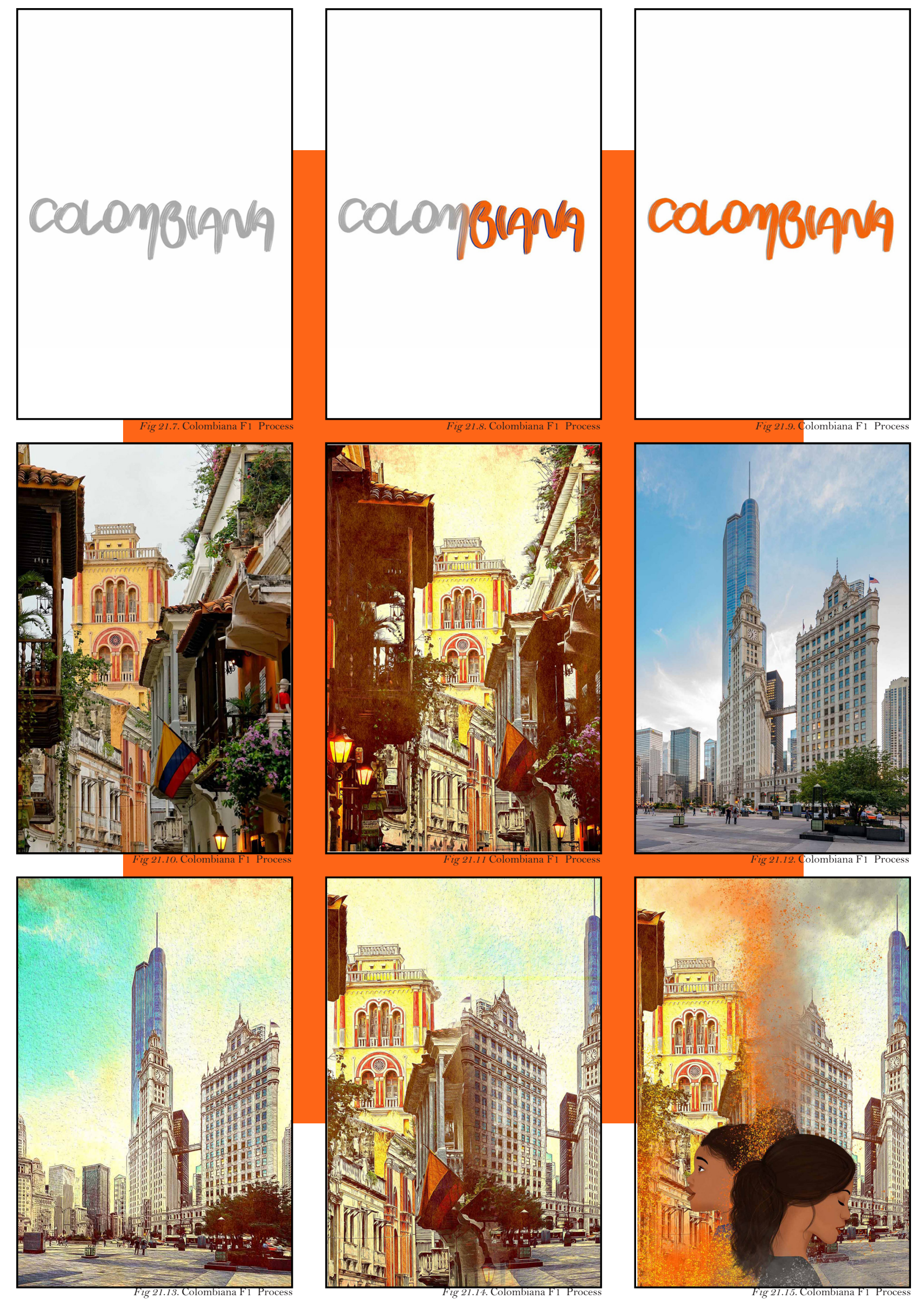


Colombiana Final Poster Design 1 
ZOE SALDANA

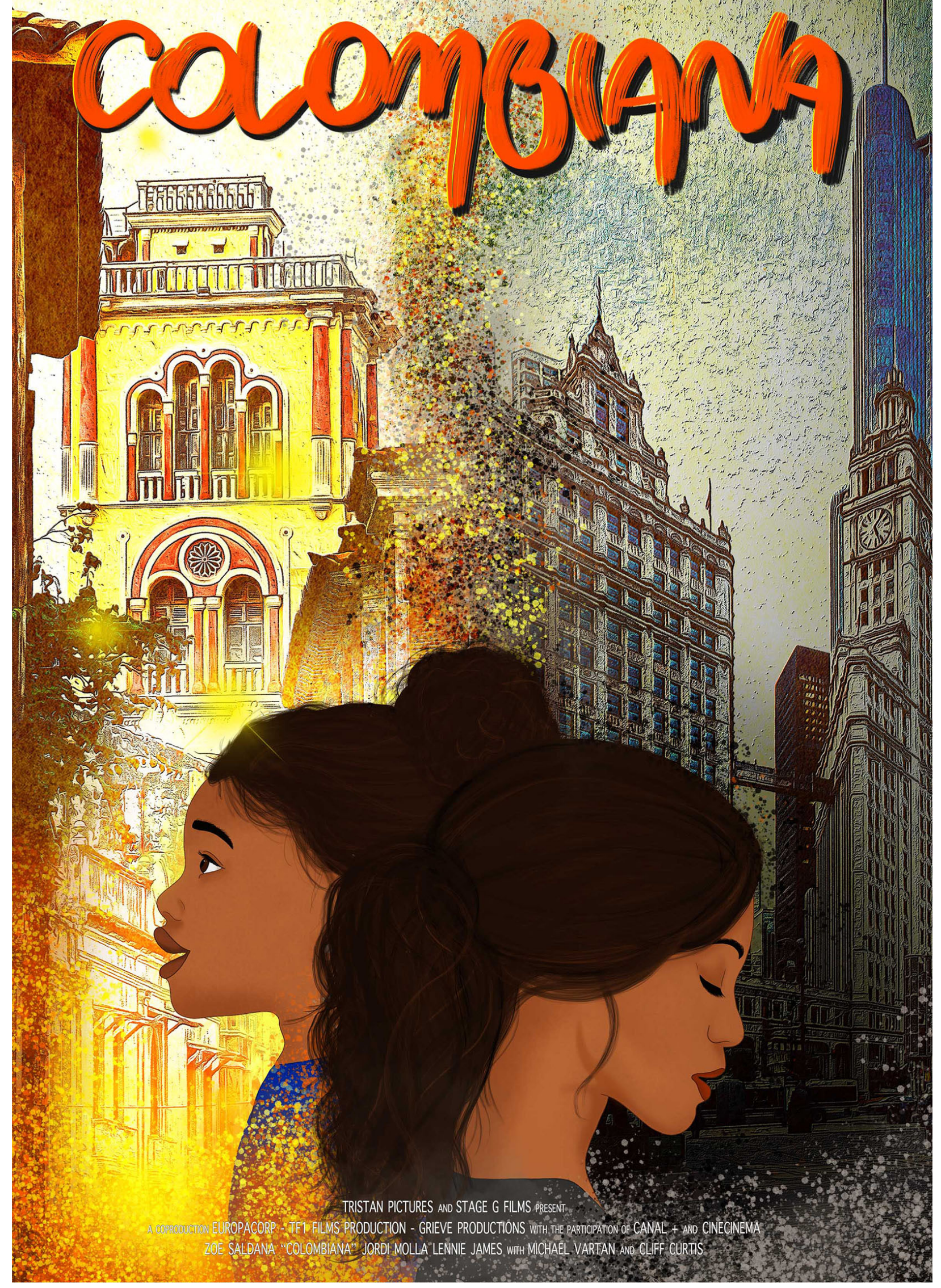

Fig 22. Colombiana F 1 Poste 
Final Poster Development

Colombiana Final Poster Design 2 Process 

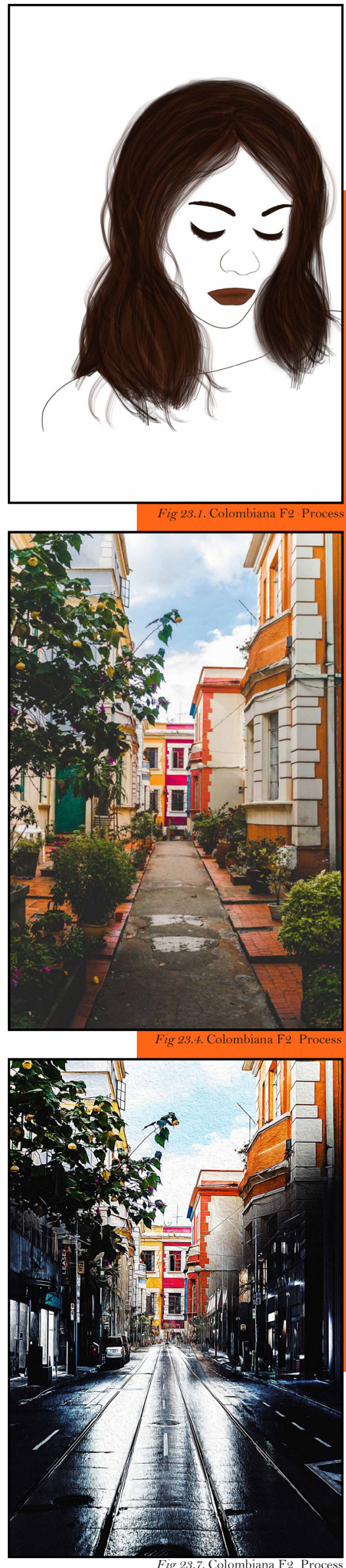
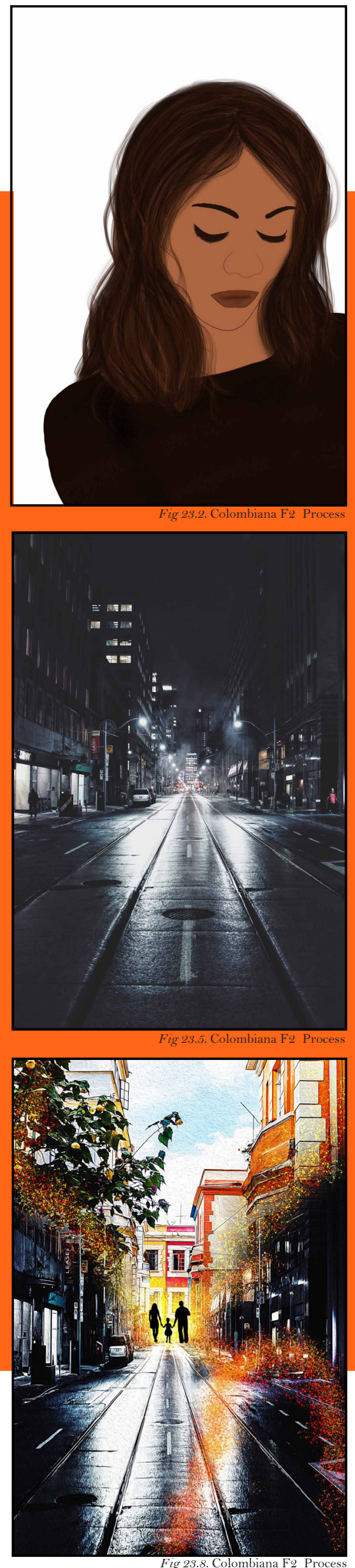
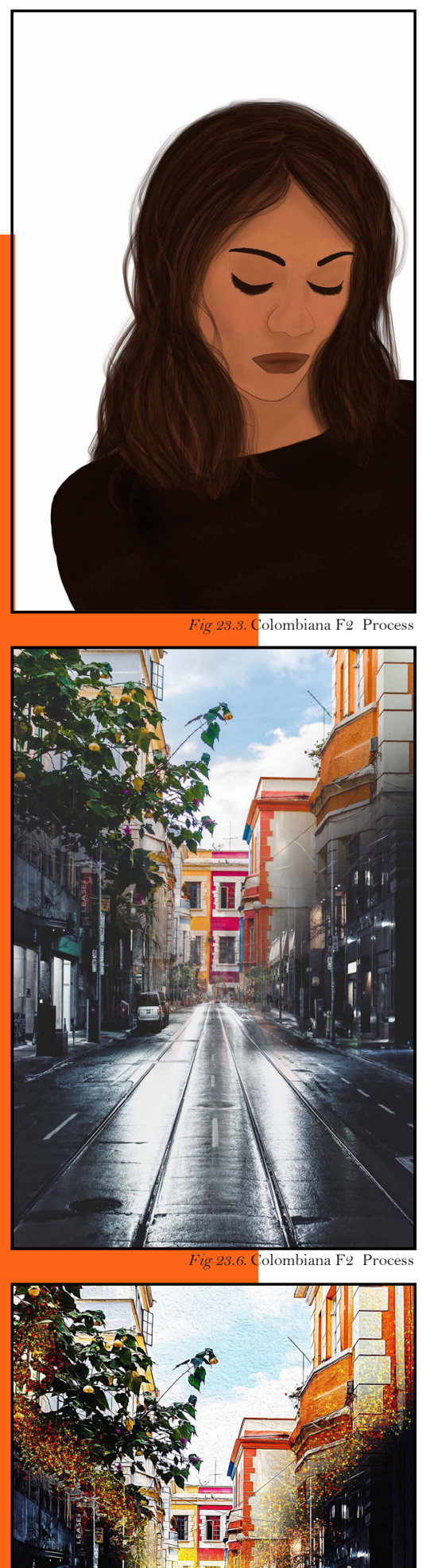

Min $=1+1$

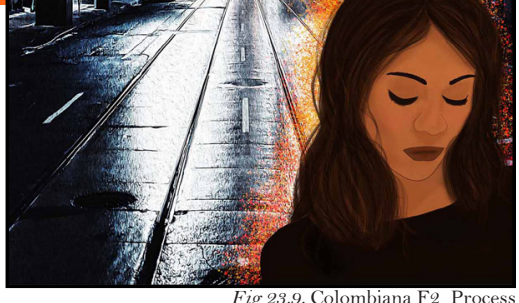


Colombiana Final Poster Design 2 


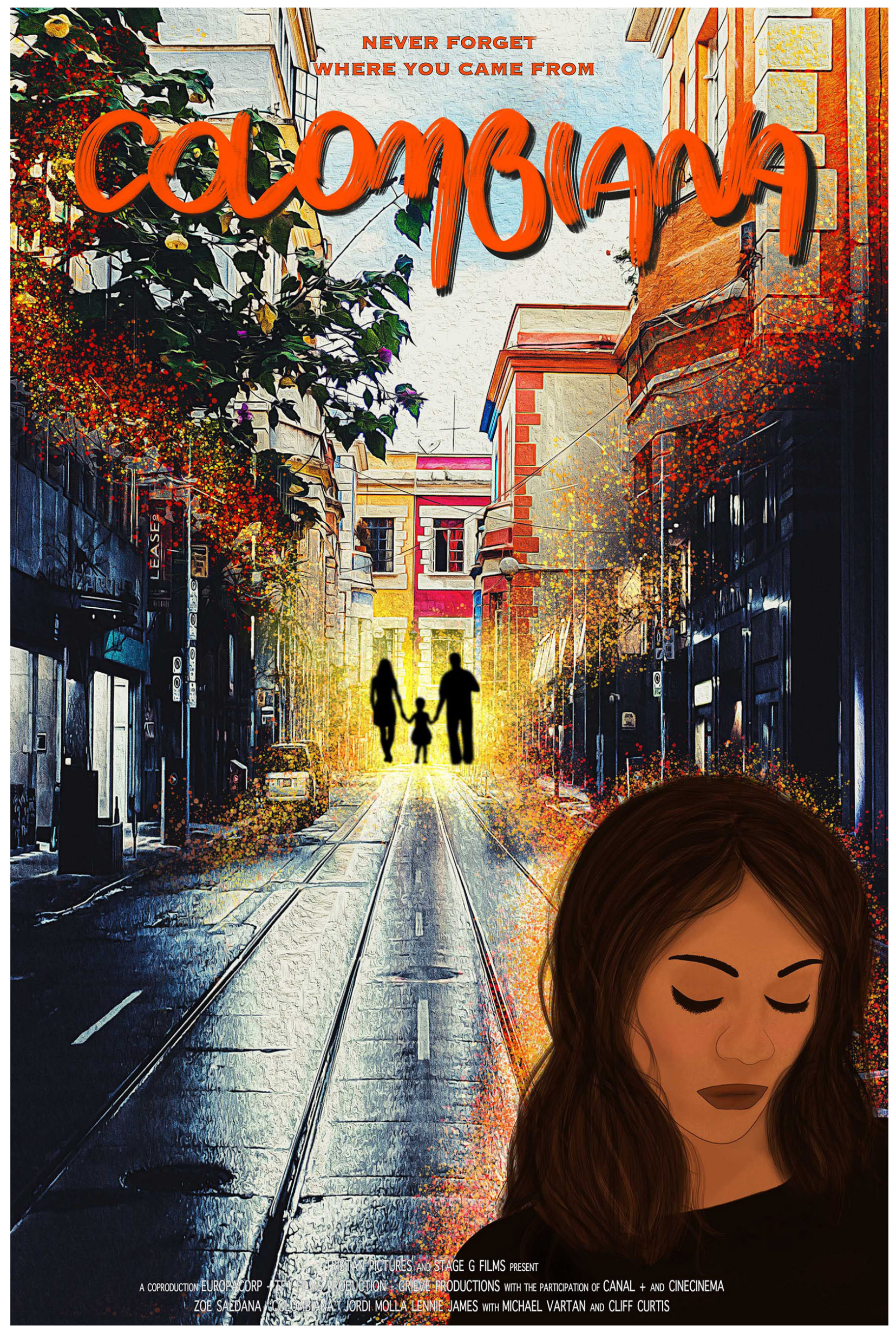


Final Poster Development

Colombiana Final Poster Design 3 Process 

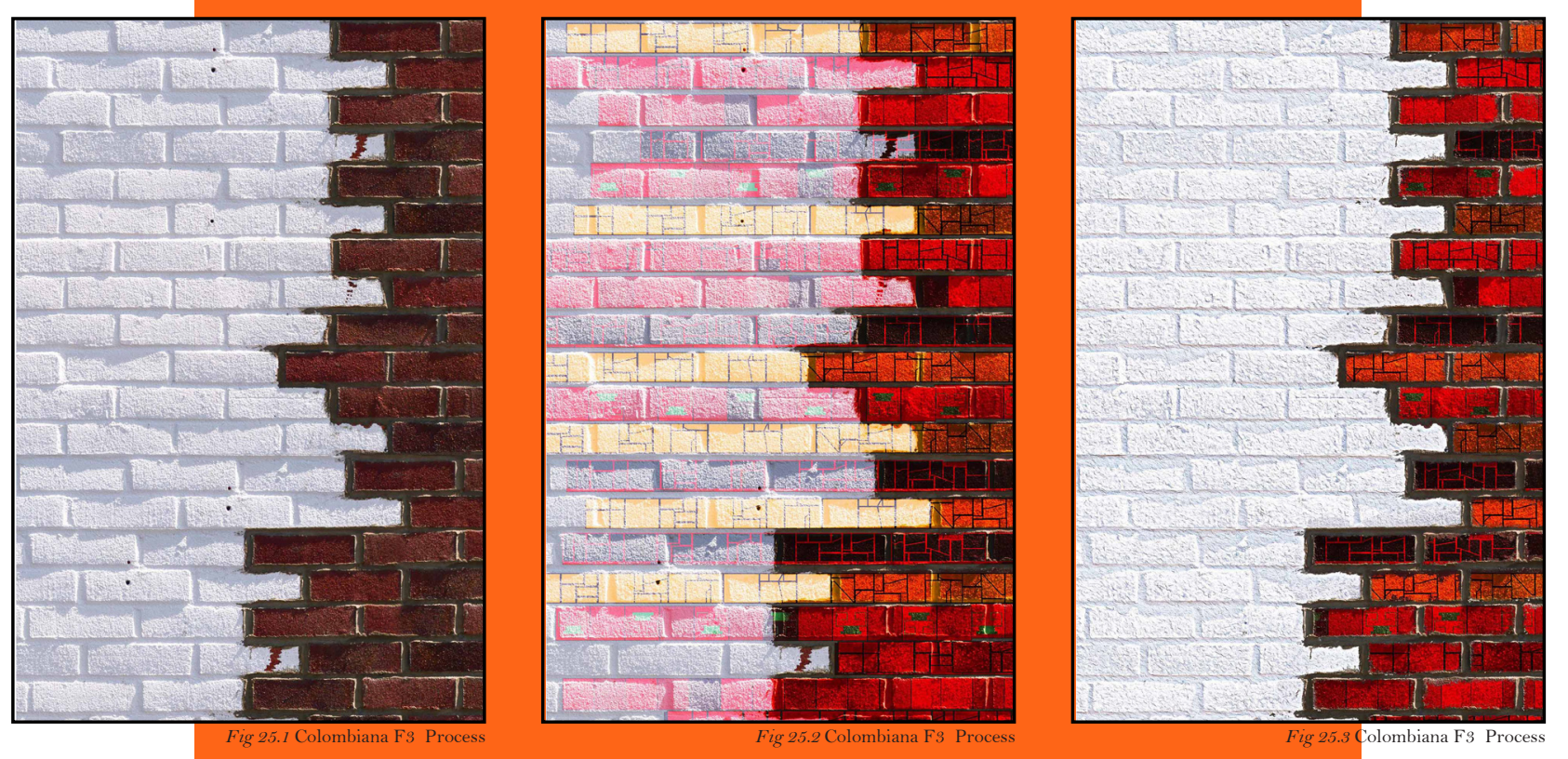
Colombiana Final Poster Design 3 


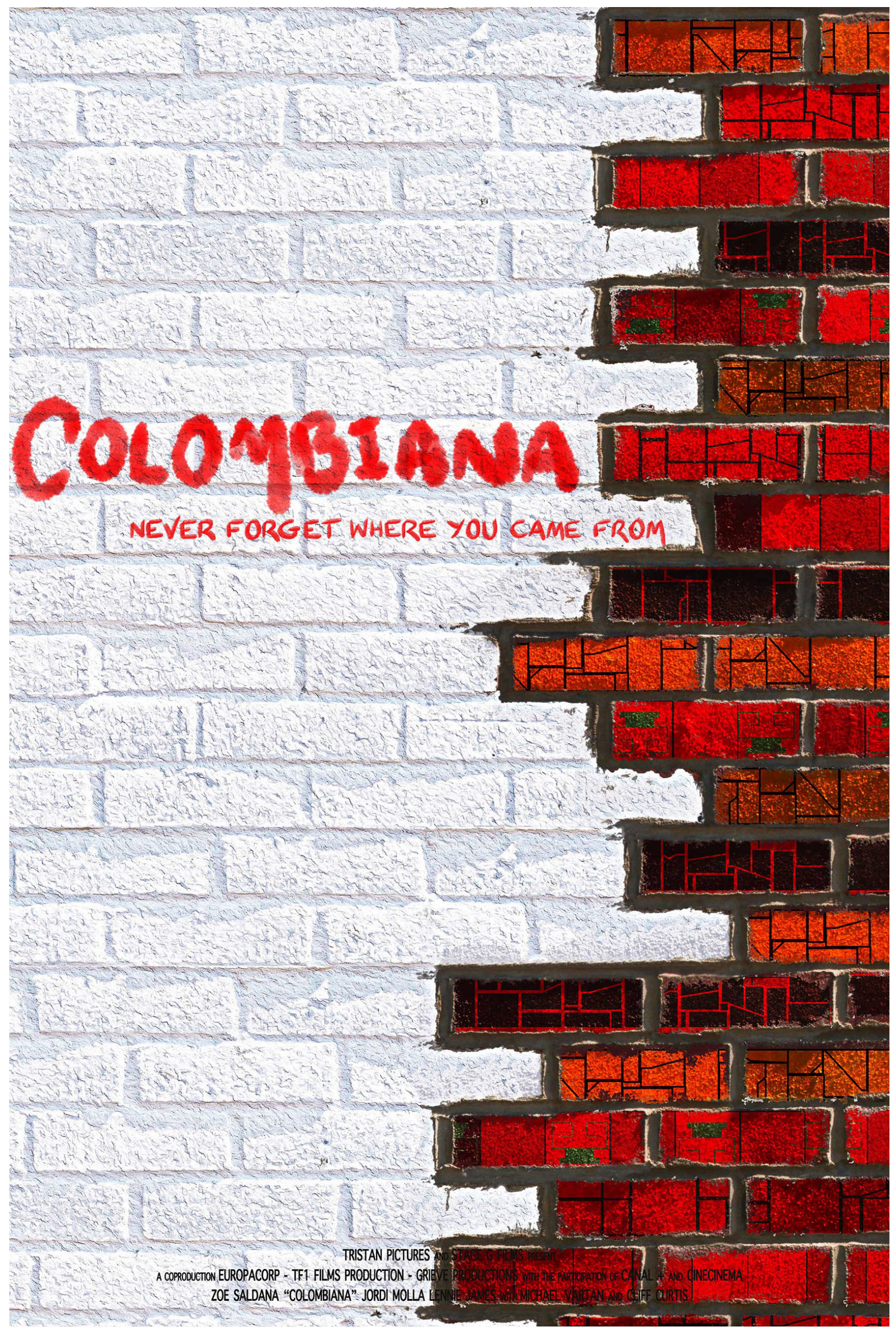




\subsection{Development Critique}

In reviewing the developed posters, both $\mathrm{EX} 2$ and $\mathrm{EX} 3$ believed these developments were taking into account their feedback to create a visual narrative that is explorative and creative. However, what these posters showed them was the film narrative repositioning the expectations of the film narrative as a whole. I believe this is appropriate considering the harmful and negative connotations that we discussed about the original poster.

EX2 believed that these developments are much less genre-orientated and communicate various ideas presented in the film narrative that is not damaging to the Latin American image, such as retaining a person's cultural background and coming of age. They still believe that the overall style of the 'Colombiana F1' and the 'Colombiana F2' poster have a connotation of a family orientated film, rather than an action one. This analysis is interesting to see since it signifies that a poster can change the perspective someone has on a film narrative, meaning that the masses could watch a film, without any predetermined negative connotations around a character.

Out of the three developed posters, the 'Colombiana F2' poster was the most successful in the eyes of EX2 and EX3. EX2 expressed that it conveys a less romantic, and idealistic narrative, that does not add any positive or negative connotations to the Latin American identity, which signifies that no stereotypical, or expectations can be placed upon it.

EX2 analysed the smaller details surrounding the composition of the posters which worked or not. They believe the 'Colombiana F 1' poster is looking balanced, and the arrangement of the two girls works very well, their hair blending emphasises that they are the same person, creating an engaging narrative for audiences. They believed that the 'Colombiana F2' poster tells an enticing narrative that needs minor adjustments to become successful; they suggested developing the text layout and the placement of the female character.

Both of the experts were pleased with the progress and believed that what needed to be developed was, and the aspects that did not work were removed. Their final thoughts will be interpreted to polish the three developments into final posters. 


\subsection{Conclusion}

These interviews were conducted with the intent of dissecting different perspectives on the proposed poster concepts. The three experts that participated in this process were able to view these posters from three different and critical perspectives that can improve the outcome of the final posters. The experts came to conclusions that I had not previously considered and that I would not have been able to review sans interviews. The act of including other viewpoints is also by itself an act of inclusion and encouragement for diversity. This followed with the belief that 'good' design cannot be realised without the inclusion of others with different skills from your own. 


\subsection{Final Posters}

After receiving a final critique on the posters they were polished and finalized into three high fidelity film poster concepts. 


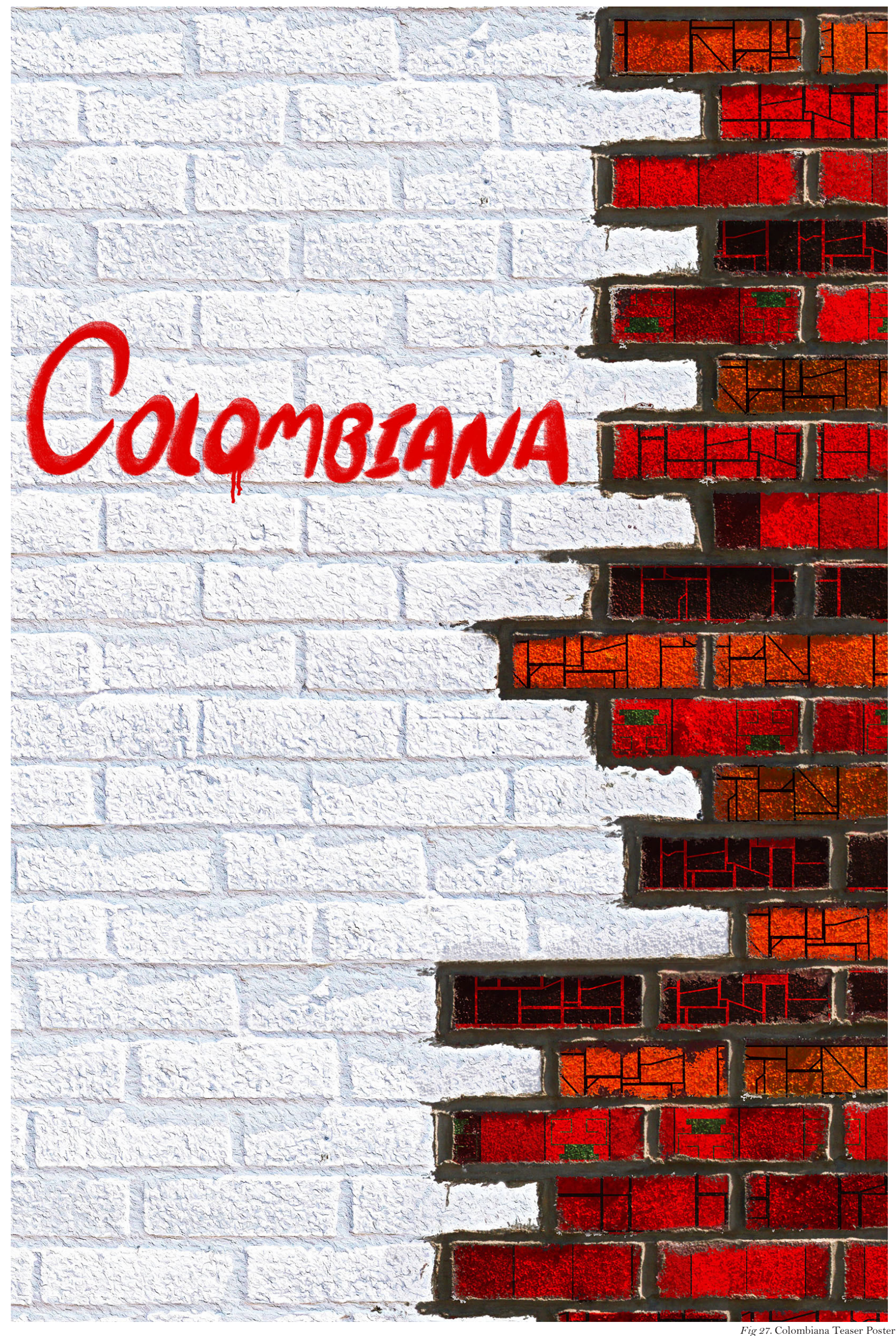




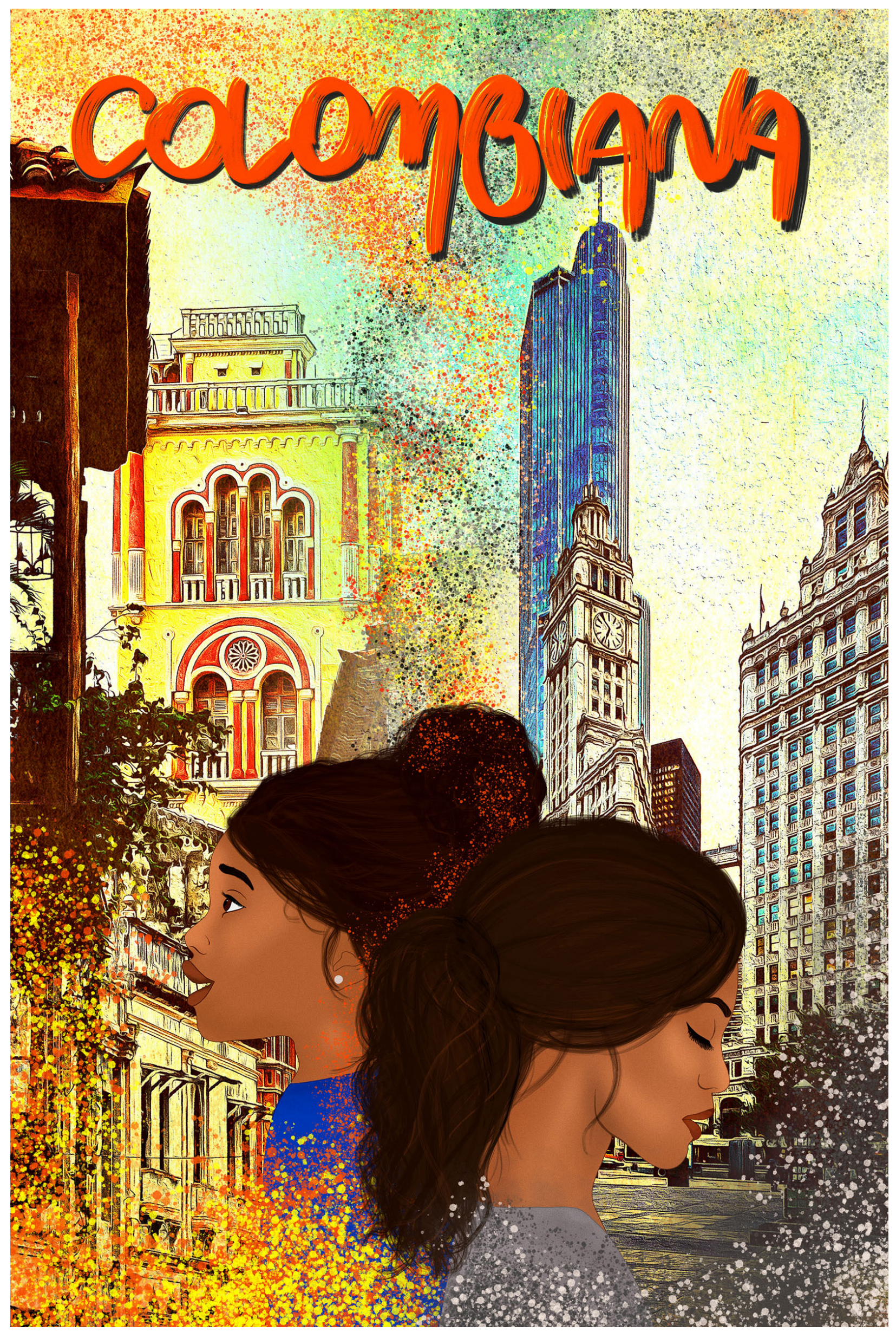




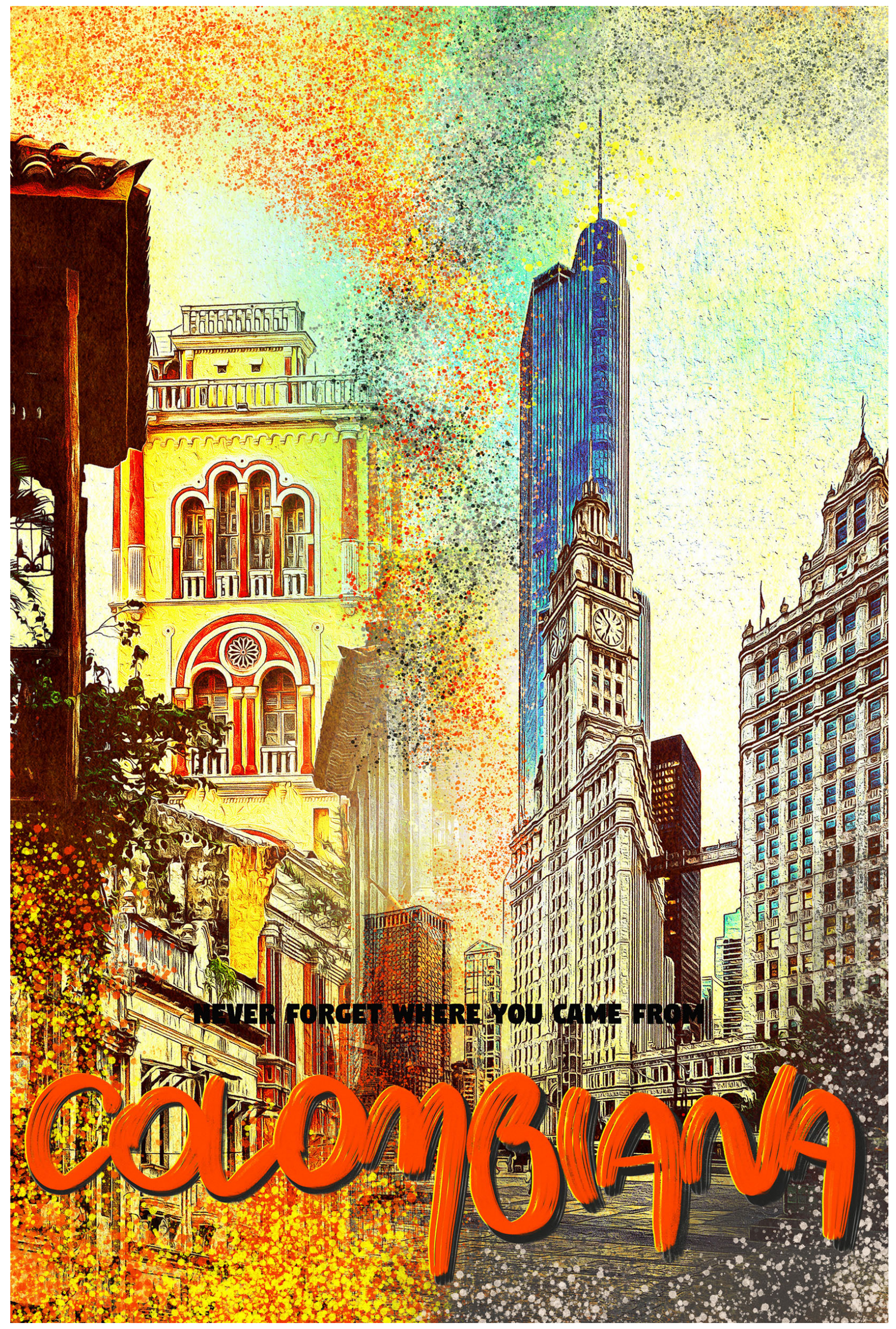




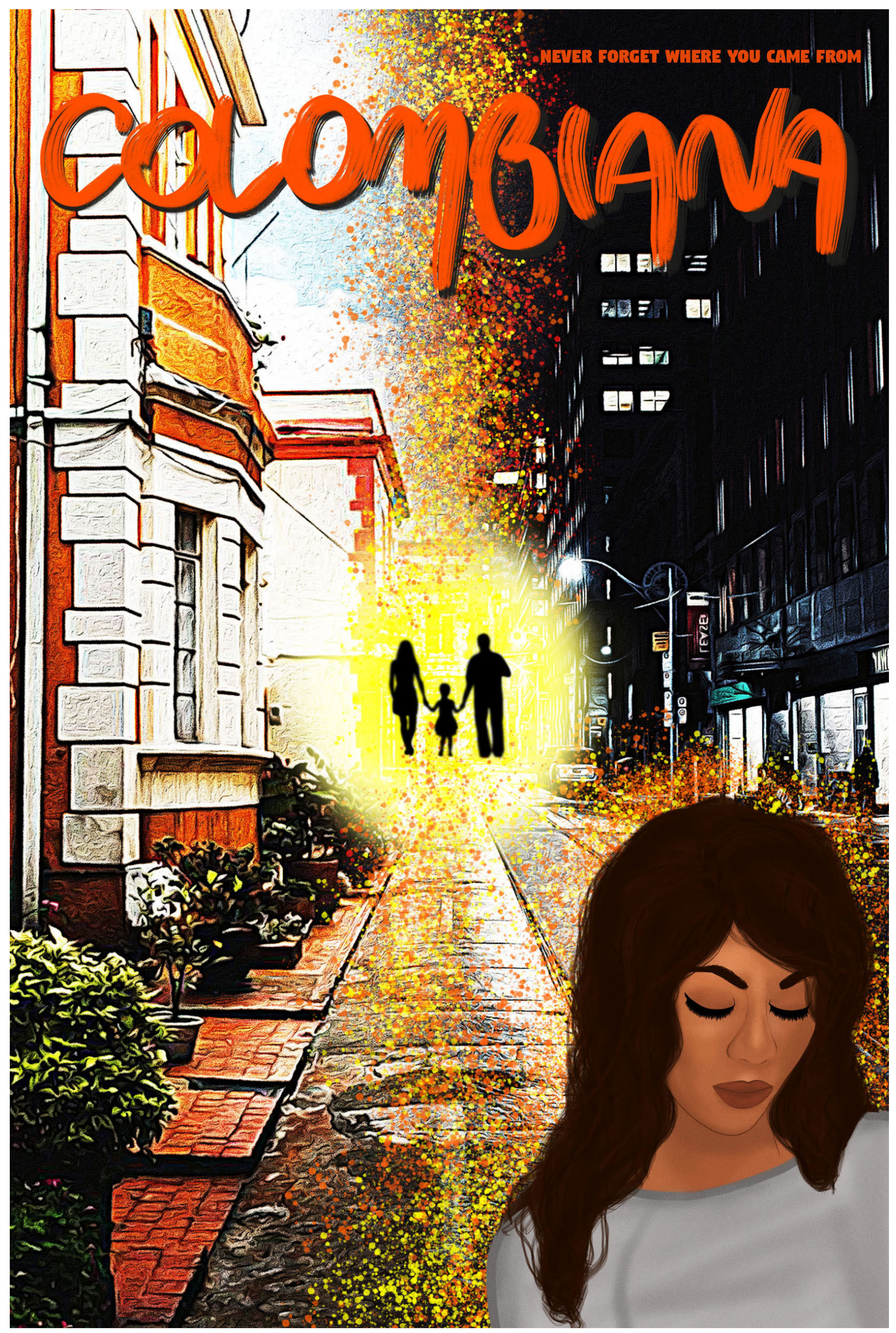




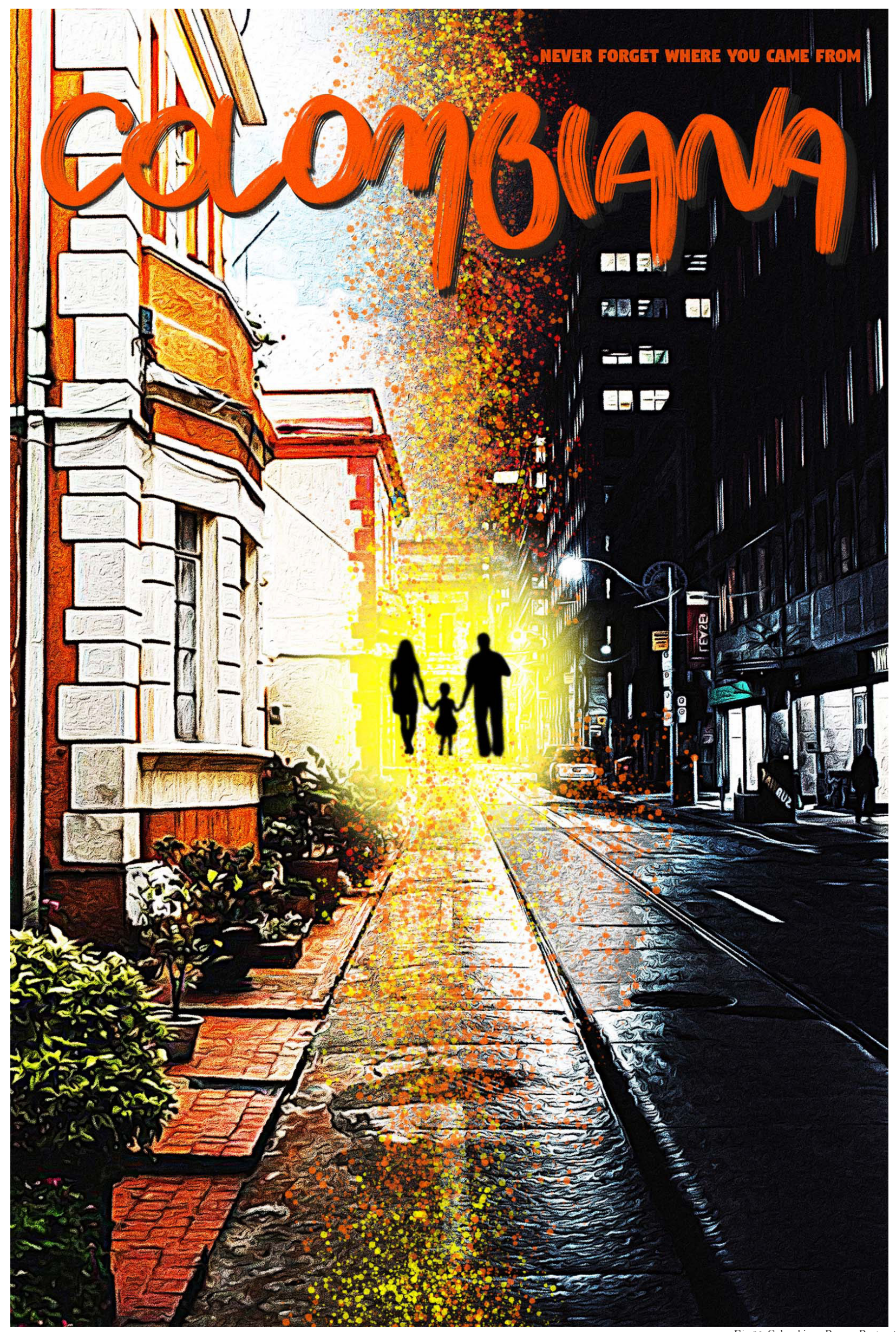


5.8 Context: Poster Installation

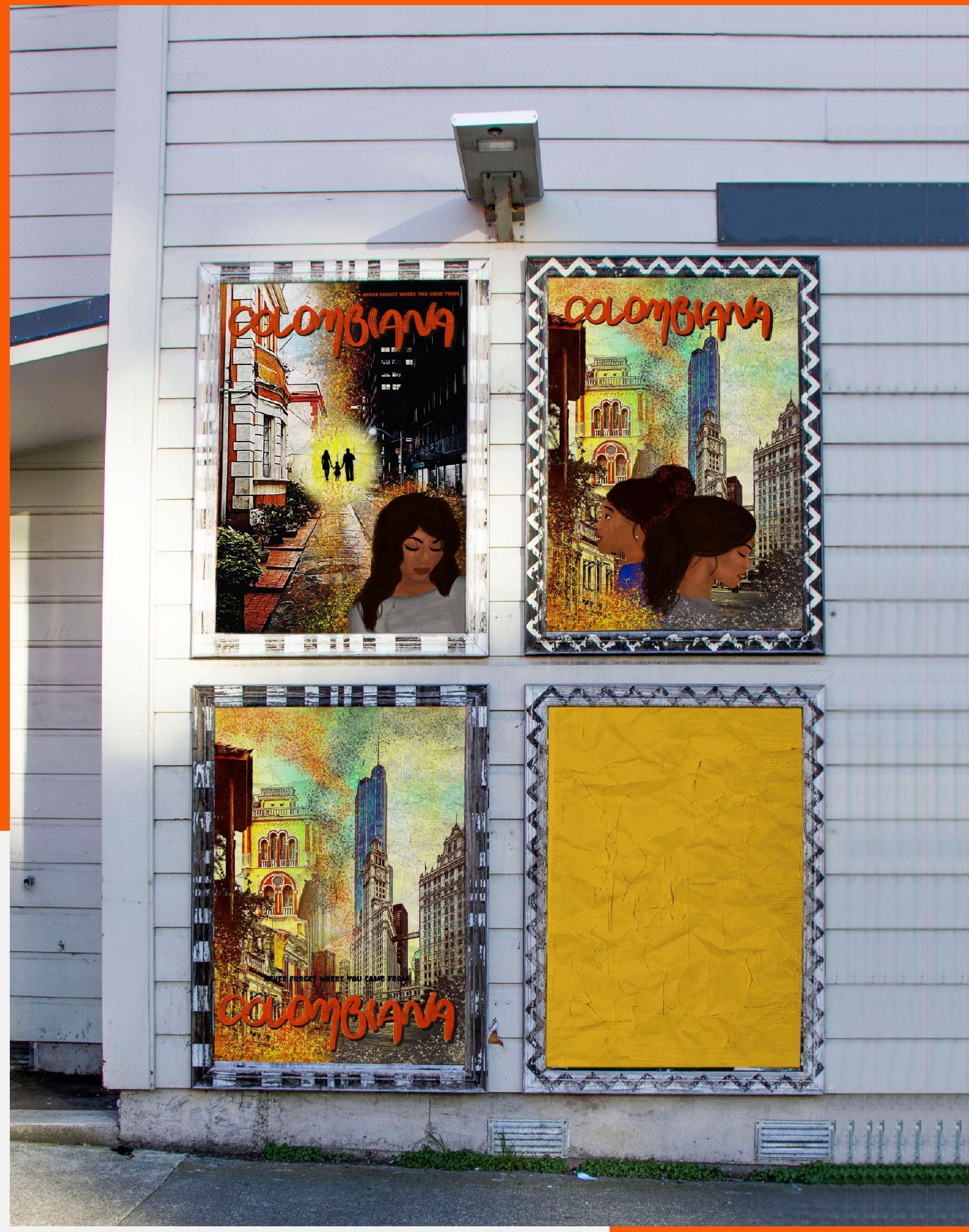




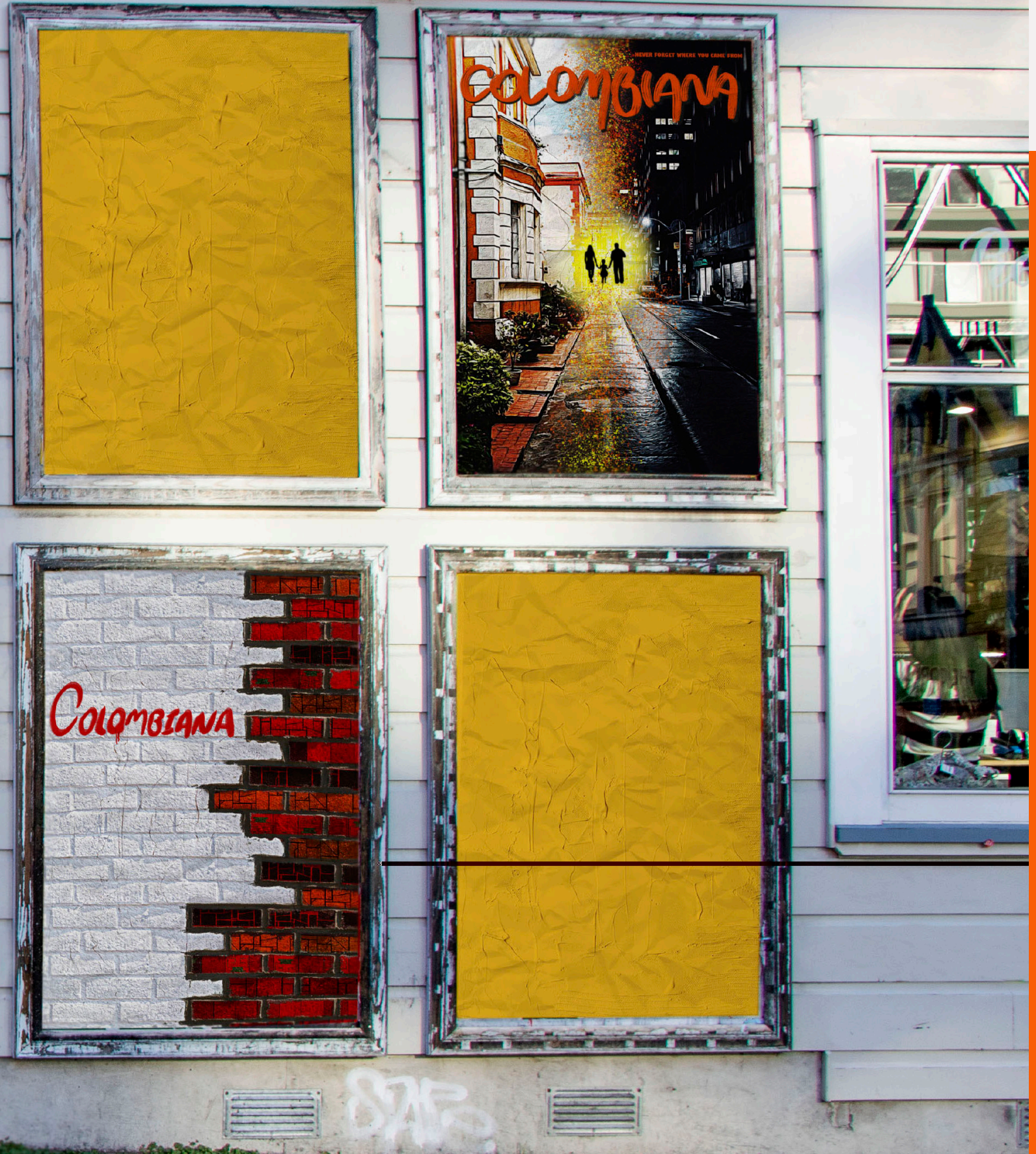

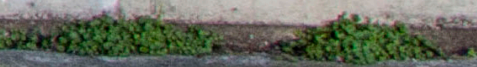




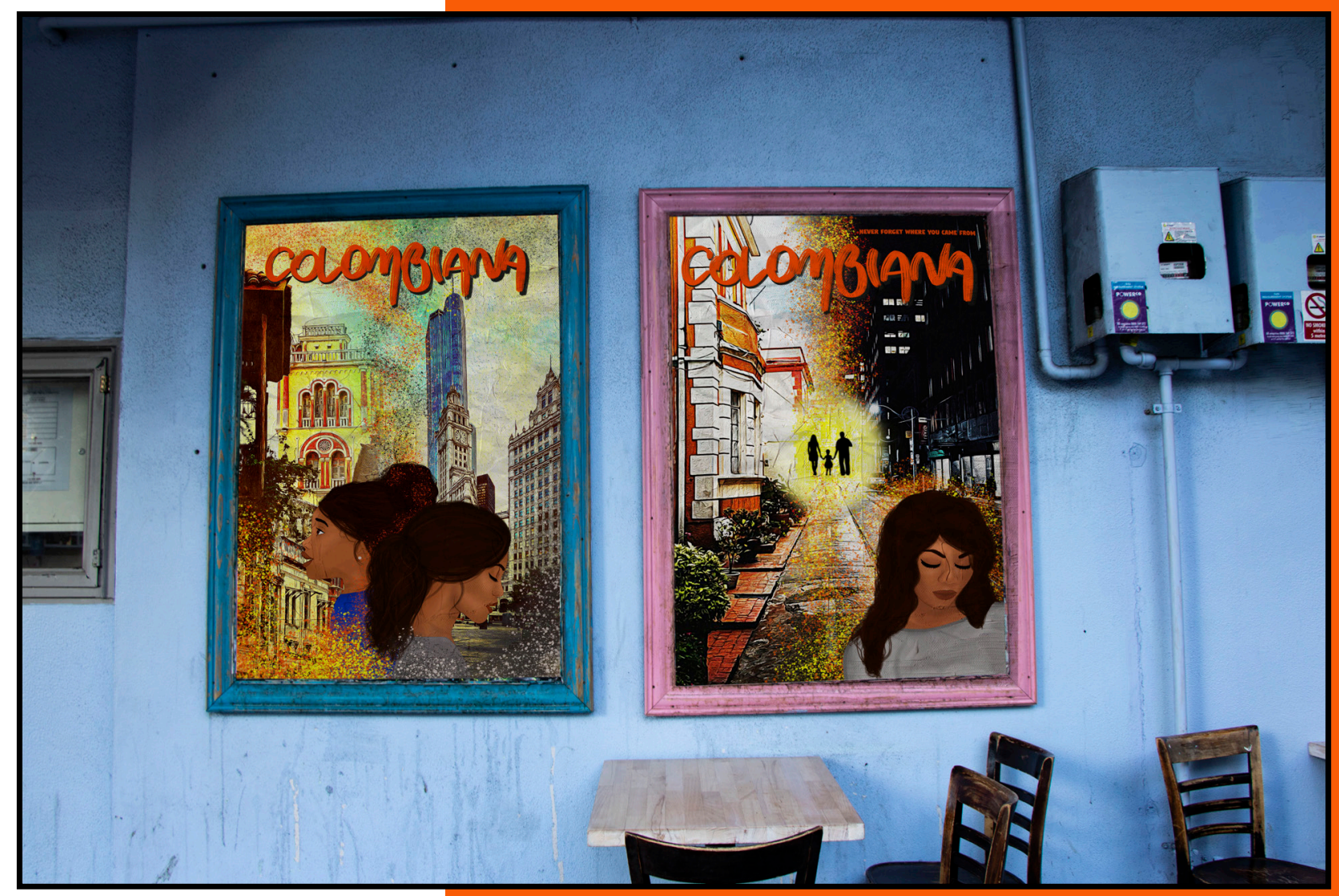

Fig 33. Poster Installation 2 


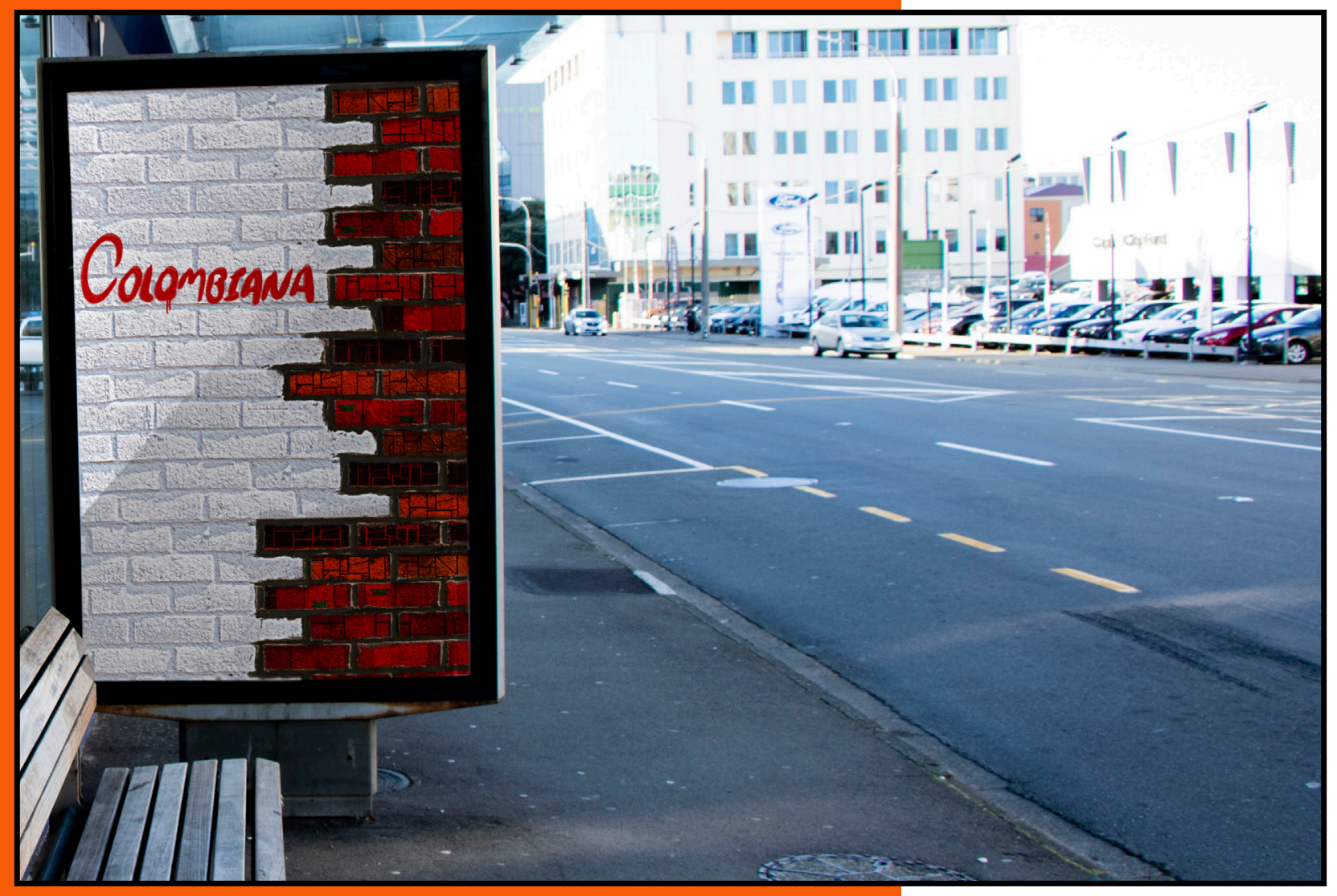

Fig 34. Poster Installation 3 


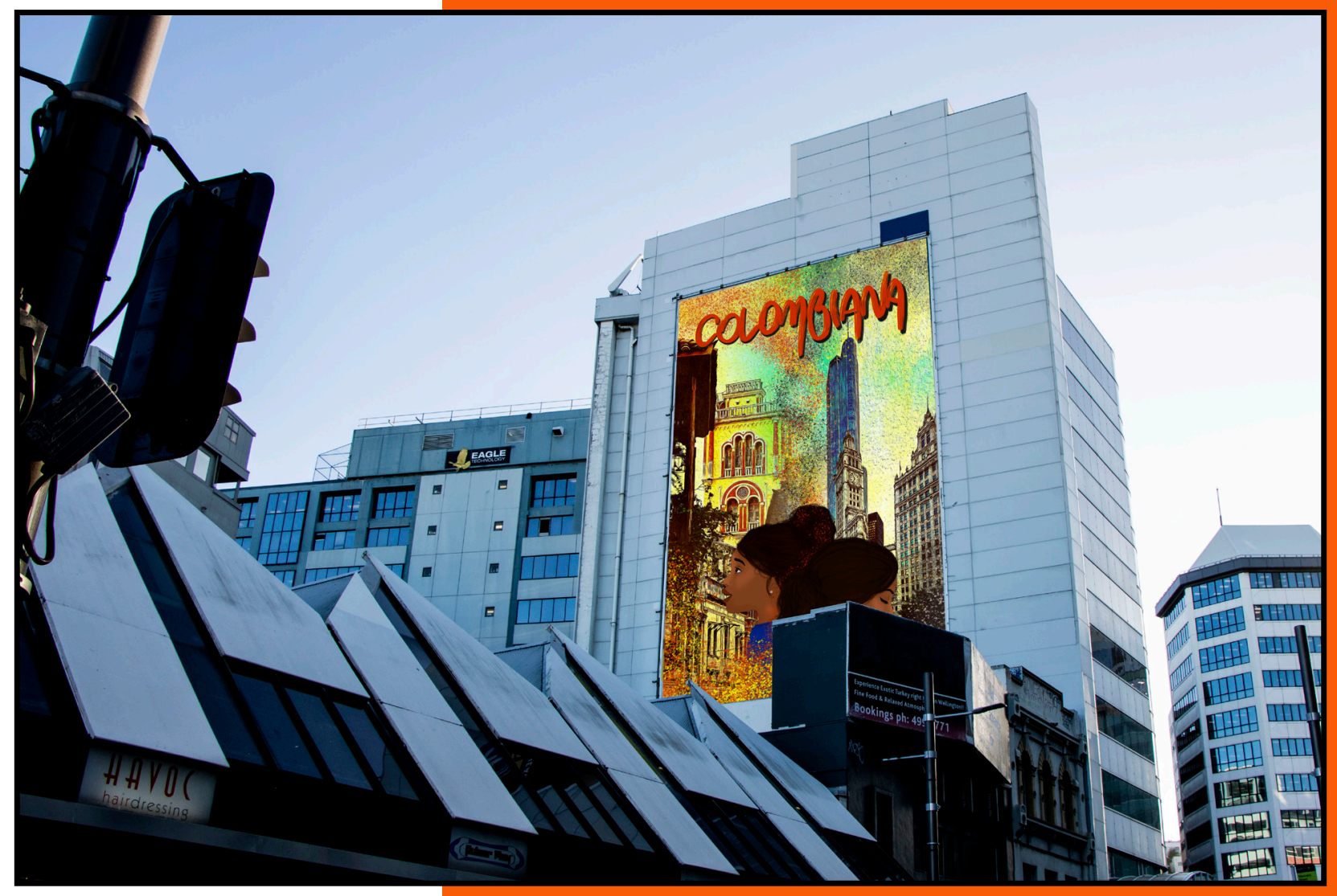

Fig 35. Poster Installation 4 


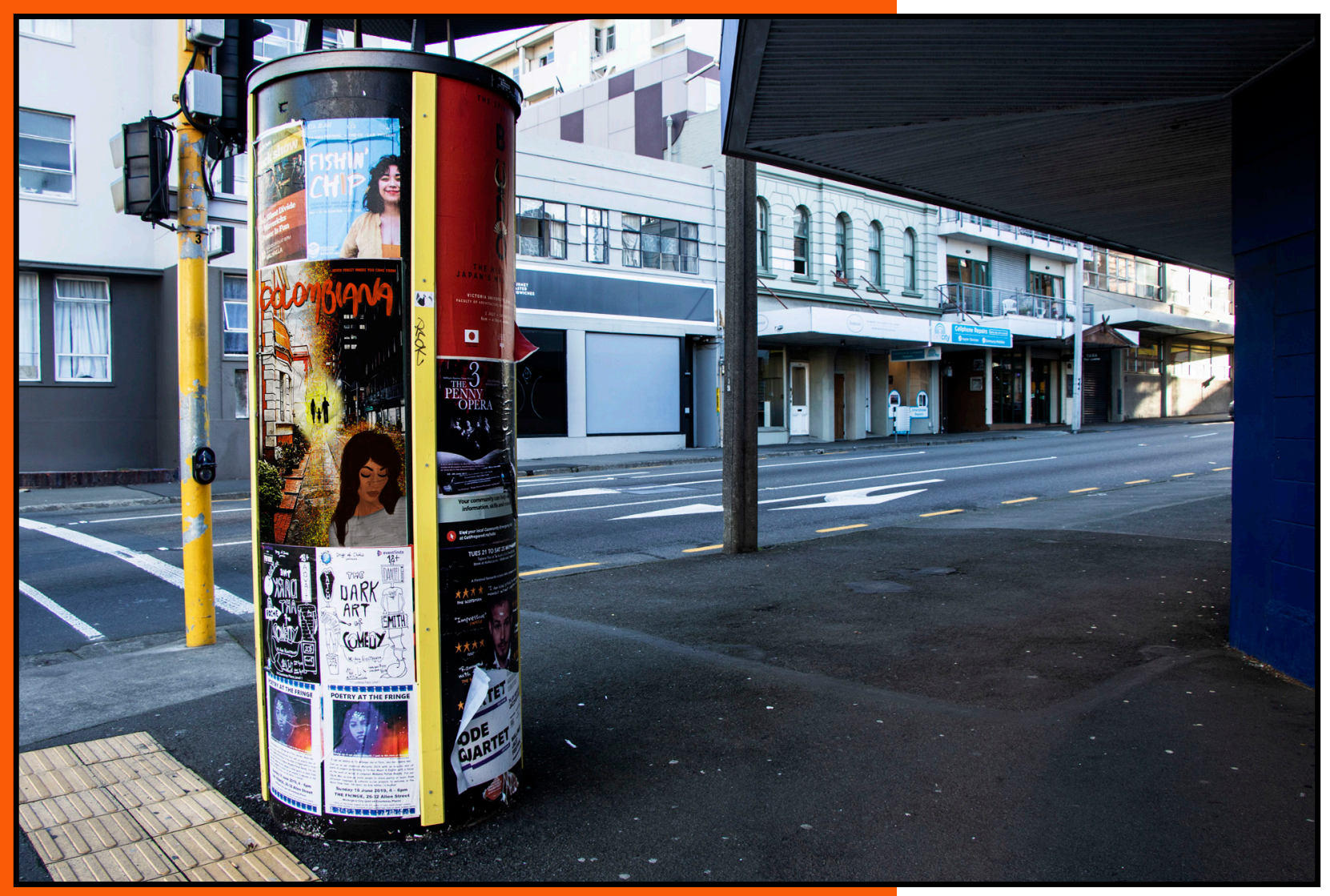

Fig 36. Poster Installation 5 


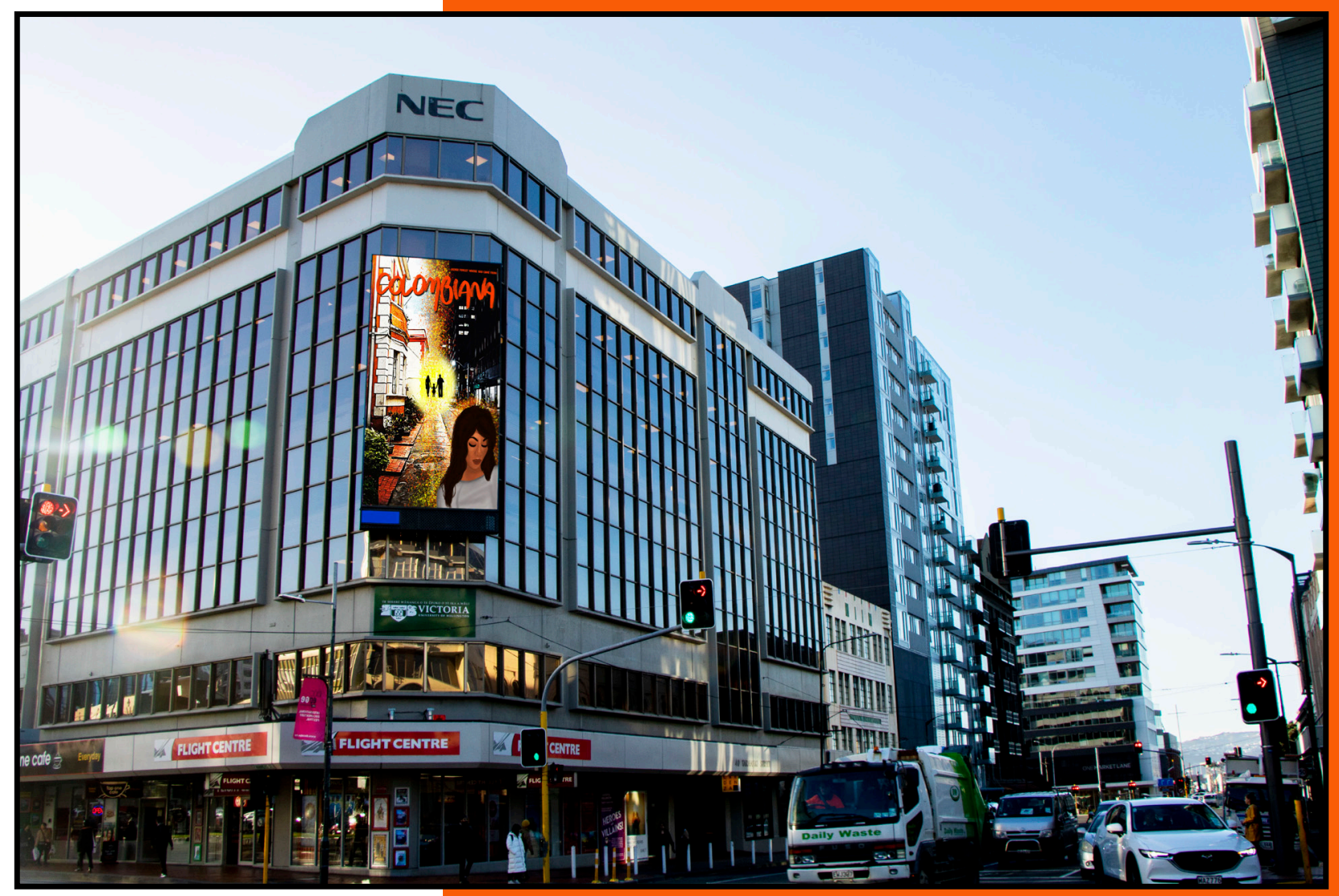

Fig 37. Poster Installation 6 


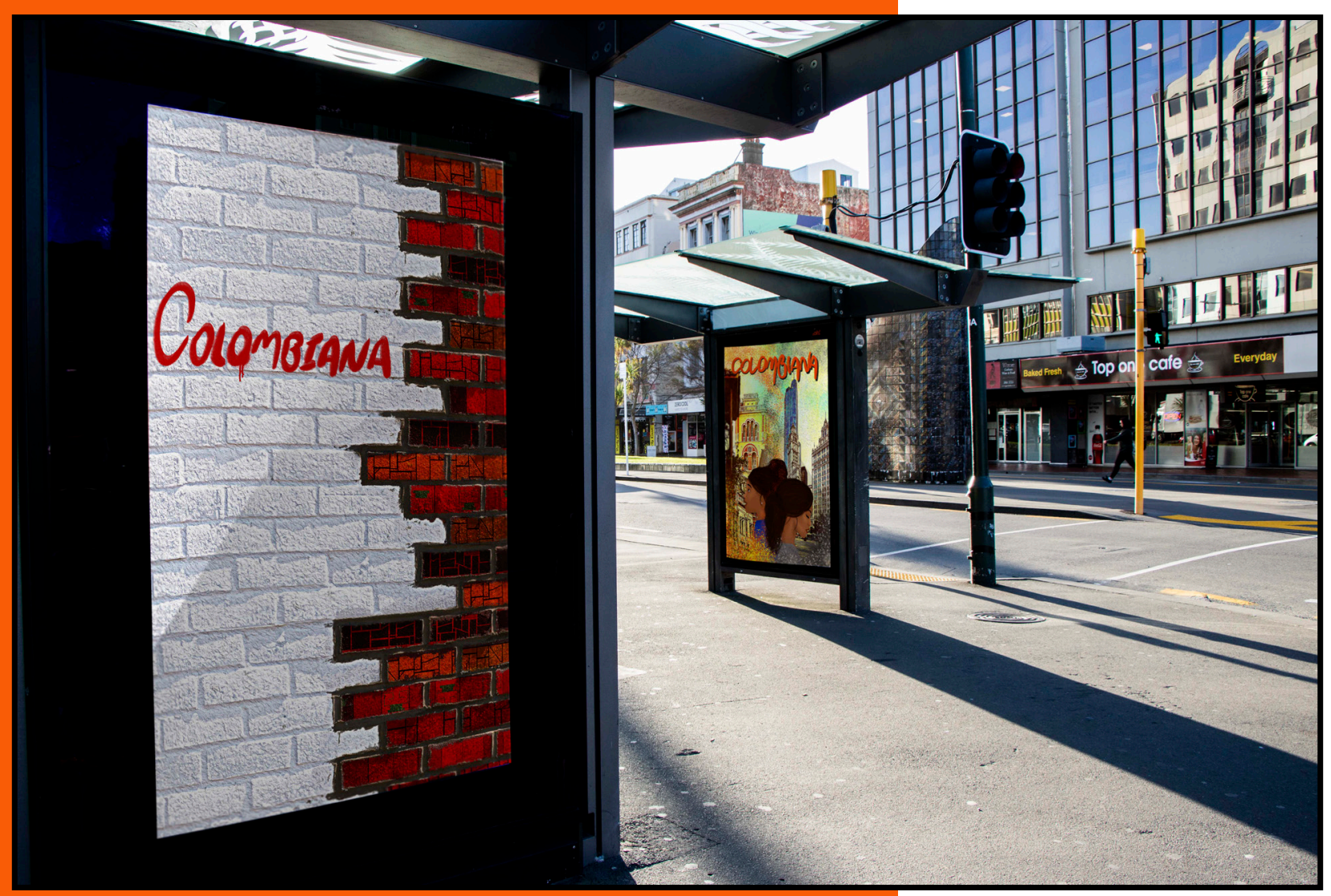

Fig 38. Poster Installation 

REFLECTIONS

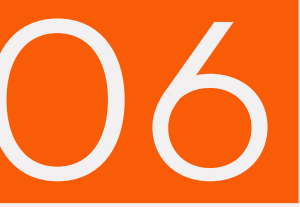




\subsection{Introduction}

Throughout this process, many aspects of it led me to think and speculate about this research. Firstly, to analyse and critique whether this research has achieved its goal, but also to reflect on what has been produced. During this research the study that was conducted held some strengths, weaknesses and limitations. Those should be acknowledged and accepted for how they've impacted the research, but also for how they influence the future of the research.

\subsection{Strengths, Weaknesses \& Limitations}

\section{Research}

The time I dedicated to initial research was expansive and thorough. It allowed me to define the research, where its value was placed and initiated questions and issues which I would not have otherwise considered. A crucial turning point in this investigation, which shaped the scope of the research, was the exploration of stereotypical visual manifestation. I would never have been compelled to explore the area if it were not for my research into the field of film narratives and how stereotypes can be interpreted in film.

The exploration done towards stereotypes was also a beneficial aspect of this design-led research. It is ubiquitous to explore cultural representations in fields such as media and cultural studies, therefore the ability to, as a designer, analyse this information added a new layer of depth to this broad field of study.

With more time and resources, interactions with the people who design film posters, and who go through this process would have added layers of depth through personal stories, interactions, and interviews. Alongside this, further interactions with the people of Latin America would have allowed me to contrast research against personal stories. In the future travel through the countries mentioned in this thesis like Colombia, Cuba and my home country of Brazil, would have brought forward more experiences and first hand contact to draw from. 


\section{Communication}

I believe communication and different viewpoints to be a crucial part of a successful design process. Once I had developed my film poster concepts, conducting semi-structured interviews with experts from different fields added a layer of richness and detail that I could not have achieved on my own.

However, a constraint within this process was the restriction of no communication until the poster concepts were in production. In the future, I would aim to interact with stakeholders from the initial phases of the research process. I believe that the type of explorations done in this study would benefit from the inclusion of co-design approaches that would create further inclusion and discussion around this broad topic.

\section{The Film Poster}

A poster is a succinct visual summary of a cinematic story. The benefit of analysing and exploring this single aspect of film culture was beneficial in the sense that it includes aspects of all the elements that are present within a film. Since it is positioned as a single still image, those aspects and narratives are saturated to tell a story, which in turn forms stereotypes. Because of this saturation, all the aspects that designers rely on to tell this story are apparent, and this research is a reminder that many elements combine to form stereotypes, and they all must be considered.

However, the limitation in this study is in the fact that regardless of the content and narratives that were redesigned in the poster concepts, they can not change the film itself. The film poster is a representation of the film. It does not influence the production that comes before it. While it is well beyond the scope of this research to address the preproduction of a film narrative, further study in this area could have this focus. My intention in the present work was to find ways to not rely on stereotypical implications to tell its story. 


\subsection{Future Consideration}

Misrepresentation in mainstream media is not only a problem found within a Latin American context. Minority cultures do not receive the diverse interpretations they deserve. Therefore the research process created in this thesis would be beneficial to be initiated within any culture and mass identity. Exploring repeatedly saturated narratives within film posters, and attempting new ways of illustrating a culture in visual narratives, would make promotional film design a more open, embracing, and positive space. There is complexity, beauty, and a richness in every culture, which is not being fully explored in mainstream media. Therefore, I believe this research could be applied to any minority culture.

Beyond the potentialities of the processes followed in this investigation, there are other possibilities to explore moving forward. This investigation was within the scope of cinematic promotional material. However, I believe that within the production of a film, many other processes could be investigated for stereotypical implications. Costume design, narrative, character development, and animation style are just some of the fields that could benefit from this inspection. Cultural communication within the field of cinema would benefit highly from the use of social design in an expansive way, and this portfolio was only a short demonstration of its possibilities.

In moving forward, I aim to explore the steps taken in the preproduction of a film where characters and narratives are created and follow the process of how the decisions that influence minorities are made. In doing so, an understanding of where stereotypical implications are placed within the making of a film would be created. This analysis could then be used to design a process that would encourage filmmakers and designers to no longer rely on stereotypical implications, resulting in a more inclusive, and diversity film industry. 


\subsection{Research Aim}

This portfolio looked to answer the question: 'How can film posters be designed to illustrate complex, multidimensional narratives of the Latin American identity in the 21 st century?’

The first step in answering said question was to explore the treatment of, and attitudes towards Latin Americans and their culture in film narratives. This was done by conducting a thorough literature review, planning a content analysis, and conducting a case study. The second step in answering this question, was to actively attempt to portray the culture within a 21 st century context. In doing this a reflection of the knowledge gained in the first step was explored, to then create film poster concepts of narratives that should be visually explored within film posters, to then get expert feedback on the matter, to create final film poster concepts that reflect the answer to my question.

Reflecting upon the steps taken, and methods used within the portfolio, a step-by-step guide was created with the goal of illustrating complex Latin American narratives within film posters. Engaging in the process followed to answer the question, and identifying the strengths and weaknesses of the process, is how this portfolio has found a way to answer the question. 



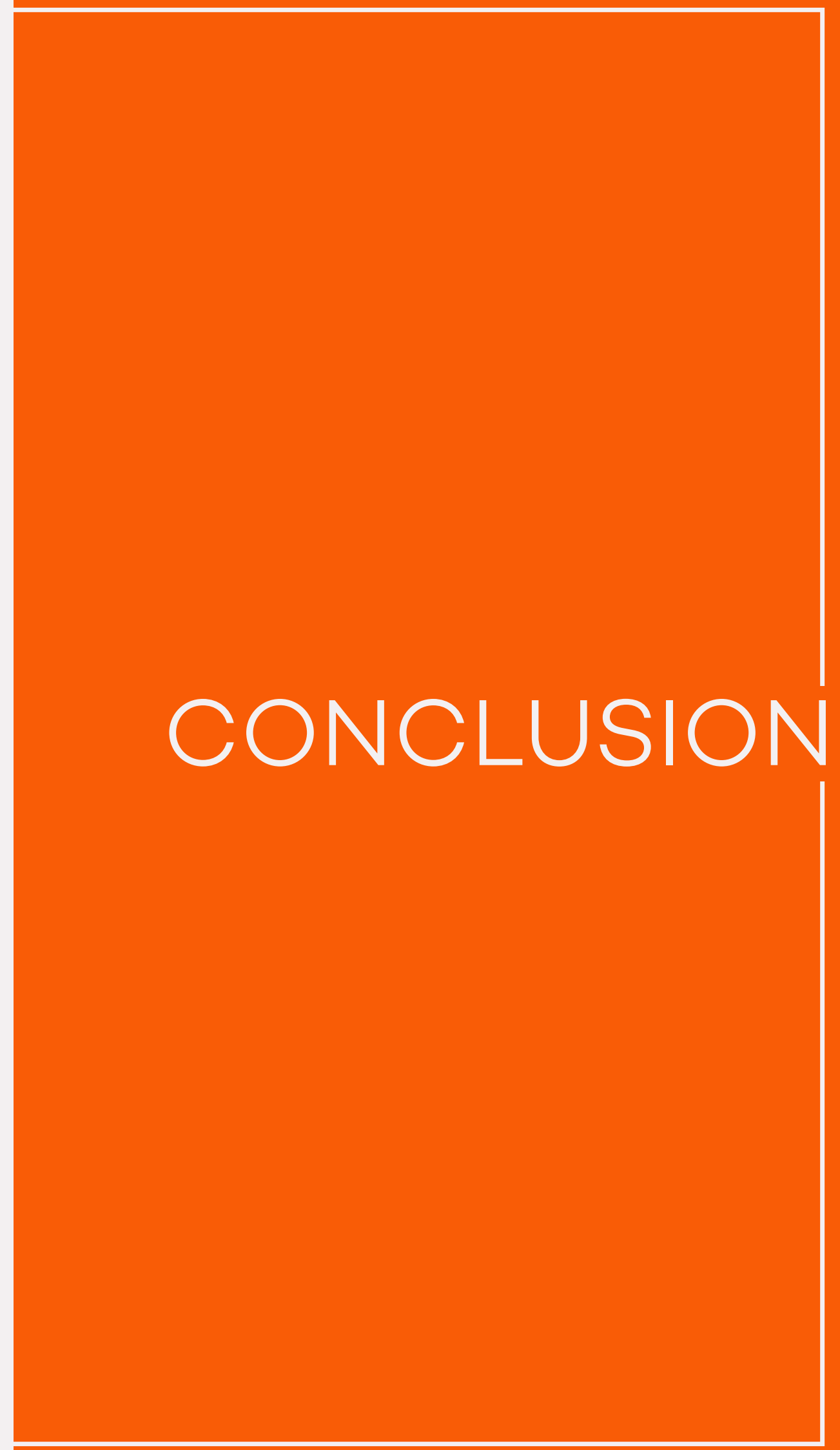


This thesis is a personal project and exploration into the treatment of my culture in the mainstream media. There are two very distinct sections within this thesis; an exploration phase, and a response.

The literature review provided insight and perspective within the distinct narratives and beliefs that combine to form the problem of misrepresentation. The history of film posters, the value of Latin American design, stereotypes, and public perceptions are presented as the foundation of this research, and the key to presenting a complex Latin American cultural identity. The literature review highlighted a significant gap in scholarly studies of film posters.

In the past, considerable research has been conducted about visual imagery. But, there was a lack of information about how to accurately visually identify cultural stereotypes in film posters. As Emmison, \& Smith (2000) state, understanding visual information is fundamental to understanding everyday social life. Therefore, the formula to identify the visual manifestation of stereotypes in posters and promotional material is worthy of exploration. The visual analysis allowed me to identify the main criteria that would inform my design direction and also presents a novel approach to studying stereotypes by systematically analysing posters over time.

Beyond my understandings of Latin American culture, it was also crucial to explore the culture's visual history and its value. To do so, I conducted a case study of Latin American art and design, tracing its historical roots through to contemporary aesthetic traditions. This knowledge forms the foundation of the visual style developed in my re-imagined film posters.

The next phase of my research was an informed response to the study and conclusions of the first section through the design of cinematic film poster concepts.

In making use of the research, Latin American narratives in three films were analysed. This exercise demonstrated the value of conducting research and viewing a story about Latin Americans through a Latin American viewpoint. It identified stereotypes, but also narratives within the film that complexly approached the humanity of the culture to reflect the Latin American identity. This process was necessary when reinterpreting cinematic film posters, and creating 
new poster concepts for these films.

To prompt discussion, critique, and further design directions, I presented my posters to experts for inspection. The act of doing so placed different perspectives and lenses upon my work. This collaborative ideation and ongoing conversation led to more well rounded, and in-depth poster narratives from viewpoints that I could not have developed as a solitary creator.

Ultimately, this research sought to re-represent Latin American culture in cinematic poster concepts by understanding and illustrating our narratives and identity. While the final creative output is the visual manifestation of this research, the exploration in this portfolio and knowledge built throughout it, are where the valuable insights are found. The research process I have undertaken and presented here demonstrates one approach to a culturally-embedded design practice that seeks to subvert cultural stereotypes.

Cultural misrepresentation as a whole will only be stopped if film embraces not only media and industrial design disciplines but also social design and other academic, cultural fields that can keep producing research that strips back predefined judgments, to expose the beauty and complexity in all of our cultures. 



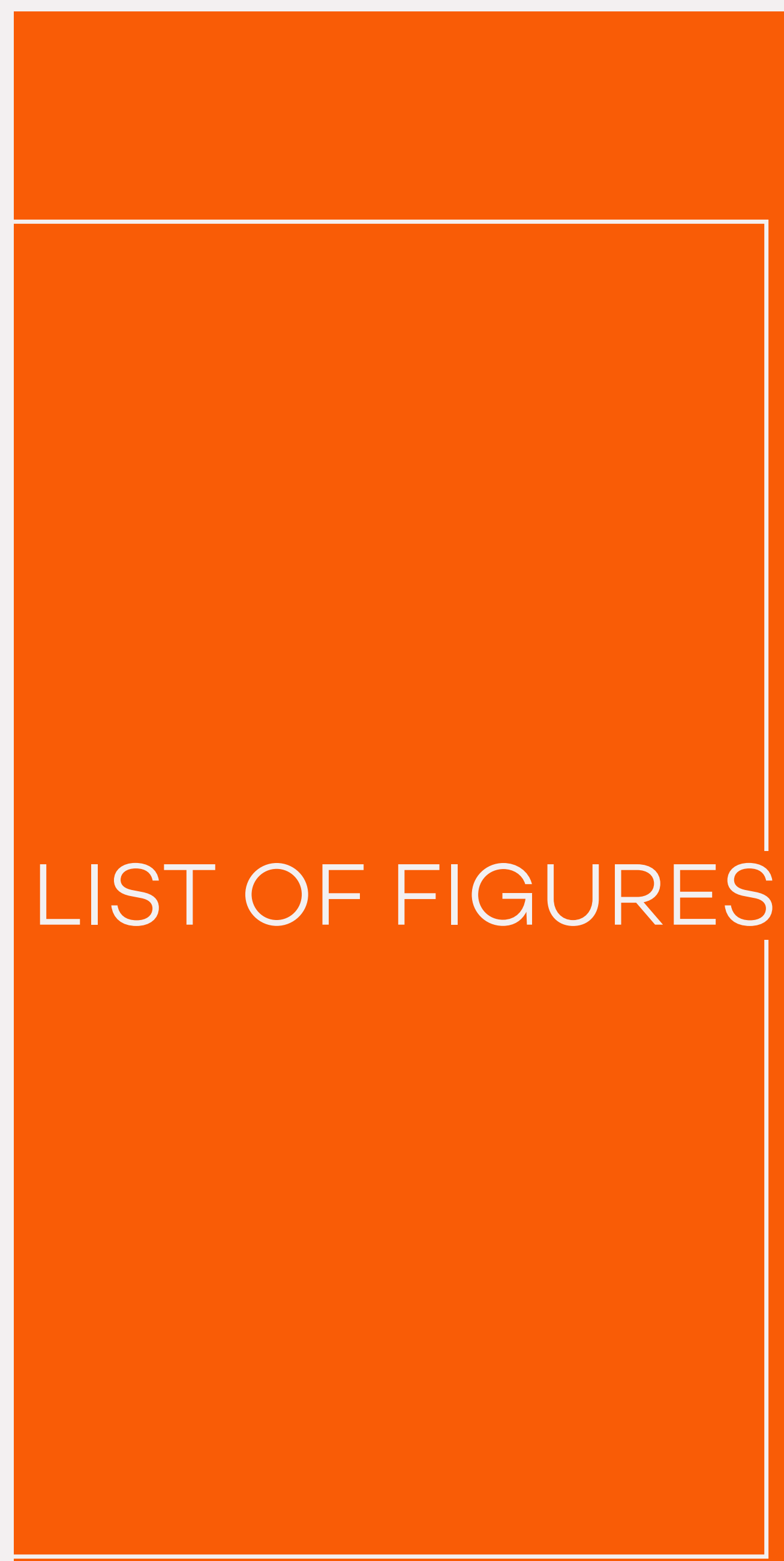


Figure 1. (By Author). Visual Design Process. p.14

Figure 2. (By Author). Themes. p.34

Figure 3. (By Author). Themes through Time. p.38

Figure 4. (By Author). Chronological Visual. p.42

Figure 5. (By Author). Color Visual. p.44

Figure 6. (By Author). Genre Visual. p.46

Figure 7.1 to Figure 7.8. (By Author). Casa D.M.P. Process. p.66

Figure 8. (By Author). Casa D.M.P. Poster. p.68

Figure 9.1 to Figure9.8. (By Author). Gringo Process. p.70

Figure 10. (By Author). Gringo Poster. p.72

Figure 11.1 to Figure 11.9. (By Author). Colombiana Process. p.74

Figure 12. (By Author). Colombiana Poster. p.76

Figure 13.1 to Figure 13.9. (By Author). Colombiana D. Process. p.78

Figure 14. (By Author). Colombiana 1 Poster. p.80

Figure 15.1 to Figure 15.9. (By Author). Colombiana2 Process. p.82

Figure 16. (By Author). Colombiana2 Poster. p.84

Figure 17.1 to Figure 17.9. Colombiana3 D. Process. p.86

Figure 17.7. Gellidon, C. J. (2018). Colombiana3 D. Process.

[Photograph]. Retrieved from https://unsplash.com/

photos/Khqmo4T-rso?fbclid=IwAR 1 cHTaeCBQhri-

AppMXdOkya06uXZBdNEhjh68rRKowu-2MlhnS7bD7y_U. p.86

Figure 18. (By Author). Colombiana3 Poster. p.88 
Figure 19.1 to Figure 19.3. Colombiana4 D. Process. p.90

Figure 20. (By Author). Colombiana4 Poster. p.92

Figure 21.1 to Figure 21.15. Colombiana F1 Process. p.104

Figure 21.10. Angel, G. R. (2018). Colombiana F1 Process

[Photograph]. Retrieved from https://unsplash.com/photos/

GcHar4P8V_Q?fbclid=IwAR2zi8wcFeqmhA8vi5zSBjb5QKO34

ZF8wSwIQPeLRz8f9JQWDPRdSzOi9WI. p104.

Figure 21.12. Walker, S. (2018). Colombiana F1 Process

[Photograph]. Retrieved from https://unsplash.com/photos/lm-

KKZEUD-k?fbclid=IwARoLsFxdOu-oQcl2 1OsNDnRAOfc939by $1 \mathrm{~g}$ oMhttfMJ32byOgwUMyKjWoBg8. p.104

Figure 22. (By Author). Colombiana F1 Poster. p. 106

Figure 23.1 to Figure 23.9 Colombiana F2 Process. p. 108

Figure 23.4. Ramirez, I. (2017). Colombiana F2 Process

[Photograph]. Retrieved from https://unsplash.com/ photos / 2 VhVKr7QbvE?fbclid=IwAR 1U-beWTwMjLfFPPq8tBiTG 3YFvoDkUv1FQh905N1idxDcybmV5MWt9IYE. p108

Figure 23.5. Tomasso, P. (2016). Colombiana F2 Process [Photograph]. Retrieved from https://unsplash.com/photos/ D6Bk1A3-gMA?fbclid=IwAR2A_lK3sU7t1y-faB160Ii3rJV8eQSdoq bYfanW1VBAXZS8LjR4WdzxjXQ. p.108.

Figure 24. (By Author). Colombiana F2 Poster. p. 110

Figure 25.1 to Figure 25.3. Colombiana F3 Process. p. 112

Figure 25.1. Forgacs, V. (2018). Colombiana F3 Process

[Photograph]. Retrieved from https://unsplash.com/photos/ aPC8ygu3bWA p. 112

Figure 26. (By Author). Colombiana F3 Poster. p.114

Figure 27. (By Author). Colombiana Teaser Poster. p.118 
Figure 28. (By Author). Colombiana Promo Poster 1. p.119

Figure 29. (By Author). Colombiana Promo Poster 2. p.120

Figure 30. (By Author). Colombiana Promo Poster 3. p.121

Figure 31. (By Author). Colombiana Promo Poster 4. p.122

Figure 32. (By Author). Poster Installation 1. p.127-123

Figure 33. (By Author). Poster Installation 2. p.125

Figure 34. (By Author). Poster Installation 3. p.126

Figure 35. (By Author). Poster Installation 4. p.127

Figure 36. (By Author). Poster Installation 5. p.128

Figure 37. (By Author). Poster Installation 6. p.129

Figure 38. (By Author). Poster Installation 7. p.130 

REFERENCES 
Amat, F., Basilico, J., Chandrashekar, A., \& Jebara, T. (2017). Retrieved October 12, 2018, from https://medium.com/netflixtechblog/artwork-personalization-c589fo74ad76

Bass, J., \& Kirkham, P. (2011). Saul Bass : A life in film $\mathcal{E}^{\circ}$ design. London, England: Laurence King.

Bender, S. W. (2003). Greasers and gringos: Latinos, law, and the American imagination. New York, NY: NYU Press

Berg, C. (2002). Latino images in film: Stereotypes, subversion and resistance. Austin, TX: University of Texas Press.

Bolls, P. D., \& Eastman, S. T. (2000). Structure and content in promotion research. In S. T. Eastman (Eds.), Research in media promotion (pp. 55-100). New York, NY: Routledge.

Bonsiepe, G., \& Cullars, J. (1991). Designing the Future: Perspectives on Industrial and Graphic Design in Latin America. Design Issues, 7(2), 17-24. DOI: $10.2307 / 1511403$

Brook, T. (2016). Hollywood's' other diversity crisis. Retrieved September 20, 2019, from http://www.bbc.com/culture/ story/20160225-hollywoods-other-diversity-crisis

Caban, G. (2004). World graphic design: Contemporary graphics from Africa, the Far East, Latin America and the Middle East. London, England: Merrell.

Castillo, M. (2018). Why 'Real Women have Curves' never got its Ladybird moment. Retrieved September 28, 2018, from https://www.nytimes.com/2018/02/23/movies/lady-birdreal-women-have-curves.html

Carrasquillo, A. (2017). Cinema smackdown: “Colombiana," starring Zoe Saldana, outrages colombians. Retrieved November, 3, 2018, from https://www.foxnews.com/entertainment/ cinema-smackdown-colombiana-starring-zoe-saldanaoutrages-colombians 
Choueiti, M., Pieper, K. \& Smith, S. (2016). Inequality in 800 popular films: Examining portrayals of gender, race/ethnicity, LGBT, and disability from 2007-2015. Media, Diversity, E Social Change Initiative. Retrieved from https:// communicationmgmt.usc.edu

Creswell, J. (2014). Research design: Qualitative, quantitative, and mixed method approaches. (4th ed.) Los Angeles, CA: SAGE.

David Consuegra. (n.d.). Chronology and bibliography. Retrieved December 13, 2018, https://davidconsuegra.com/en/ cronology-and-bibliography/

Dennison, S. \& Shaw, L. (2005). Pop Culture Latin America! Media, Arts, and Lifestyle. Santa Barbara, CA: ABC-CLIO.

Denzin, N., \& Lincoln, Y. (2005). The SAGE handbook of qualitative research. (3rd ed.). Los Angeles, CA: SAGE.

DePyssler, B., \& Vargas, L. (1998). Using media literacy to explore stereotypes of mexican immigrants. Social Education Vol. 62(7), 407-12. Retrieved from https://search-proquest-com. helicon.vuw.ac.nz/docview/62474468? accountid $=14782$

Diaz, R. (2018). Pepe Menendez long live editorial design. Retrieved December 14, 2018, from https://amanoempire.com/pepemenendez-long-live-editorial-design/

Donoghue, B. C. (2014). The rise of the Brazilian blockbuster: how ideas of exceptionality and scale shape a booming cinema. Media, Culture $\xi^{2}$ Society, 36(4), 536-550. https://doi. org/10.1177/0163443714527566

Don Quijote. (n.d.). Colombian art. Retrieved December 11, 2018, from https://www.donquijote.org/colombian-culture/art/

Emmison, M., \& Smith, P. (2000). Researching the visual images, objects, contexts and interactions in social and cultural Inquiry. London, England: SAGE. 
Erigha, M. (2015). Race, gender, Hollywood: Representation in cultural production and digital media's potential for change: Representation in Hollywood cultural production. Sociology Compass, 9(1), 78-89. https://doi.org/10.1111/soc4.12237

Felipe Taborda Co-operation. (n.d.). Felipe Taborda Design. Retrieved December 11, 2018, from http://www.felipetaborda.com.br/ en/

Fraunhar, A. (2005). Re-visioning the Mulata in Cuban Visual Culture. Santa Barbara, CA: University of California Press.

Fox, M. (1996). Design from the southern continent. Print, 5o(2) Retrieved from http://go.galegroup.com.helicon.vuw.ac.nz ps/dispBasicSearch do? userGroupName=vuw\&prodId $=$ AONE

Fu, Z., Li, B., Li, J., \& Wei, S. (2015). Fast film genres classification combining poster and synopsis. Intelligence Science and Big Data Engineering, 9242, 72-81. https://doi.org/10.1007/9783-319-23989-7_8

Gordon, M., Rivadeneyra, R., \& Ward, L. M. (2007). Distorted reflections: Media exposure and Latino adolescents' conceptions of self. Media Psychology, 9, 261-290. https://doiorg.helicon.vuw.ac.nz/10.1080/15213260701285926

Grass, K. (2018). Fernando Botero's guide to colombian history and culture. Retrieved December 11, 2018 from http://www. dailyartmagazine.com/boteros-guide-to-colombia/

Graham, L., \& Lawson, C. J. D. (Producers), \& Burke, K. (Director). (2017). 24x36: A movie about movie posters [Documentary]. United States: Snowfort Pictures.

Guzmán, I., \& Valdivia, A. (2004). Brain, brow, and booty: Latina iconicity in U.S. popular culture. The Communication review, $7(2), 205-221$. https://doi-org.helicon.vuw. ac.nz/10.1080/107 14420490448723 
Guzmán, I. (2016). \#OscarsSoWhite: how Stuart Hall explains why nothing changes in Hollywood and everything is changing. Critical Studies in Media Communication, 33(5), 438-454. https://doi.org/10.1080/15295036.2016.1227864

Hwang, S. H., \& Matsumoto, D. (2011) Reading facial expressions of emotion: Basic research leads to training programs that improve people's ability to detect emotions. American Psychological Association Retrieved from https://www.apa.org/ index

Jesson, J., Lacey, F. \& Matheson, L. (2011). Doing your literature revierw: Traditional and systematic techniques. Los Angeles, CA: SAGE.

Jorge, M. (n.d.) History of Brazilian 19th century art. Retrieved December 11, 2018 from https://www.artrenewal.org/ Article/Title/history-of-brazilian-19th-century-art

Katzew, A. (2011). Shut up! Representations of the Latino/a body in Ugly Betty and their educational implications. Latino Studies, 9(2-3), 300-320. https://doi.org/10.1057/lst.2011.16

King, G. (2002). New Hollywood cinema: An introduction. New York, NY: Columbia University Press.

Kline, H. \& McGreevey, W. (2018) Colombia. Retrieved December 11, 2018, from https://www.britannica.com/place/Colombia/ The-arts

Knapp, G. (2002). Introduction: Latin America in the 21 st century. Yearbook. Conference of Latin Americanist Geographers, 27, 5-6. Retrieved from http://www.jstor.org/stable/25765901

Kumar, R. (2014). Research methodology: A step by step guide for beginners. (4th ed.). Los Angeles, CA: SAGE.

Lambrecht, W. (2012) They shoot typo, don't they? : a collection of film poster design. Ghent, Belgium: Grafische Cel 
Lear, J. (2014). Representing workers, the workers represented.

Third Text, 28(3), 235-255. https://doi-org.helicon.vuw.ac. $\mathrm{nz} / 10.1080 / 09528822.2014 .903605$

Lee, E. K. O., \& Priester, M. A. (2014). Who is the help? Use of film to explore Diversity. Affilia, 29(1), 92-104. https:// doi.org/10.1177/0886109913509545

Lee, B. (2016). Gone to the wall-why modern posters are dreadful. Retrieved November 4, 2018, from https://www.theguardian.com/ film/2016/jan/28/why-modern-movie-posters-are-sodreadful

Lucas, G. (2011). Making the cut.. Creative Reviere, 31(3), 3640. Retrieved from https://search-proquest-com.helicon.vuw. ac.nz/? accountid $=14782$

Macdonald, N. (2014). Art you can't avoid: Brazil's art stars Os Gemeos fit perfectly with the spirit of Vancouver's Biennale. Maclean's, 127(36), 64. http://go.galegroup.com.helicon.vuw.ac.nz

Machado, Y. (2018). 'Lady bird' was influenced by 'Real Women have Curves' and no one outside of the Latinx community is acknowledging it. Retrieved January 12, 2019 from https:// www.marieclaire.com/culture/a15931477/lady-bird-realwomen-have-curves/

Marich, R. (2005). Marketing to Moviegoers. Retrieved from https://www.oreilly.com/library/view/marketing-tomoviegoers/9780240806877/?ar

Mckee, Alan. (2003). Textual Analysis: A Beginner's Guide. Los Angeles, CA: SAGE.

Novin, G. (n.d). Guity Novin's a history of graphic design: The online textbook. Retrieved December 6, 2018, from http://guitynovin.blogspot.com/2011/12/graphic-design-in-latinamerica-part-ii.html

Olivarez, A. (1998). Studying Representations of U.S. Latino Culture. Journal of Communication Inquiry, 22(4), 426-437.

DOI: 10.1177/0196859998022004006 
Perez-Barreiro, G. (2005) The accidental tourist: american collections of latin american art. In Altshuler, B. (Eds.) Collecting the New: Museums and Contemporary Art. Princeton, NJ: Princeton University Press.

Petersen, S. (2012). The little known secrets of latin american design. Retrieved August 5, 2018 from https://www.huffingtonpost. com/soren-petersen/the-little-known-secrets-_b_1769071. html

Phillips, T. (2008). Artistry in the blood. Retrieved December 11, 2018 from https://www.theguardian.com/news/2008/ mar/14/tomphillips.insidebrazil

Ryan, H. E. (2017). Political street art: Communication, culture and resistance in Latin America. New York, NY: Routledge Taylor \& Francis Group.

Ryzik, M. (2016). What it's really like to work in Hollywood*: if you're not a straight white male. Retrieved August 10, 2018 from https://www.nytimes.com/interactive/2016/02/24/arts/ hollywood-diversity-inclusion.

Rodriguez, M. (2018). Real women have curves writer Josefina Lopez on lady bird. Retrieved November 17, 2018 from http:/ / remezcla.com/film/real-women-have-curves-josefina-lopezlady-bird/

Rose, G. (2007). Visual methodologies : An introduction to the interpretation of visual materials (2nd ed.). London, England: SAGE.

Saldana, J. (2009) The coding manual for qualitative researchers. Thousand Oaks, CA: SAGE.

Samson, L. (2018). Felipe Taborda on latin american graphic design, Beatles album cover and his latest project. Retrieved August 20, 2018 from http://www.designindaba.com/articles/creativework/felipe-taborda-latin-american-graphic-design-beatlesalbum-covers-and-his 
Saucier, J. K. (2010). America on Film: representing race, class, gender, and sexuality at the movies. Historical Journal of Film, Radio and Television, 30(1), 139-141. https://doi. org/10.1080/01439680903577474

Shutt, B. (2003). Research and the movies. Design research: Methods and perspectives. Cambridge, MA: The MIT Press.

Silverman, D. (2017). Doing qualitative research. (5th ed.). Los Angeles, CA: SAGE.

Simons, H. (2009). Case Study Research in Practice. London, England: SAGE.

Souter, A. (2018). Mexican muralism movement overview and analysis. Retrieved January 5 2019, from https://www.theartstory.org/ movement-mexican-muralism.html

Sottek, T. C. (2016). The thumbnails are always changing on Netflix because you're being tested. Retrieved April 20, 2019 from https://www. theverge.com/2016/5/3/11582382/netflix-thumbnail-test

Stone, T. (2010). Managing the design process-concept development.

Retrieved from https://learning.oreilly.com/home/

Taborda, F. \& Wiedemann, J. (2008). Latin American graphic design. Italy: Taschen Publishers.

Thomas, J. (2014). Maid in america: top 5 latina media stereotypes. Retrieved December 5, 2018, from http://www.tuvez.com/ maid-america-top-5-latina-media-stereotypes/

Time Staff. (2015). Here's Donald Trump's presidential announcement Speech. Retrieved from July 26, 2018 http://time. com/3923128/donald-trump-announcement-speech/

USC Annenberg (2016, March 9). Inclusion or invisibility? [Video file]. Retrieved from https://www.youtube.com/watch?v=fLPg b2PgBeA\&index $=7 \&$ list $=$ PL7vJSMloWnGlhAfoPoKIyREMU_d9wei7\&t=os 
Woll, A. (1974). Hollywood's good neighbor policy: The Latin image in American film, 1939-1946. Journal of Popular Film and Television, 3(4), 278-293. Retrieved from https://www. proquest.com 

APPENDIX 
Jessica Freire 